Supporting Information for:

\title{
Preparation of Enantiomerically Pure Perfluorobutanesulfinamide and Its Application in the Asymmetric Synthesis of $\alpha$-Amino Acids
}

\author{
Apiwat Wangweerawong ${ }^{\dagger}$, Joshua R. Hummel ${ }^{\dagger}$, and Jonathan A. Ellman*† \\ ${ }^{\dagger}$ Department of Chemistry, Yale University, 225 Prospect Street, New Haven, Connecticut 06520-8170, \\ United States
}

Contents

Page

I. X-ray Crystallography

S-2

II. NMR Spectra of Products

S-6

III. HPLC Data

S-45 


\section{X-ray Crystallography}

\section{Product 11a-amide}

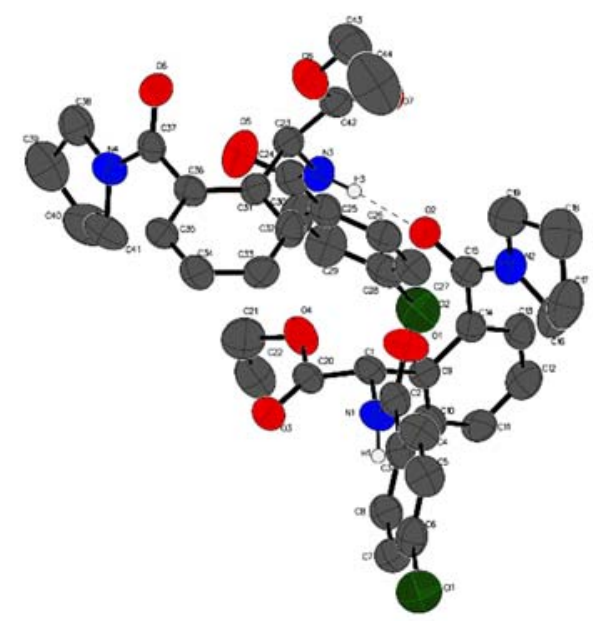

Figure 1. ORTEP representation of 11a-amide. All atoms shown are depicted with $50 \%$ thermal contours. Most of the hydrogen atoms have been omitted for clarity.

Table 1. Crystal data and structure refinement for 11a-amide

\begin{tabular}{lll}
\hline Identification code & $007-15175$ & \\
Empirical formula & $\mathrm{C}_{22} \mathrm{H}_{23} \mathrm{ClN}_{2} \mathrm{O}_{4}$ & \\
Formula weight & 414.87 & \\
Temperature & $173(2) \mathrm{K}$ & \\
Wavelength & $1.54178 \AA$ & \\
Crystal system & Triclinic & $\alpha=103.623(9)^{\circ}$. \\
Space group & $\mathrm{P} 1$ & $\beta=99.874(8)^{\circ}$. \\
Unit cell dimensions & $\mathrm{a}=8.5086(6) \AA$ & $\gamma=90.545(9)^{\circ}$. \\
& $\mathrm{b}=10.4268(8) \AA$ & \\
& $\mathrm{c}=13.8730(10) \AA$ & \\
Volume & $1176.83(16) \AA$ & \\
Z & 2 & \\
Density (calculated) & $1.171 \mathrm{Mg} / \mathrm{m}^{3}$ & \\
Absorption coefficient & $1.665 \mathrm{~mm}^{-1}$ & \\
F(000) & 436 & $0.300 \times 0.220 \times 0.020 \mathrm{~mm}^{3}$ \\
Crystal size &
\end{tabular}


Crystal color and habit

Diffractometer

Theta range for data collection

Index ranges

Reflections collected

Independent reflections

Observed reflections (I > 2sigma(I))

Completeness to theta $=58.931^{\circ}$

Absorption correction

Max. and min. transmission

Solution method

Refinement method

Data / restraints / parameters

Goodness-of-fit on $\mathrm{F}^{2}$

Final $\mathrm{R}$ indices [I $>2 \operatorname{sigma}(\mathrm{I})]$

$\mathrm{R}$ indices (all data)

Absolute structure parameter

Largest diff. peak and hole
Colorless Plate

Rigaku Saturn 944+ CCD

3.331 to $58.931^{\circ}$.

$-9<=\mathrm{h}<=9,-10<=\mathrm{k}<=11,-15<=\mathrm{l}<=15$

23371

$6208[\mathrm{R}(\mathrm{int})=0.2300]$

4293

$99.0 \%$

Semi-empirical from equivalents

0.823 and 0.399

SHELXT-2014/5 (Sheldrick, 2014)

SHELXL-2014/7 (Sheldrick, 2014)

6208 / 5 / 533

1.004

$\mathrm{R} 1=0.0792, \mathrm{wR} 2=0.1985$

$\mathrm{R} 1=0.1181, \mathrm{wR} 2=0.2282$

$0.03(3)$

0.286 and -0.262 e. $\AA^{-3}$ 


\section{Product 15d-amine salt}

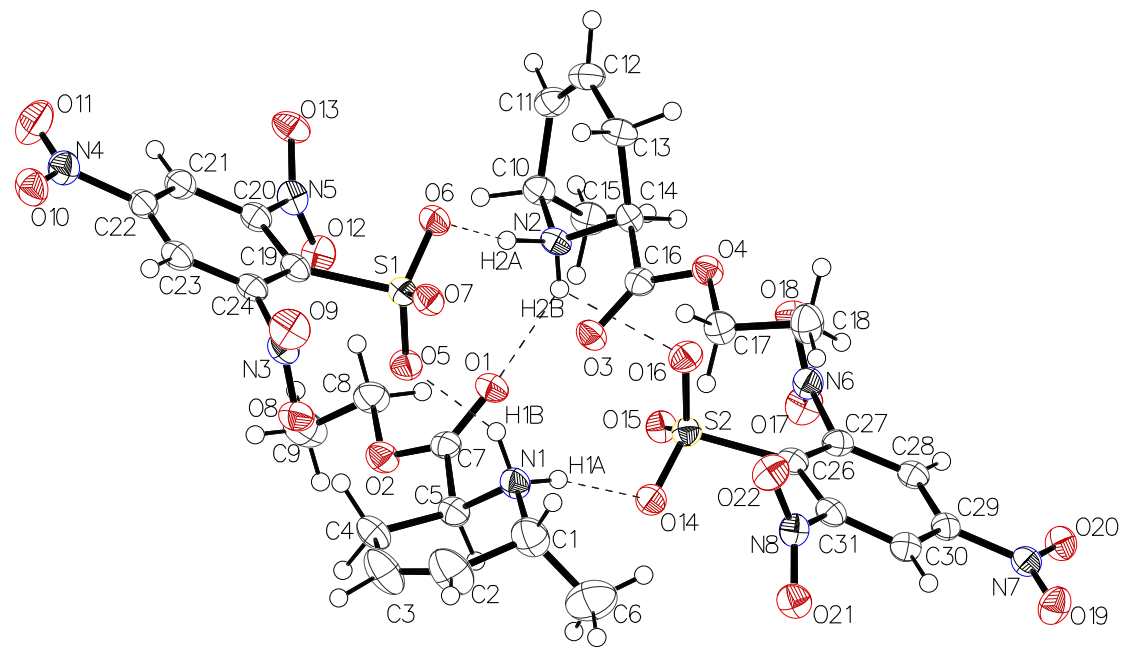

Figure 2. ORTEP representation of $[\mathbf{1 5 d} \text {-amine-H }]^{+}$with 2,4,6-trinitrobenzenesulfonate anion. All atoms shown are depicted with 50\% thermal contours. Dashed lines highlight hydrogen bonding.

Table 2. Crystal data and structure refinement for $\mathbf{1 5 d - a m i n e}$

Identification code

Empirical formula

Formula weight

Temperature

Wavelength

Crystal system

Space group

Unit cell dimensions

Volume

Z

Density (calculated)

Absorption coefficient
007-15116

$\mathrm{C}_{15} \mathrm{H}_{18} \mathrm{~N}_{4} \mathrm{O}_{11} \mathrm{~S}$

462.39

93(2) K

$1.54178 \AA$

Monoclinic

P 21

$\mathrm{a}=10.2071(7) \AA$

$\alpha=90^{\circ}$.

$\mathrm{b}=16.4858(12) \AA$

$\beta=113.189(2)^{\circ}$.

$\mathrm{c}=12.6284(9) \AA$ $\gamma=90^{\circ}$.
4

$1.572 \mathrm{Mg} / \mathrm{m}^{3}$

$2.123 \mathrm{~mm}^{-1}$ 
$\mathrm{F}(000)$

Crystal size

Crystal color and habit

Diffractometer

$\theta$ range for data collection

Index ranges

Reflections collected

Independent reflections

Observed reflections $(\mathrm{I}>2 \sigma(\mathrm{I}))$

Completeness to $\theta=67.679^{\circ}$

Absorption correction

Max. and min. transmission

Solution method

Refinement method

Data / restraints / parameters

Goodness-of-fit on $\mathrm{F}^{2}$

Final R indices [I $>2 \sigma(\mathrm{I})]$

$\mathrm{R}$ indices (all data)

Absolute structure parameter

Largest diff. peak and hole
960

$0.230 \times 0.200 \times 0.080 \mathrm{~mm}^{3}$

Colorless Plate

Rigaku Saturn 944+ CCD

3.808 to $68.184^{\circ}$.

$-12 \leq h \leq 12,-19 \leq k \leq 19,-15 \leq l \leq 15$

67247

$6943[\mathrm{R}(\mathrm{int})=0.0667]$

6866

$98.0 \%$

Semi-empirical from equivalents

0.849 and 0.615

SHELXT-2014/5 (Sheldrick, 2014)

SHELXL-2014/7 (Sheldrick, 2014)

$6943 / 1 / 579$

1.026

$\mathrm{R} 1=0.0307, \mathrm{wR} 2=0.0829$

$\mathrm{R} 1=0.0309, \mathrm{wR} 2=0.0830$

$0.043(5)$

0.621 and -0.296 e. $\AA^{-3}$ 


\section{NMR Spectra of Products}
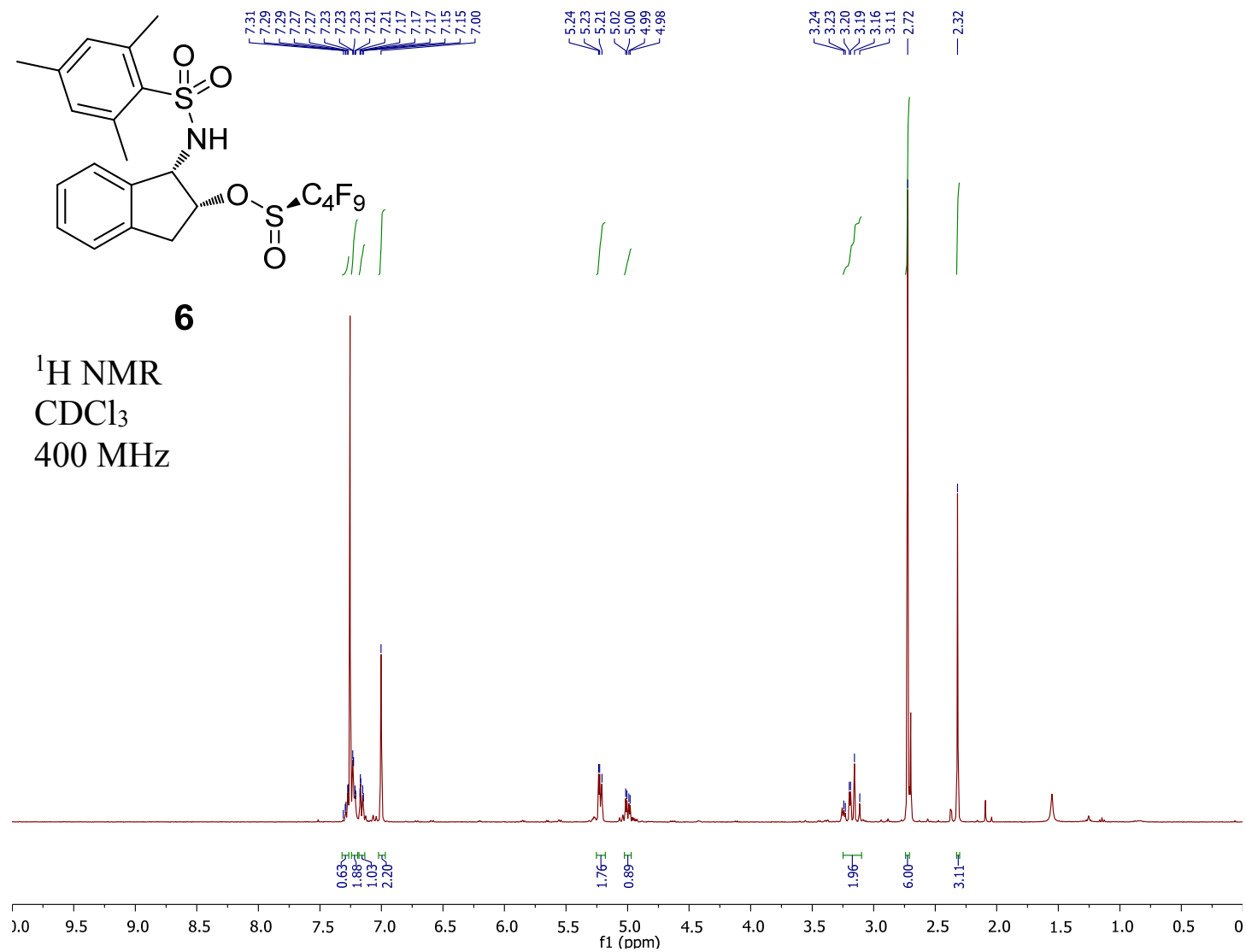

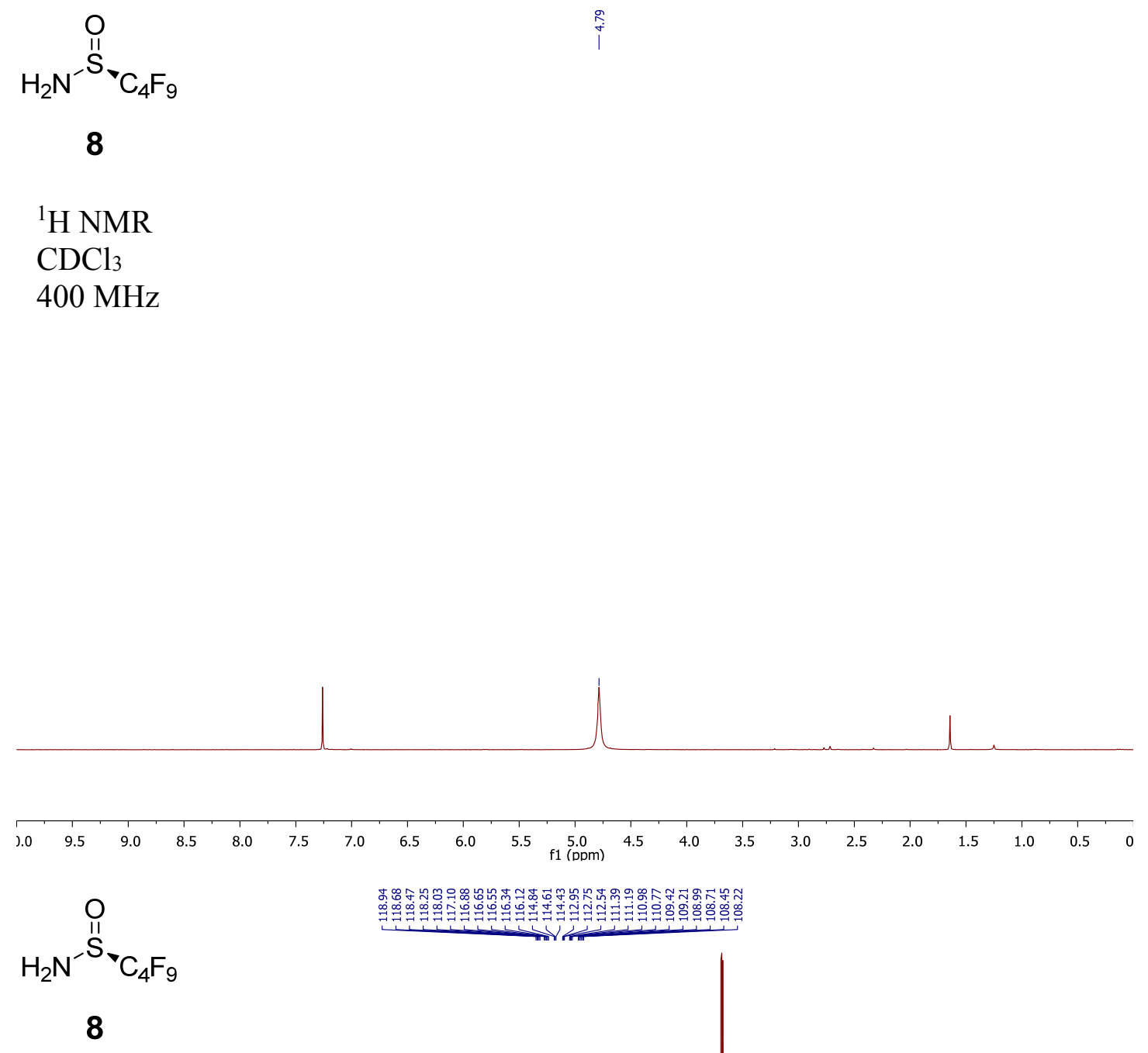

${ }^{13} \mathrm{C}$ NMR

$\mathrm{CDCl}_{3}$

$151 \mathrm{MHz}$

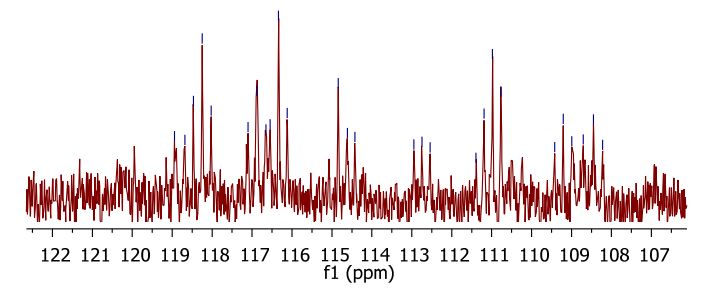

indilen.

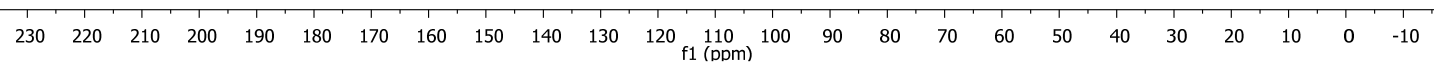




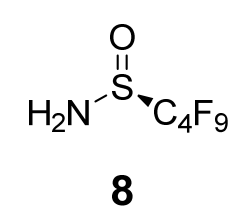

${ }^{19} \mathrm{~F}$ NMR

$\mathrm{CDCl}_{3}$

$376 \mathrm{MHz}$

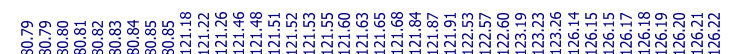

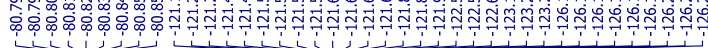

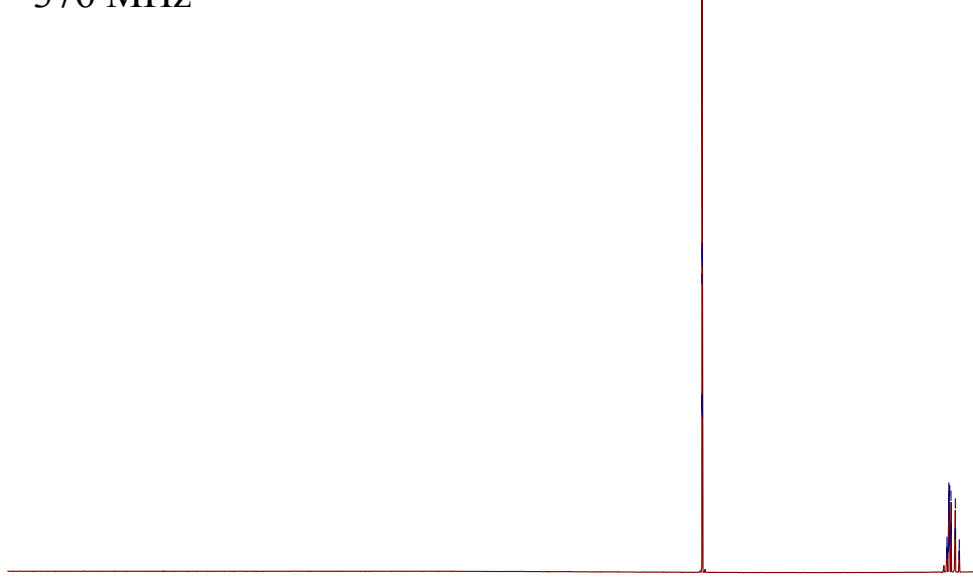

$\begin{array}{lllllllllllllllllllllllll}30 & 20 & 10 & 0 & -10 & -20 & -30 & -40 & -50 & -60 & -70 & -80 & -90 & -100 & -110 & -120 & -130 & -140 & -150 & -160 & -170 & -180 & -190 & -200\end{array}$ 


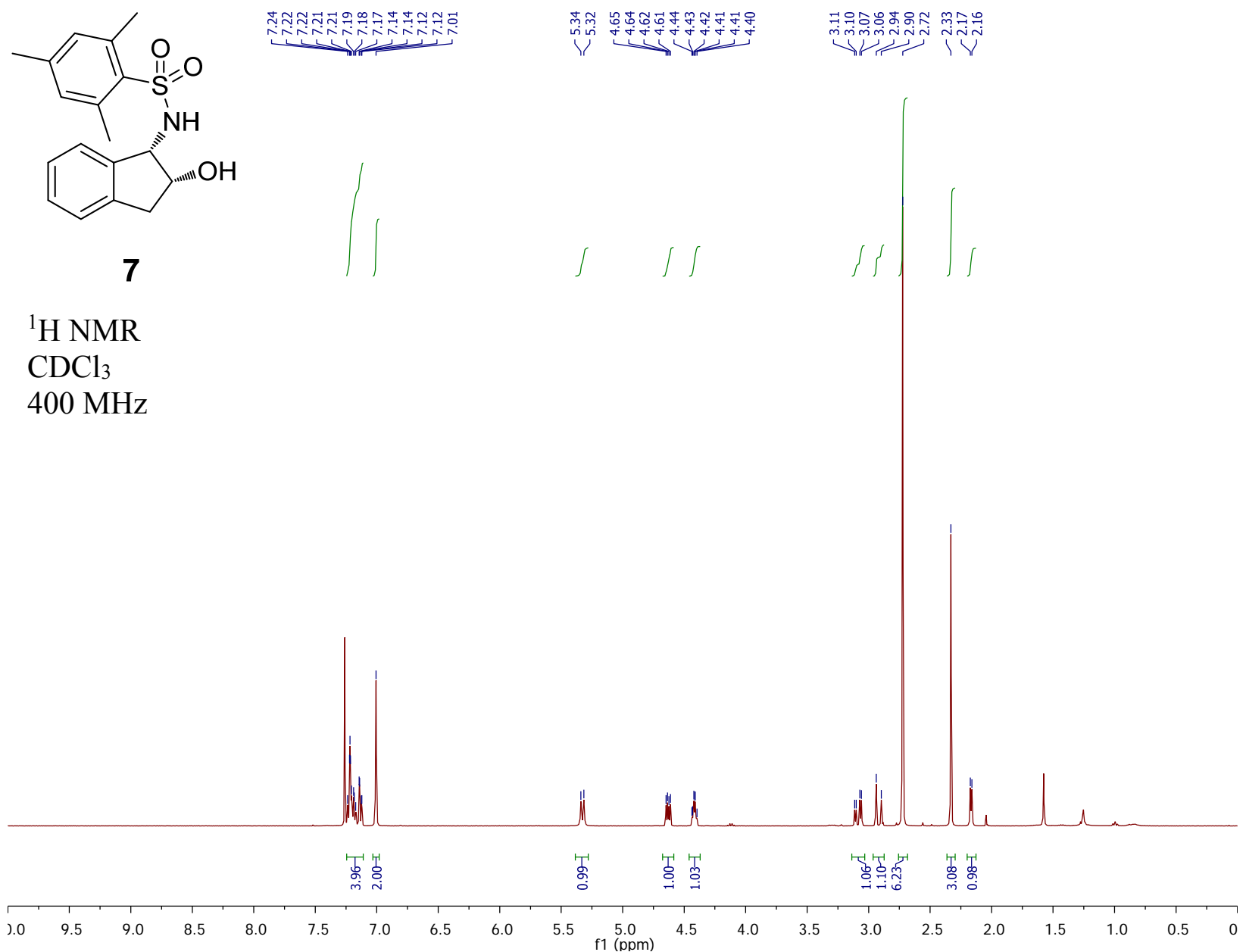



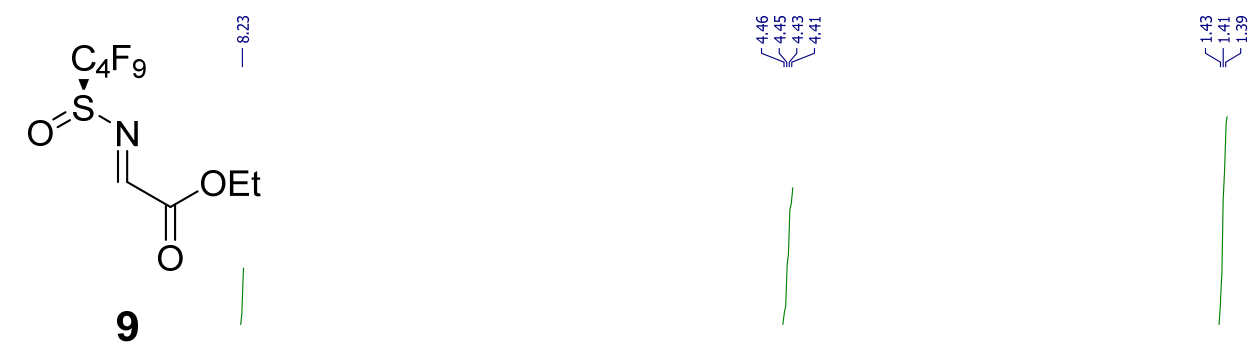

${ }^{1} \mathrm{H}$ NMR

$\mathrm{CDCl}_{3}$

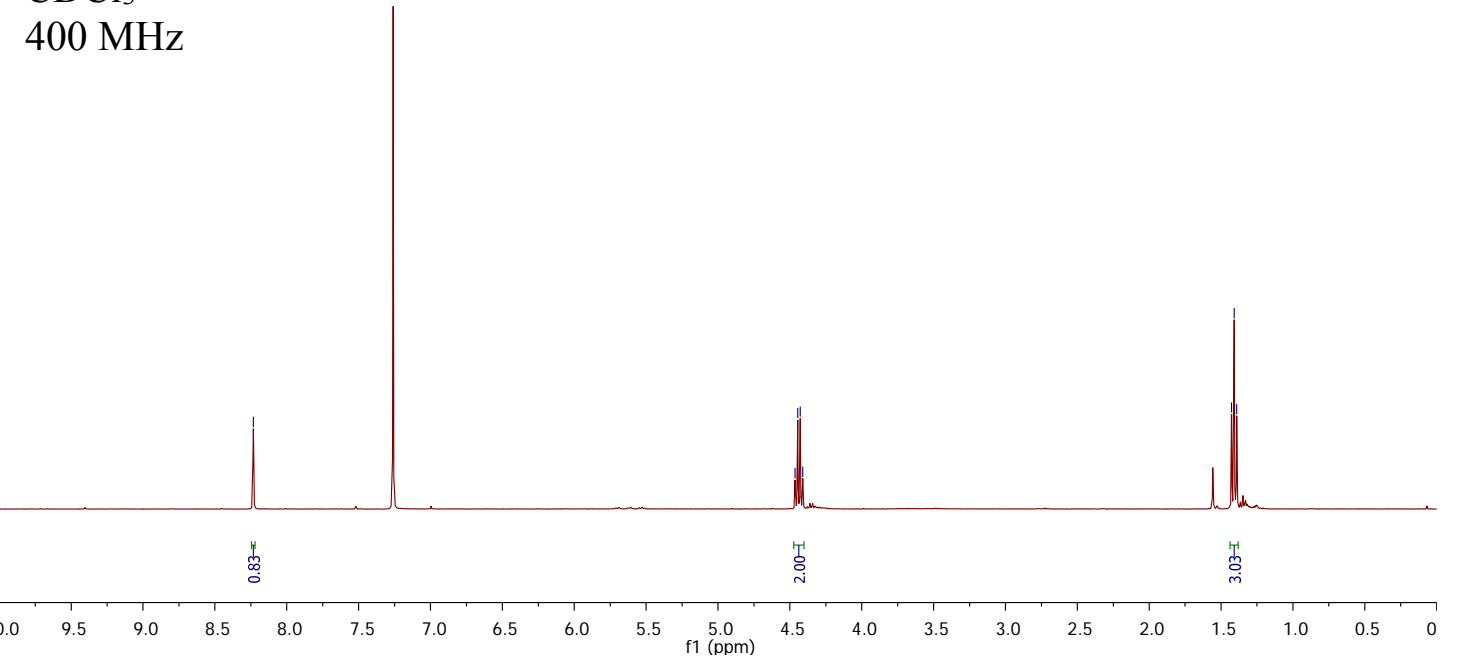



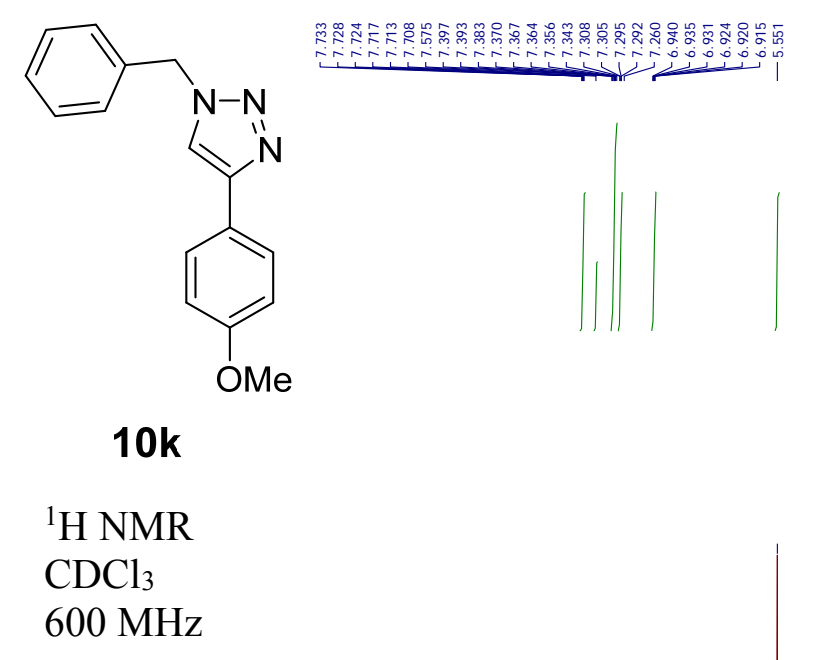

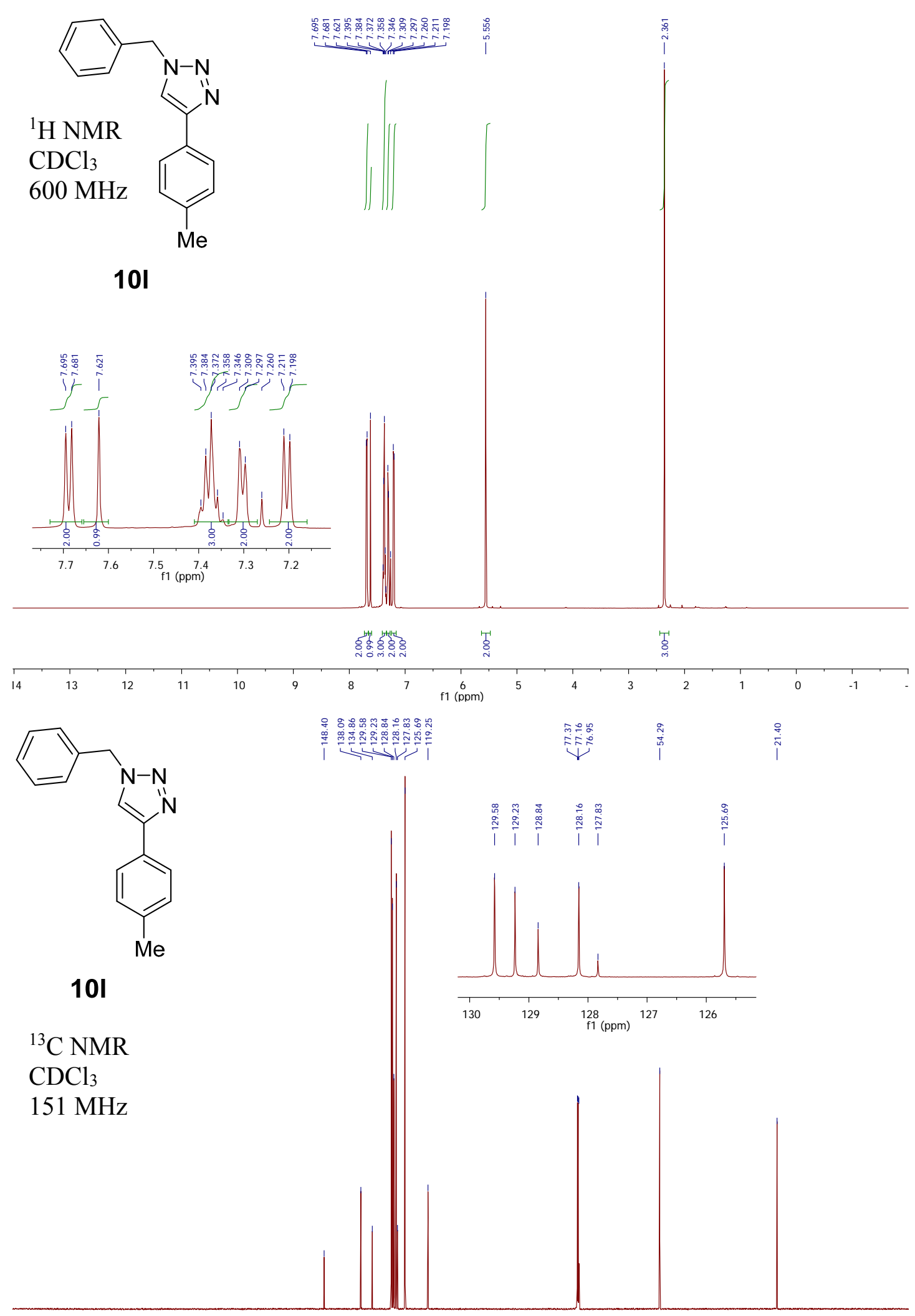

$\begin{array}{lllllllllllllllllllllllllllllll}230 & 220 & 210 & 200 & 190 & 180 & 170 & 160 & 150 & 140 & 130 & 120 & 110 & 100 & 90 & 80 & 70 & 60 & 50 & 40 & 30 & 20 & 10 & 0 & -10\end{array}$ 


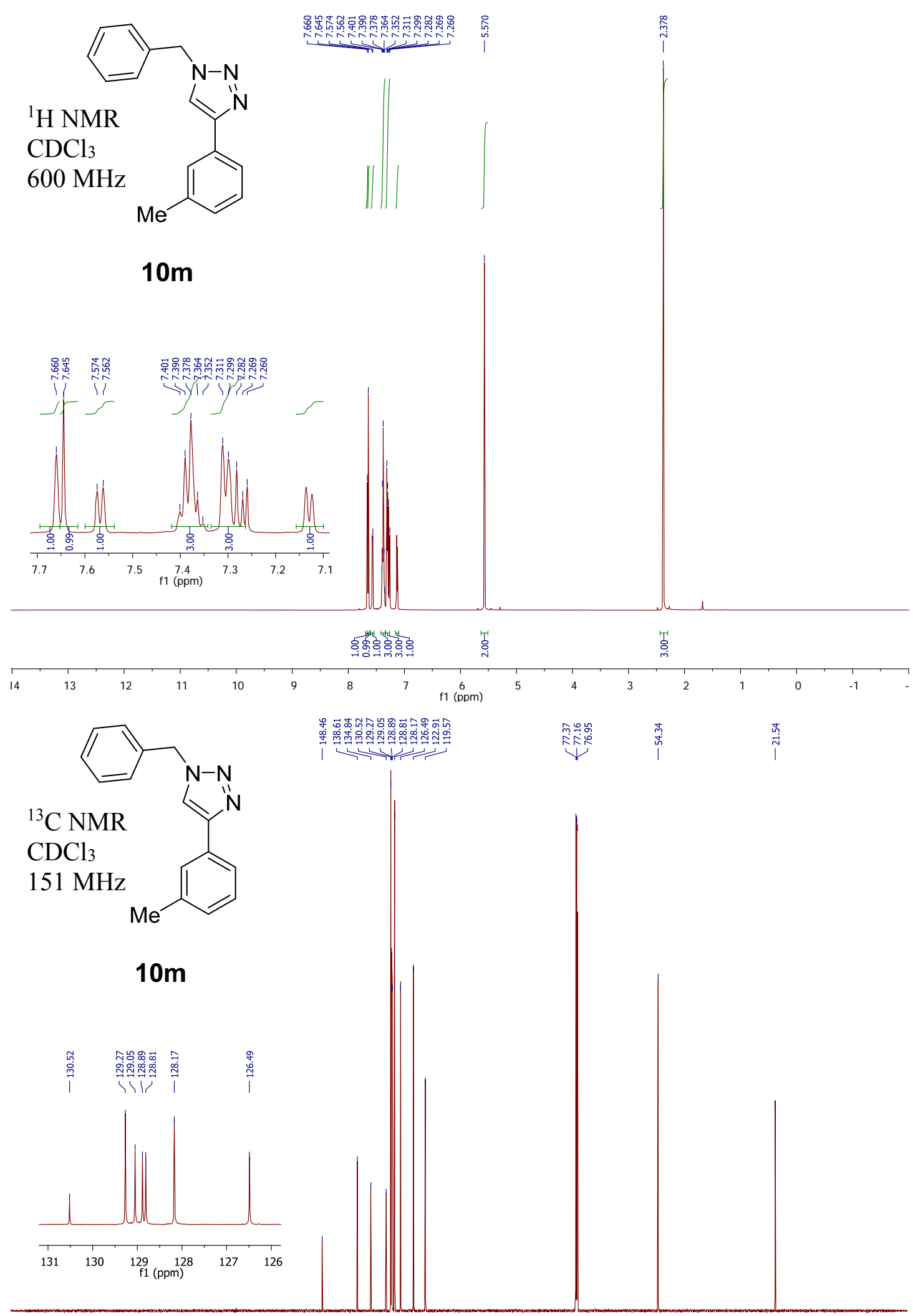

$\begin{array}{llllllllllllllllllllllllllllll} & 230 & 220 & 210 & 200 & 190 & 180 & 170 & 160 & 150 & 140 & 130 & 120 & 110 & 100 & 90 & 80 & 70 & 60 & 50 & 40 & 30 & 20 & 10 & 0 & -10\end{array}$ 

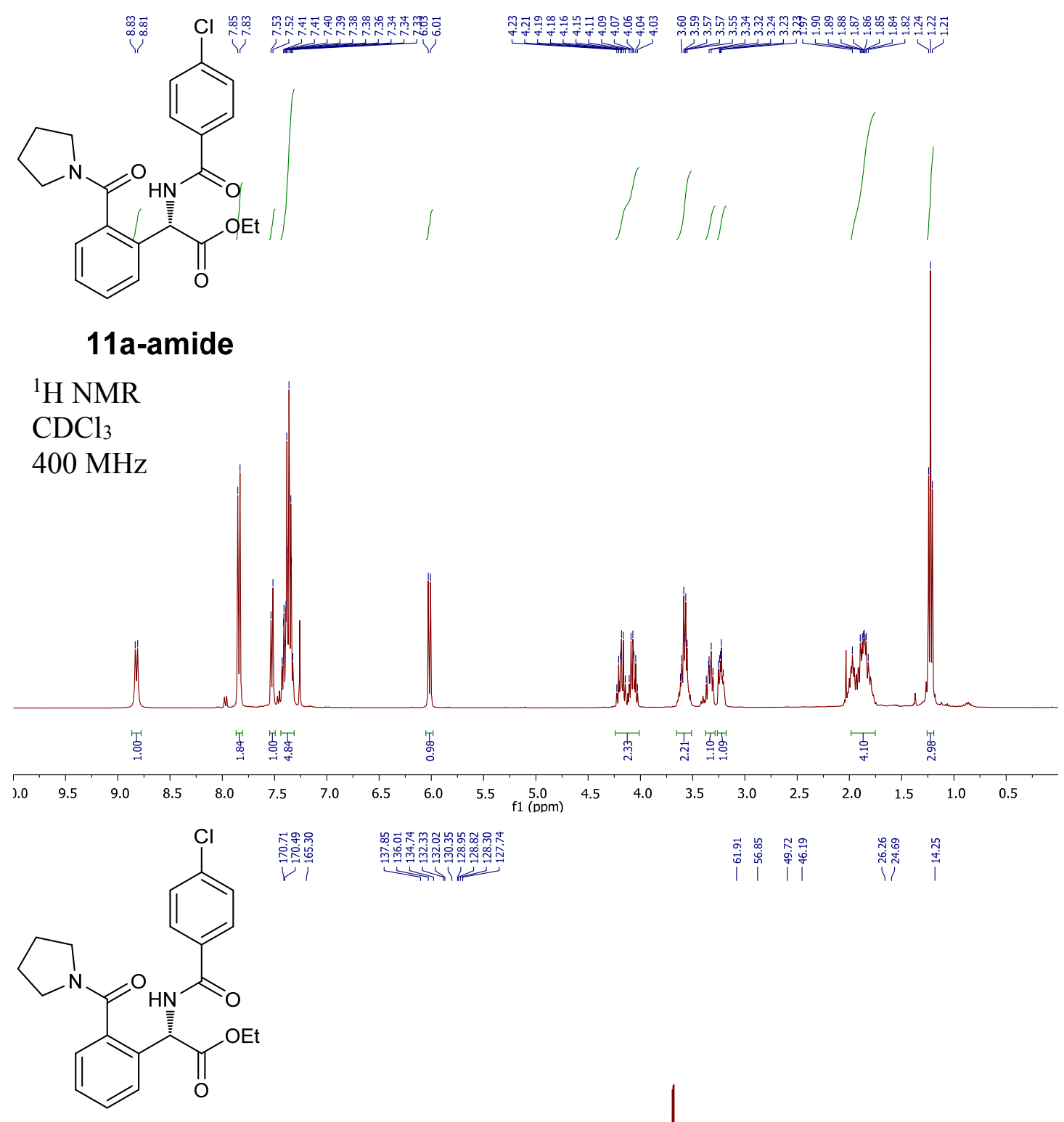

11a-amide

${ }^{13} \mathrm{C}$ NMR

$\mathrm{CDCl}_{3}$

$151 \mathrm{MHz}$
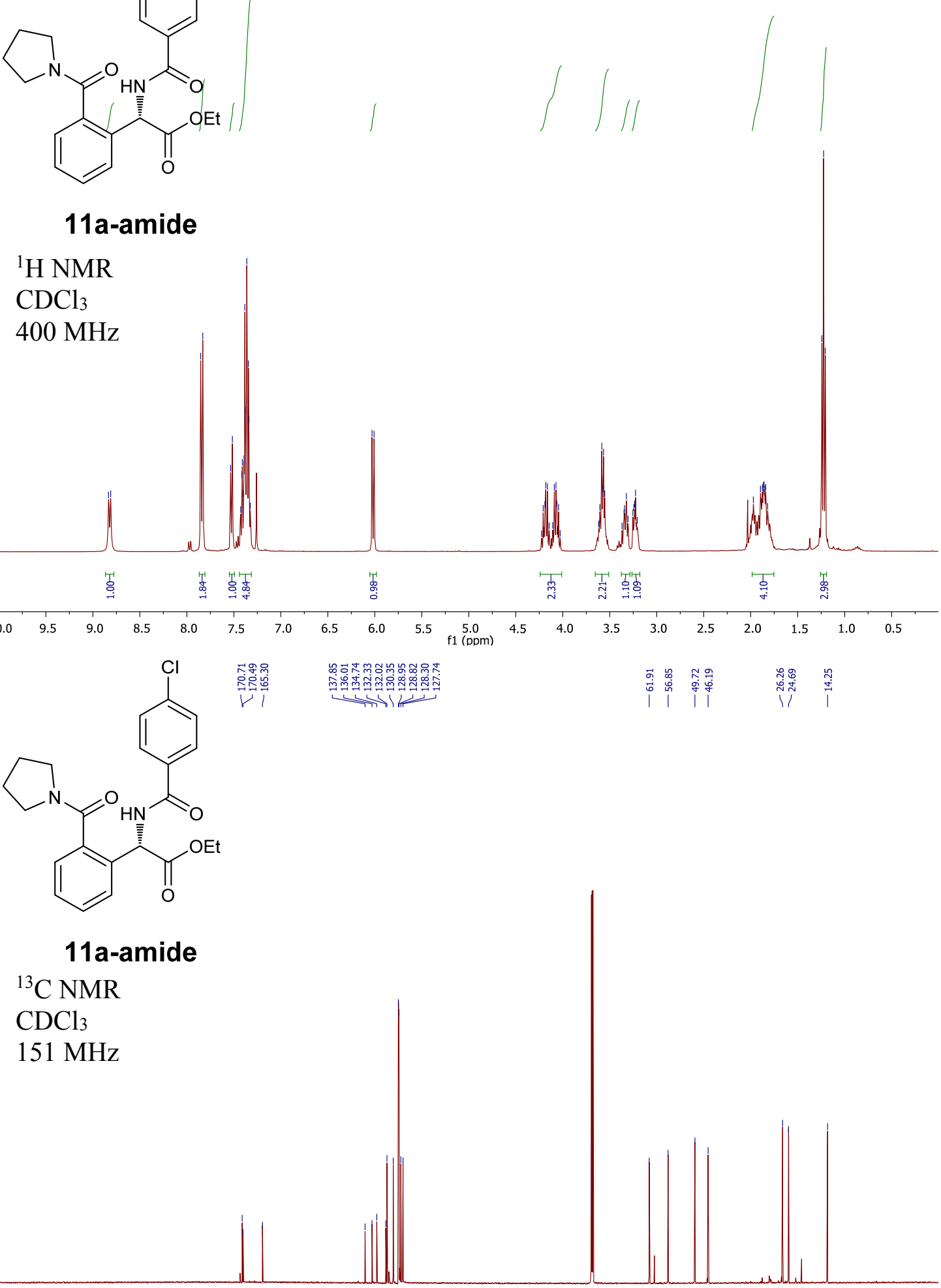

$\begin{array}{lllllllllllllllllllllllll}230 & 220 & 210 & 200 & 190 & 180 & 170 & 160 & 150 & 140 & 130 & 120 & \begin{array}{l}110 \\ \mathrm{f} 1\end{array}(\mathrm{ppm}) & 100 & 90 & 80 & 70 & 60 & 50 & 40 & 30 & 20 & 10 & 0 & -10\end{array}$ 


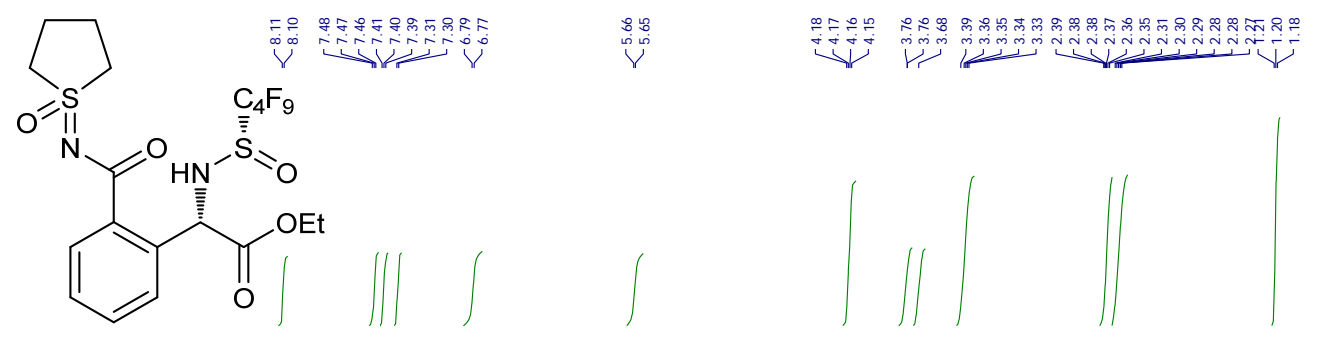

11d

${ }^{1} \mathrm{H}$ NMR

$\mathrm{CDCl}_{3}$

$600 \mathrm{MHz}$

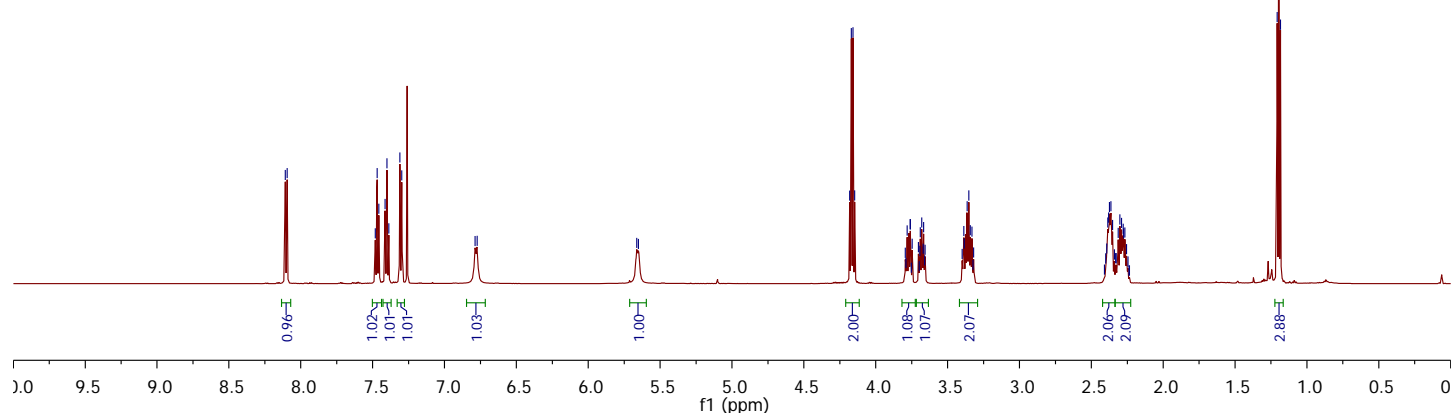



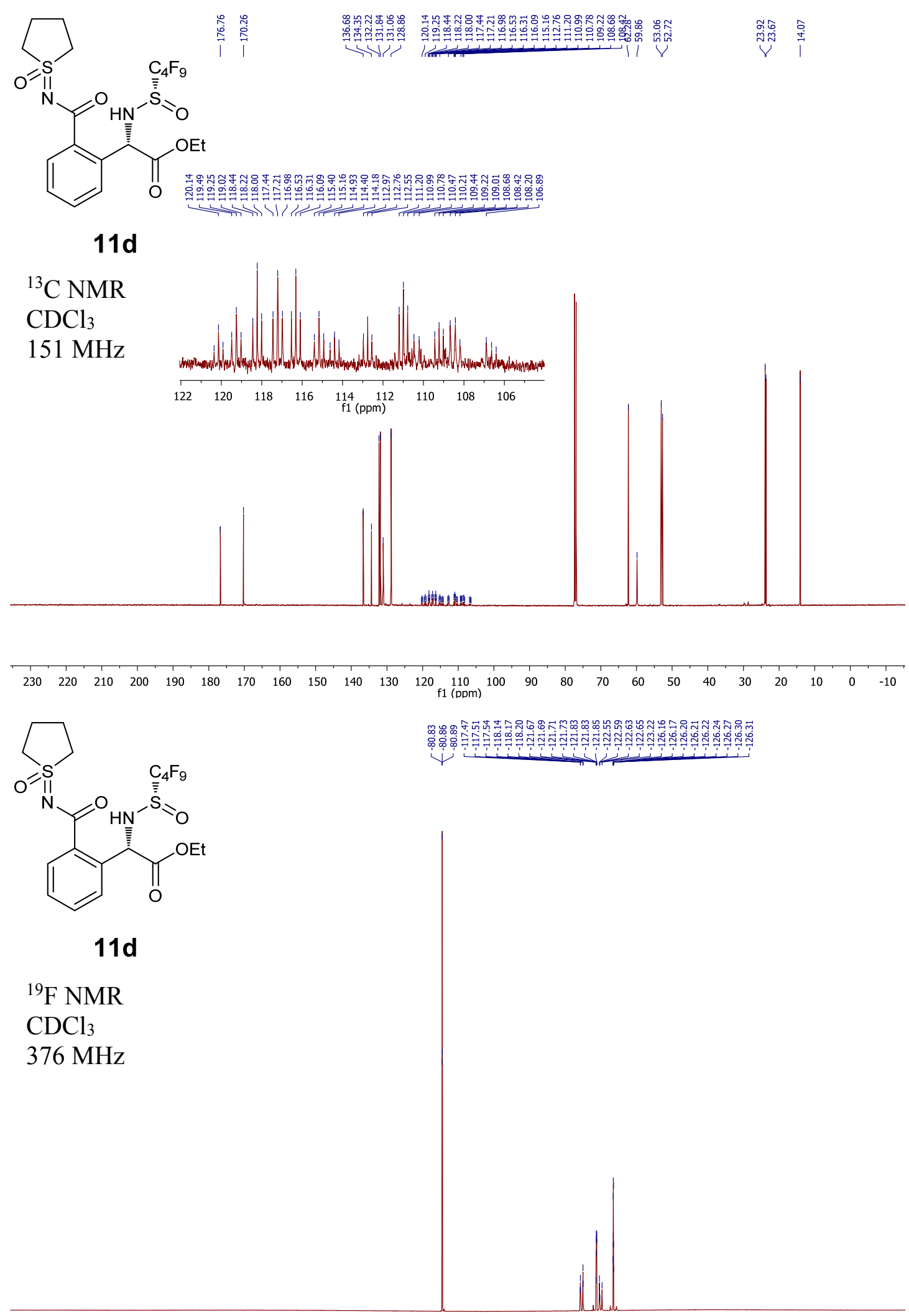

\begin{tabular}{llllllllllllllllllllllllllll}
\hline & 10 & 20 & 10 & 0 & -10 & -20 & -30 & -40 & -50 & -60 & -70 & -80 & -90 & -100 & -110 & -120 & -130 & -140 & -150 & -160 & -170 & -180 & -190 & -200
\end{tabular} 
<smiles>O=C(O[Na])[C@H](NS(=O)C(F)(F)F)c1ccccc1-n1cccn1</smiles>

$11 \mathrm{e}$

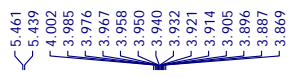

${ }^{1} \mathrm{H}$ NMR

$\mathrm{CDCl}_{3}$

$400 \mathrm{MHz}$
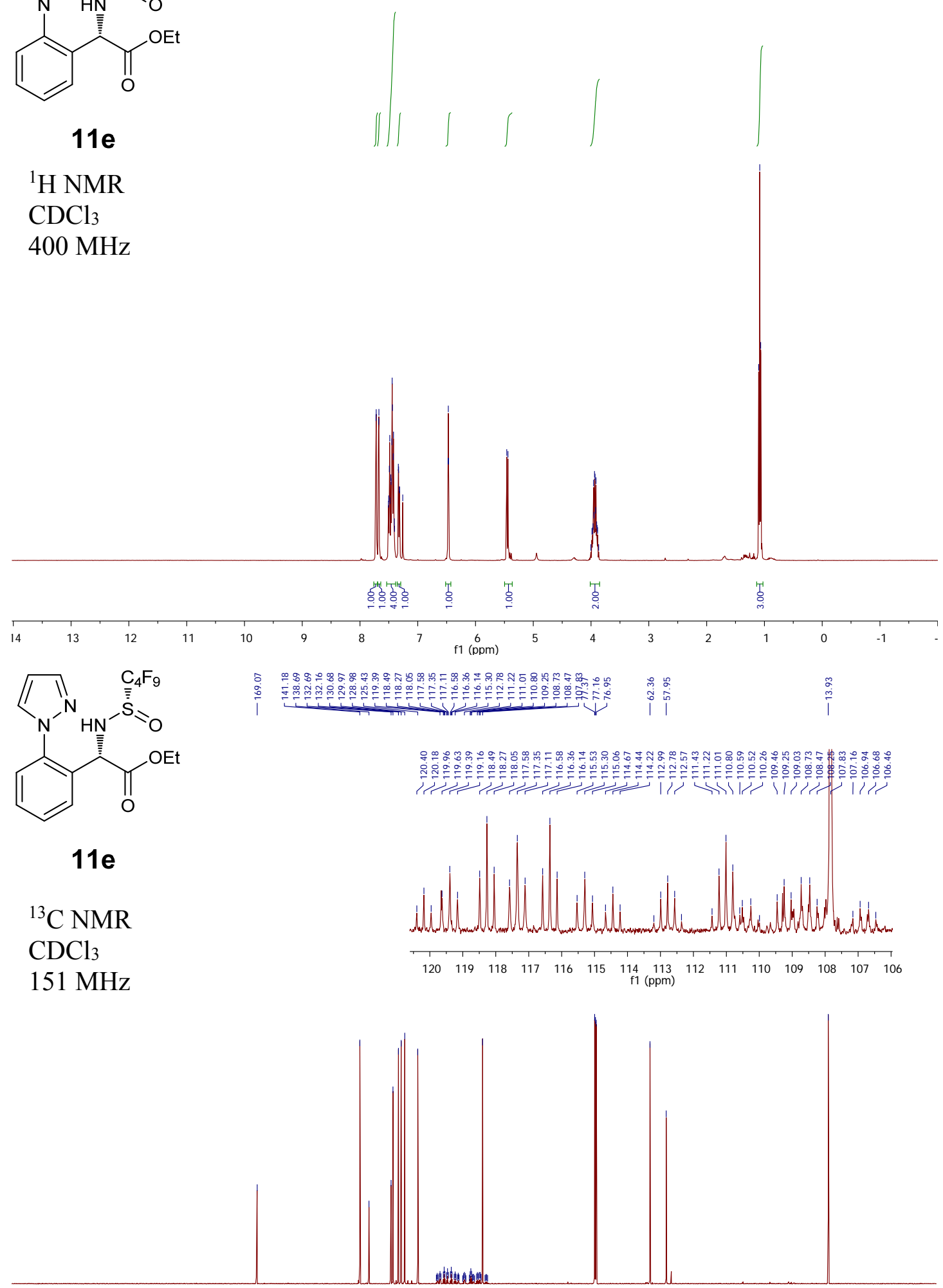

$\begin{array}{llllllllllllllllllllllllllllll}230 & 220 & 210 & 200 & 190 & 180 & 170 & 160 & 150 & 140 & 130 & 120 & 110 & 100 & 90 & 80 & 70 & 60 & 50 & 40 & 30 & 20 & 10 & 0 & -10\end{array}$ 


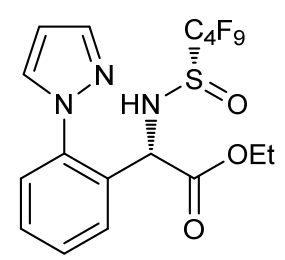

$11 \mathrm{e}$

${ }^{19} \mathrm{~F}$ NMR

$\mathrm{CDCl}_{3}$

$376 \mathrm{MHz}$

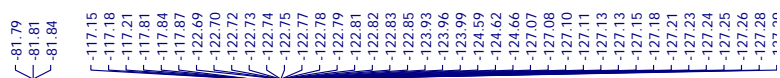

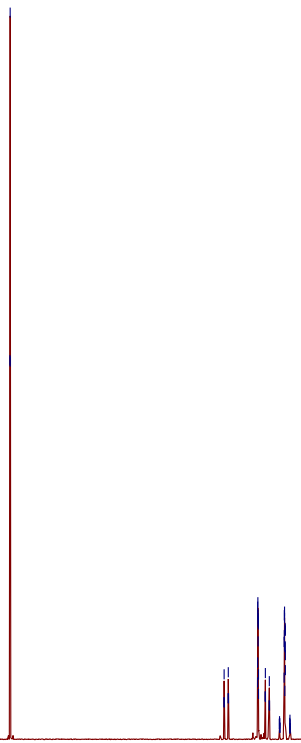

\begin{tabular}{llllllllllllllllllllllllllllllll}
\hline 30 & 20 & 10 & 0 & -10 & -20 & -30 & -40 & -50 & -60 & -70 & -80 & -90 & -100 & -110 & -120 & -130 & -140 & -150 & -160 & -170 & -180 & -190 & -200
\end{tabular} 


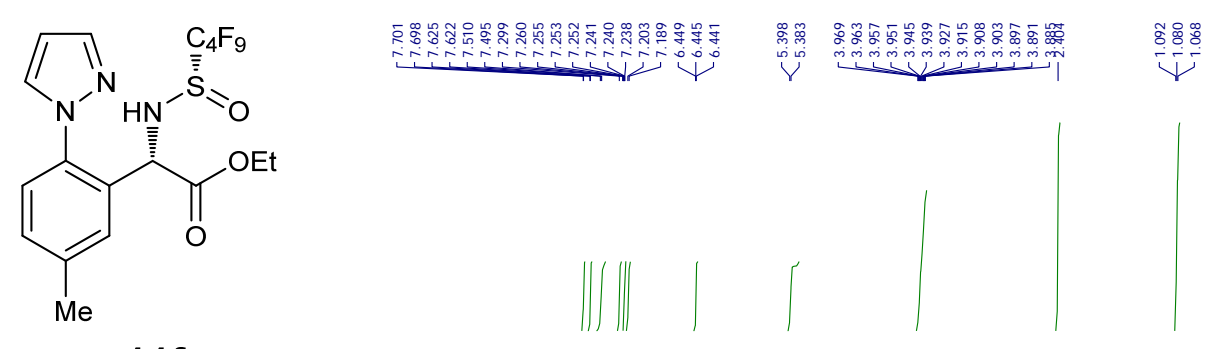

\section{$11 f$}

${ }^{1} \mathrm{H}$ NMR

$\mathrm{CDCl}_{3}$

$600 \mathrm{MHz}$
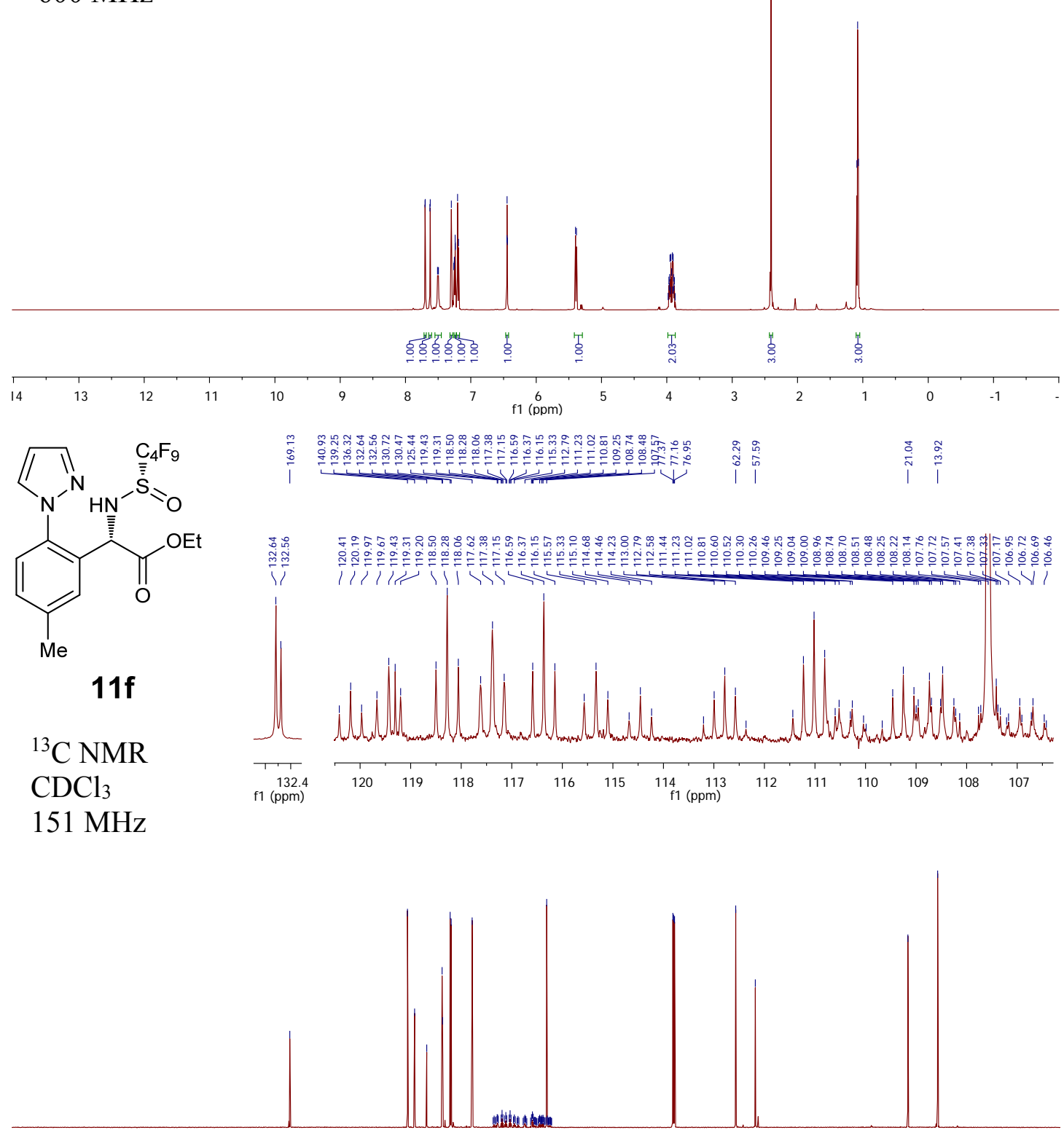

$\begin{array}{llllllllllllllllllllllllll}230 & 220 & 210 & 200 & 190 & 180 & 170 & 160 & 150 & 140 & 130 & 120 & 110 & 100 & 90 & 80 & 70 & 60 & 50 & 40 & 30 & 20 & 10 & 0 & -10\end{array}$ 


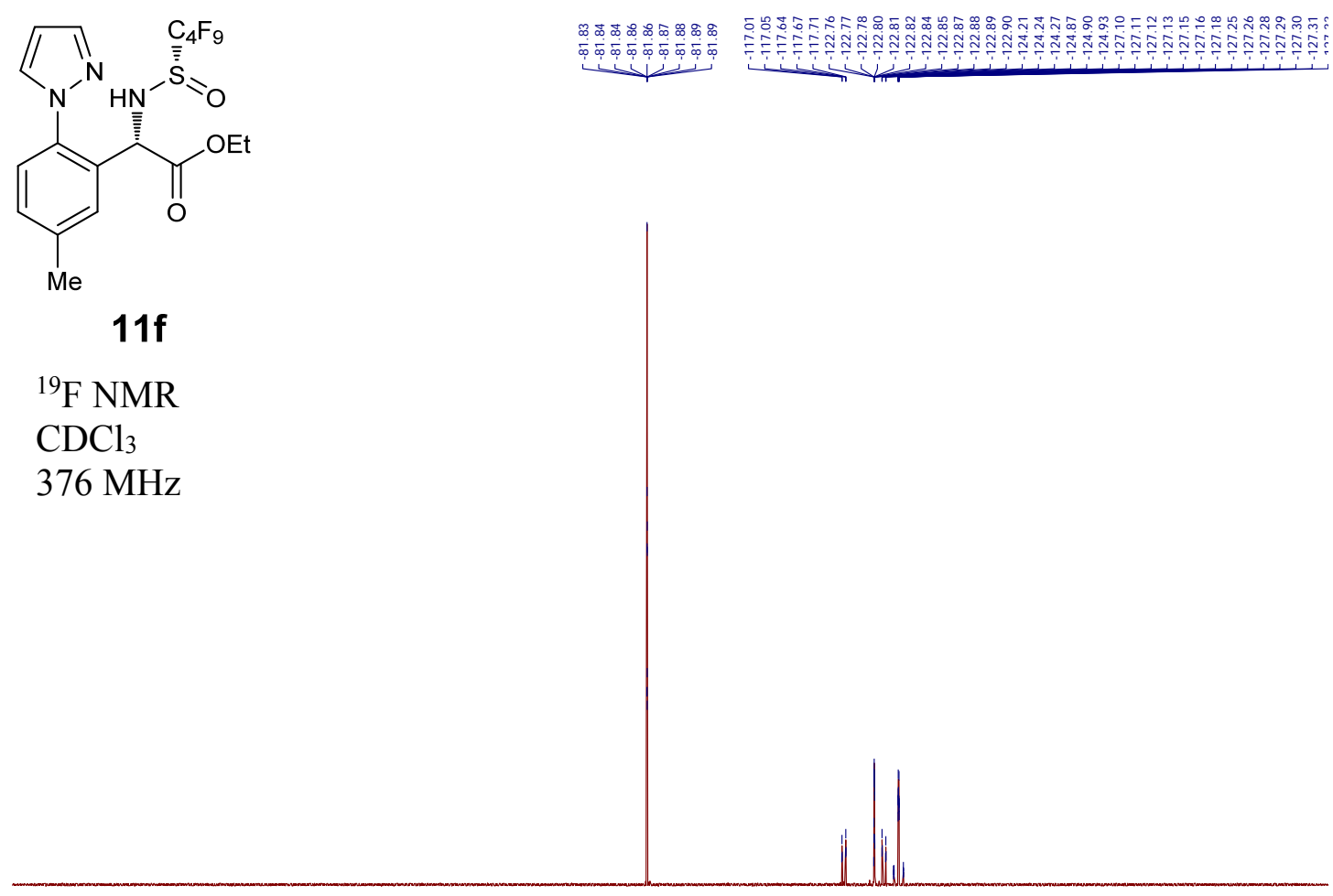

$\begin{array}{llllllllllllllllllllllllllllll} & 30 & 20 & 10 & 0 & -10 & -20 & -30 & -40 & -50 & -60 & -70 & -80 & -90 & -100 & -110 & -120 & -130 & -140 & -150 & -160 & -170 & -180 & -190 & -200\end{array}$ 

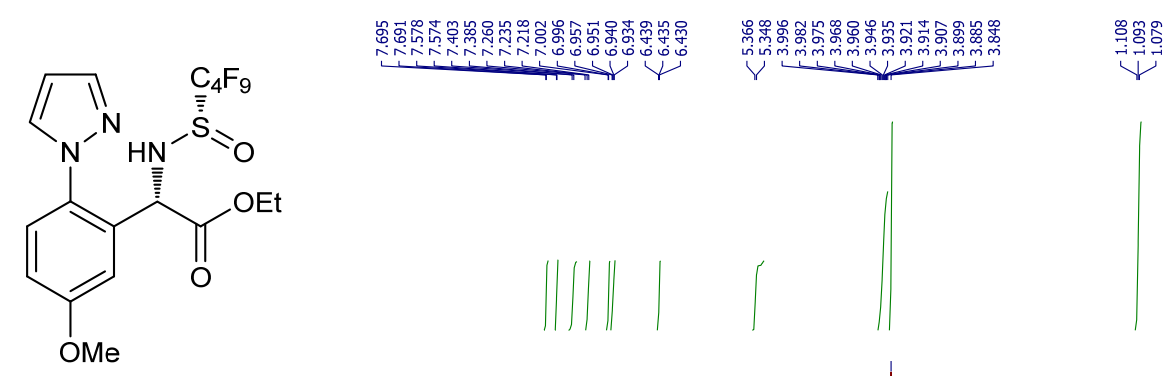

\section{1g}

\section{${ }^{1} \mathrm{H}$ NMR}

$\mathrm{CDCl}_{3}$

$500 \mathrm{MHz}$
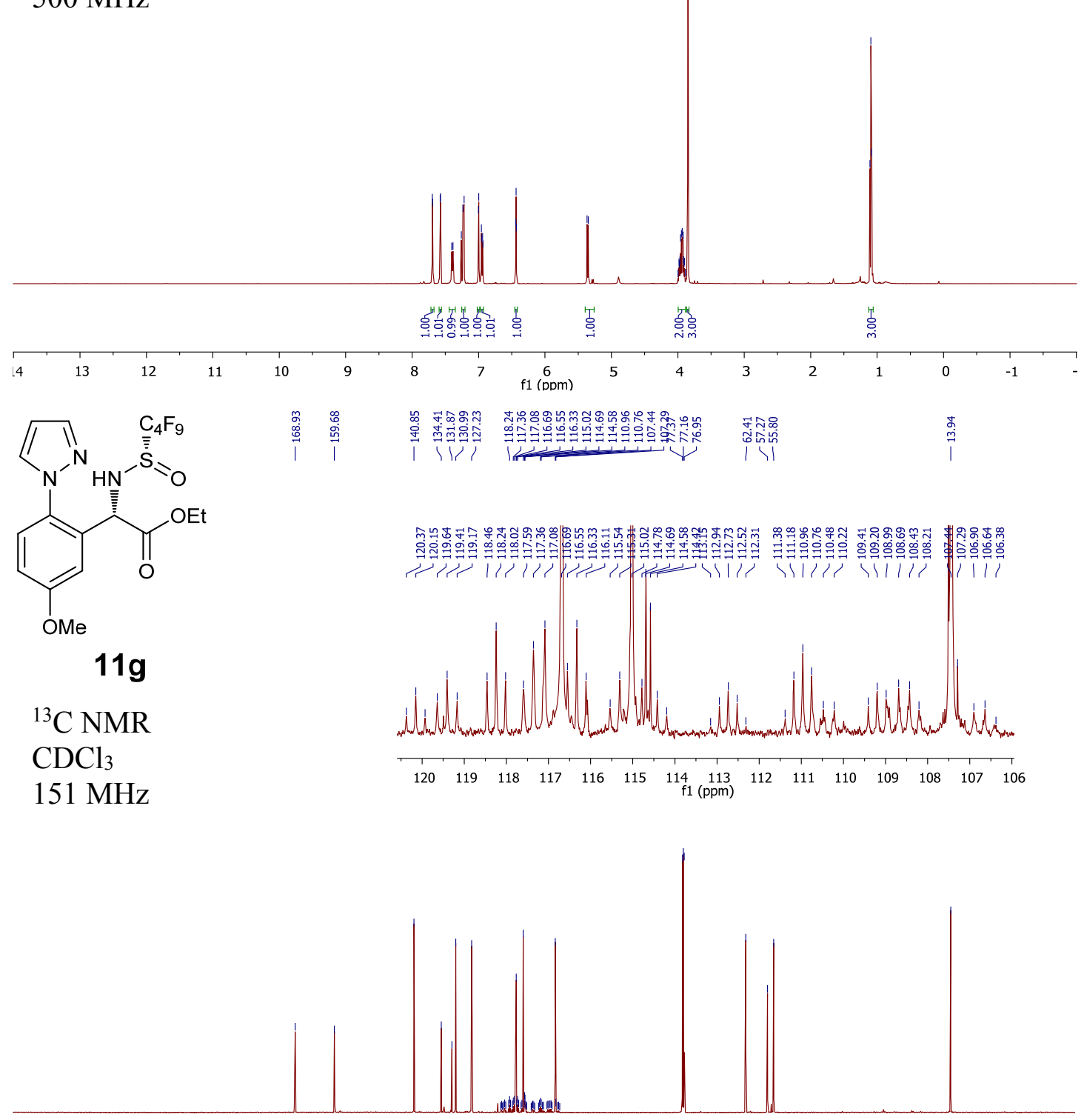

$\begin{array}{lllllllllllllllllllllllllllll}230 & 220 & 210 & 200 & 190 & 180 & 170 & 160 & 150 & 140 & 130 & 120 & \begin{array}{l}110 \\ \mathrm{f} 1\end{array}(\mathrm{ppm}) & 100 & 90 & 80 & 70 & 60 & 50 & 40 & 30 & 20 & 10 & 0 & -10\end{array}$ 


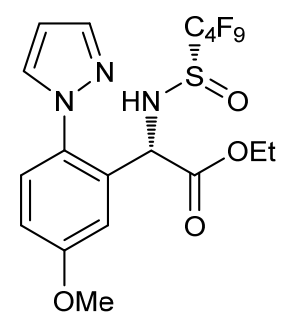

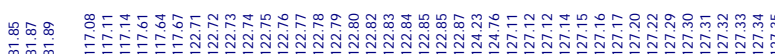

$11 \mathrm{~g}$

${ }^{19} \mathrm{~F}$ NMR

$\mathrm{CDCl}_{3}$

$471 \mathrm{MHz}$

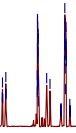

\begin{tabular}{lllllllllllllllllllllllllllllll}
\hline 20 & 10 & 0 & -10 & -20 & -30 & -40 & -50 & -60 & -70 & -80 & -90 & -100 & -110 & -120 & -130 & -140 & -150 & -160 & -170 & -180 & -190 & -20
\end{tabular}




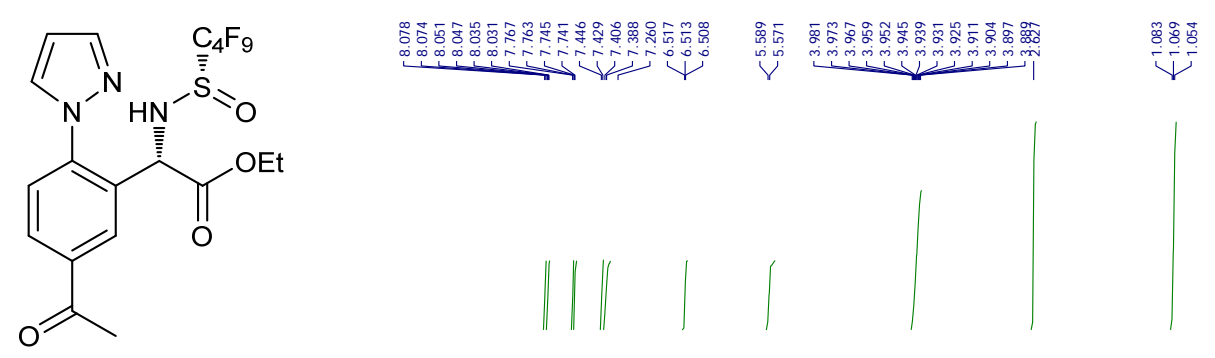

$11 \mathrm{~h}$

${ }^{1} \mathrm{H}$ NMR

$\mathrm{CDCl}_{3}$

$500 \mathrm{MHz}$

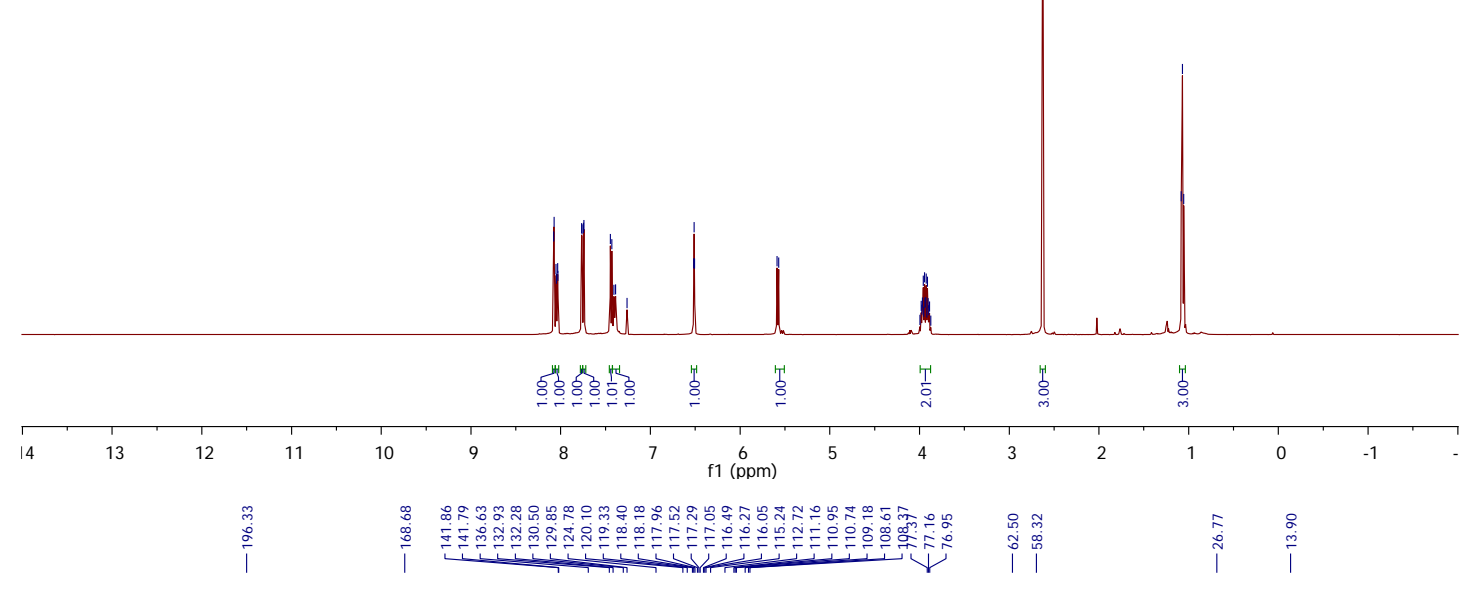<smiles>CCOC(=O)[C@H](NS(=O)C(F)(F)F)c1cc(C(C)=O)ccc1-n1cccn1</smiles>

$11 \mathrm{~h}$

${ }^{13} \mathrm{C}$ NMR

$\mathrm{CDCl}_{3}$

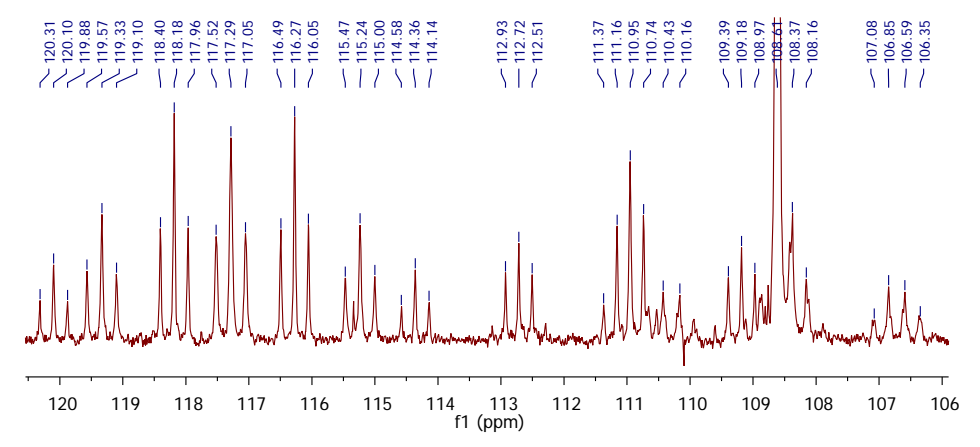

$151 \mathrm{MHz}$

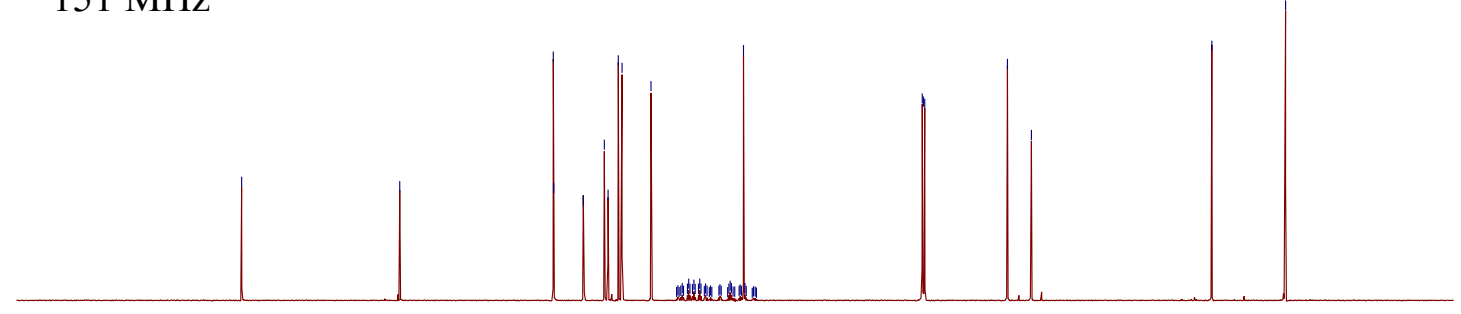

\begin{tabular}{llllllllllllllllllllllllllll}
\hline 230 & 220 & 210 & 200 & 190 & 180 & 170 & 160 & 150 & 140 & 130 & 120 & 110 & 100 & 90 & 80 & 70 & 60 & 50 & 40 & 30 & 20 & 10 & 0 & -10
\end{tabular} 

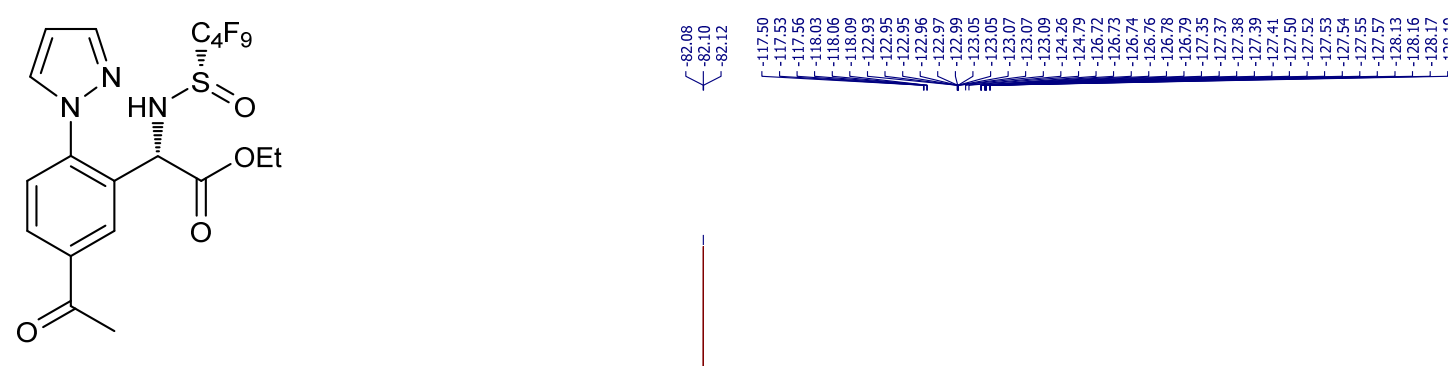

\section{1h}

${ }^{19} \mathrm{~F}$ NMR

$\mathrm{CDCl}_{3}$

$471 \mathrm{MHz}$

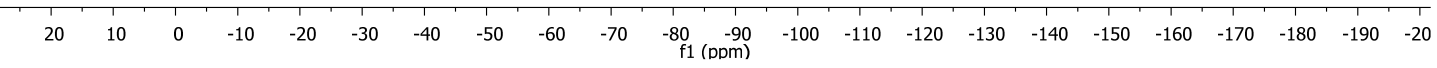


<smiles>CCOC(=O)[C@H](NS(=O)C(F)(F)F)c1ccc(C)cc1-n1cccn1</smiles>

$11 i$
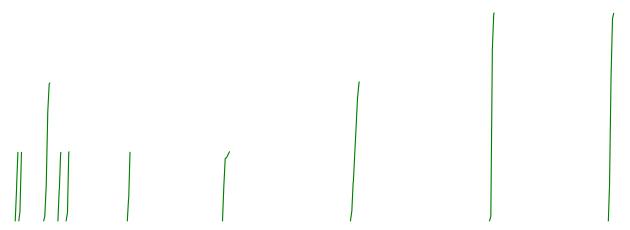

\section{${ }^{1} \mathrm{H}$ NMR \\ $\mathrm{CDCl}_{3}$ \\ $600 \mathrm{MHz}$}
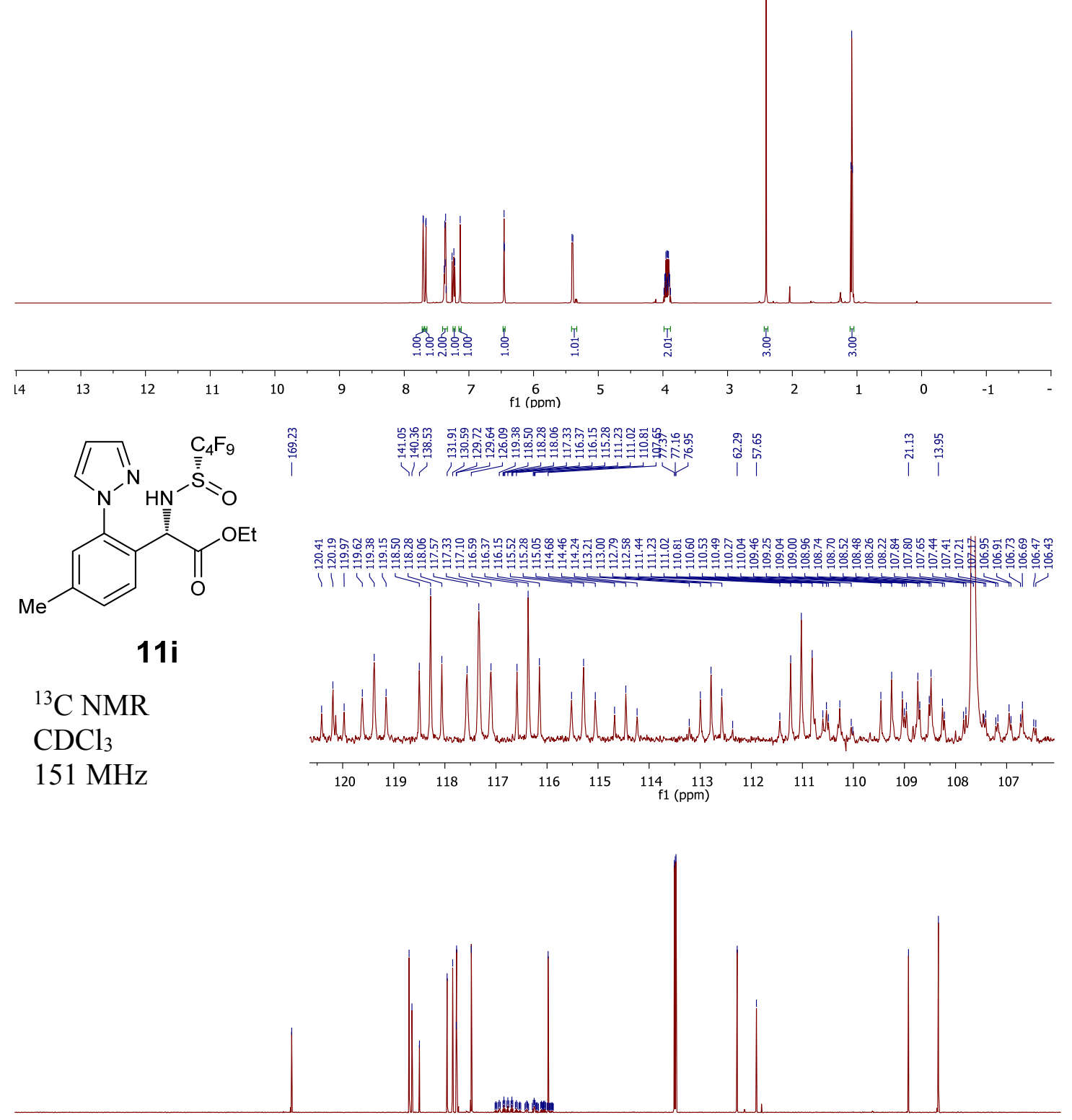

$\begin{array}{lllllllllllllllllllllllll}230 & 220 & 210 & 200 & 190 & 180 & 170 & 160 & 150 & 140 & 130 & 120 & 110 & 100 & 90 & 80 & 70 & 60 & 50 & 40 & 30 & 20 & 10 & 0 & -10\end{array}$ 
<smiles>CCOC(=O)[C@H](NS(=O)C(F)(F)F)c1ccc(C)cc1-n1cccn1</smiles>

$11 i$

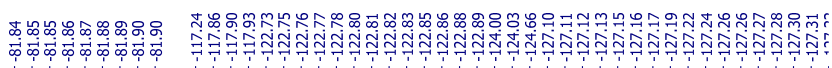

4

\section{${ }^{19} \mathrm{~F}$ NMR $\mathrm{CDCl}_{3}$ $376 \mathrm{MHz}$}

$\begin{array}{lllllllllllllllllllllllll} & 20 & 20 & 10 & 0 & -10 & -20 & -30 & -40 & -50 & -60 & -70 & -80 & -90 & -100 & -110 & -120 & -130 & -140 & -150 & -160 & -170 & -180 & -190 & -200\end{array}$ 


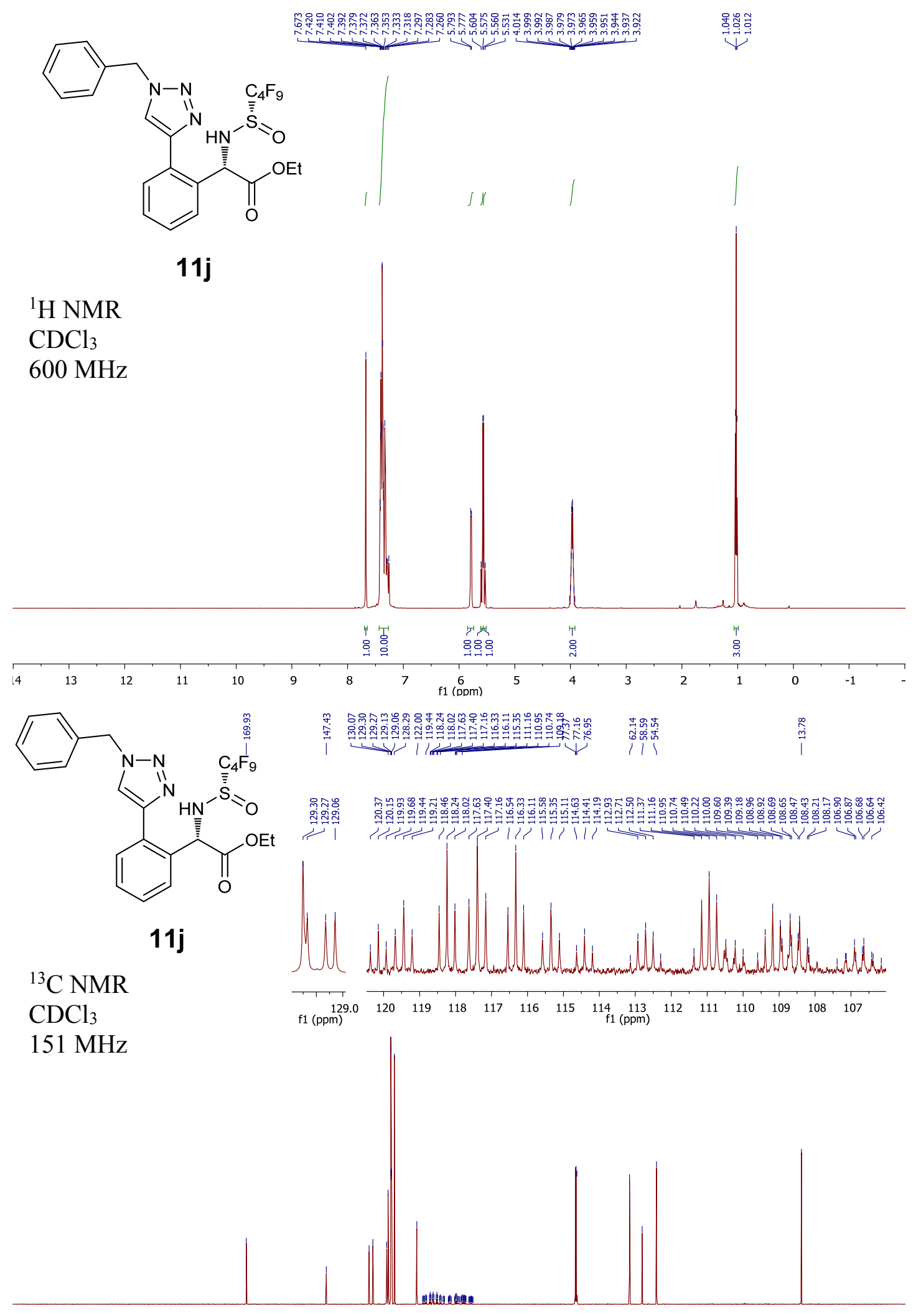

$\begin{array}{llllllllllllllllllllllllll}230 & 220 & 210 & 200 & 190 & 180 & 170 & 160 & 150 & 140 & 130 & 120 & \underset{\mathrm{f} 1}{110}(\mathrm{ppm}) & 100 & 90 & 80 & 70 & 60 & 50 & 40 & 30 & 20 & 10 & 0 & -10\end{array}$ 


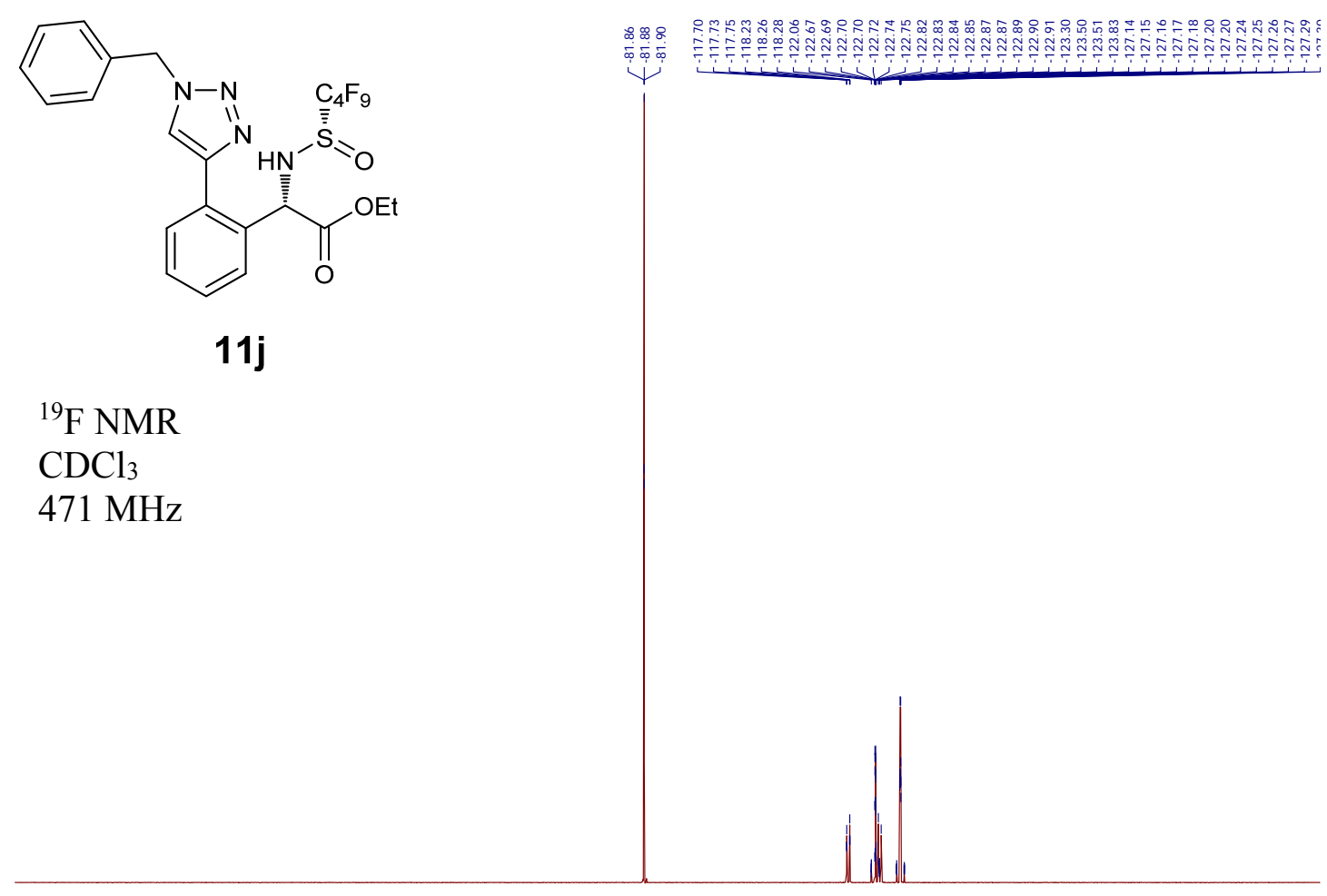

\begin{tabular}{rlllllllllllllllllllllllll}
\hline & 10 \\
& 10 & 0 & -10 & -20 & -30 & -40 & -50 & -60 & -70 & -80 & -90 & -100 & -110 & -120 & -130 & -140 & -150 & -160 & -170 & -180 & -190 & -20
\end{tabular}



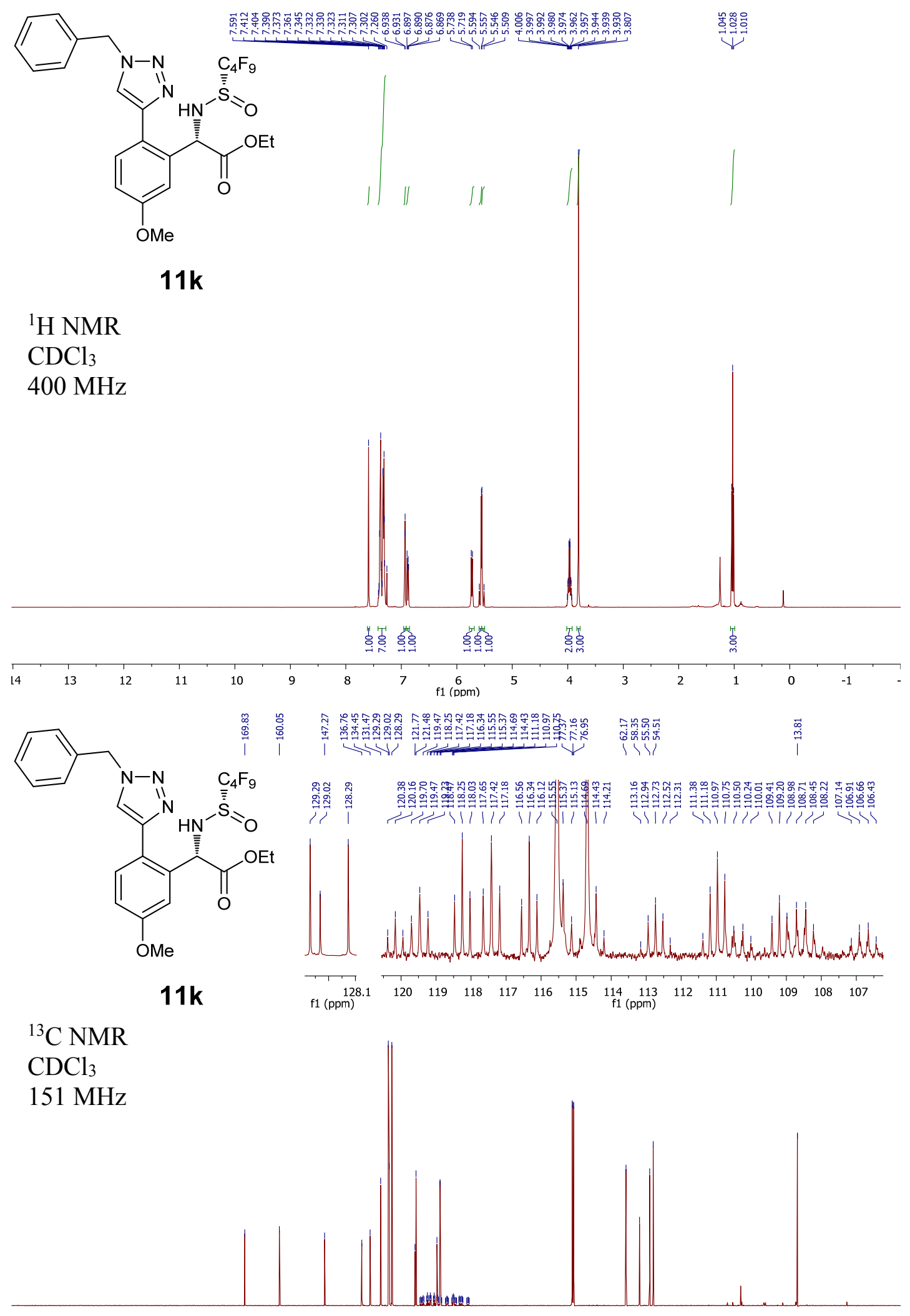

$\begin{array}{llllllllllllllllllllllllllll}230 & 220 & 210 & 200 & 190 & 180 & 170 & 160 & 150 & 140 & 130 & 120 & \underset{\mathrm{f} 1}{110}(\mathrm{ppm}) & 100 & 90 & 80 & 70 & 60 & 50 & 40 & 30 & 20 & 10 & 0 & -10\end{array}$ 


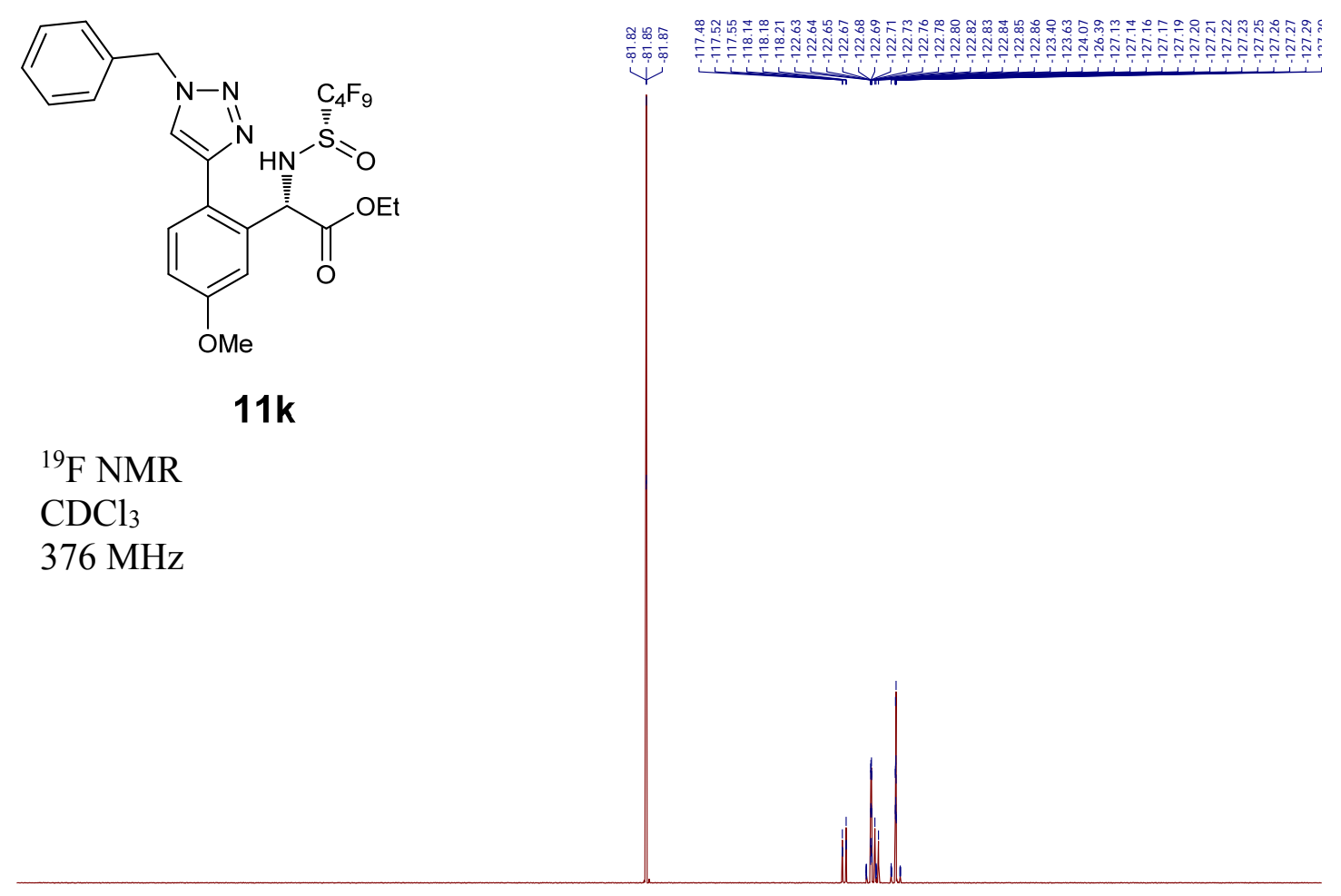

$\begin{array}{llllllllllllllllllllllllllllllll} & 30 & 20 & 10 & 0 & -10 & -20 & -30 & -40 & -50 & -60 & -70 & -80 & -90 & -100 & -110 & -120 & -130 & -140 & -150 & -160 & -170 & -180 & -190 & -200\end{array}$ 


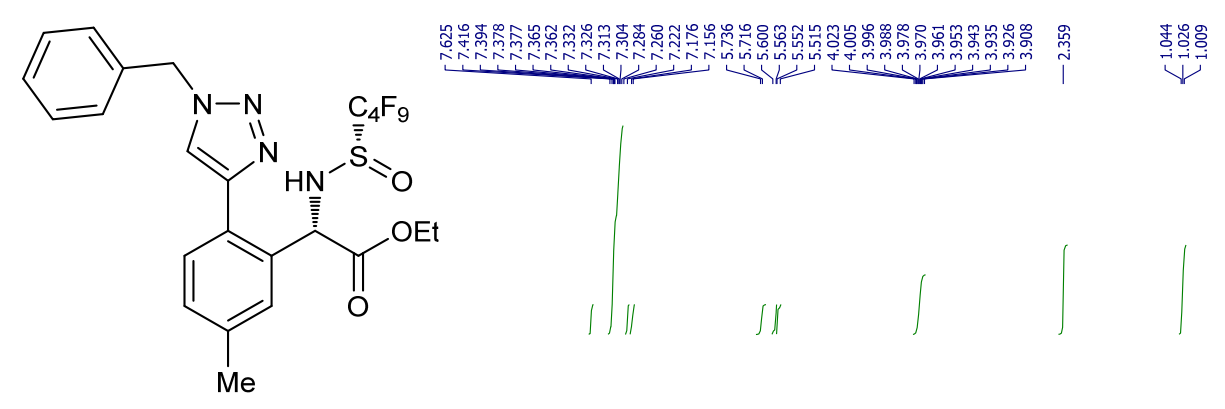

11

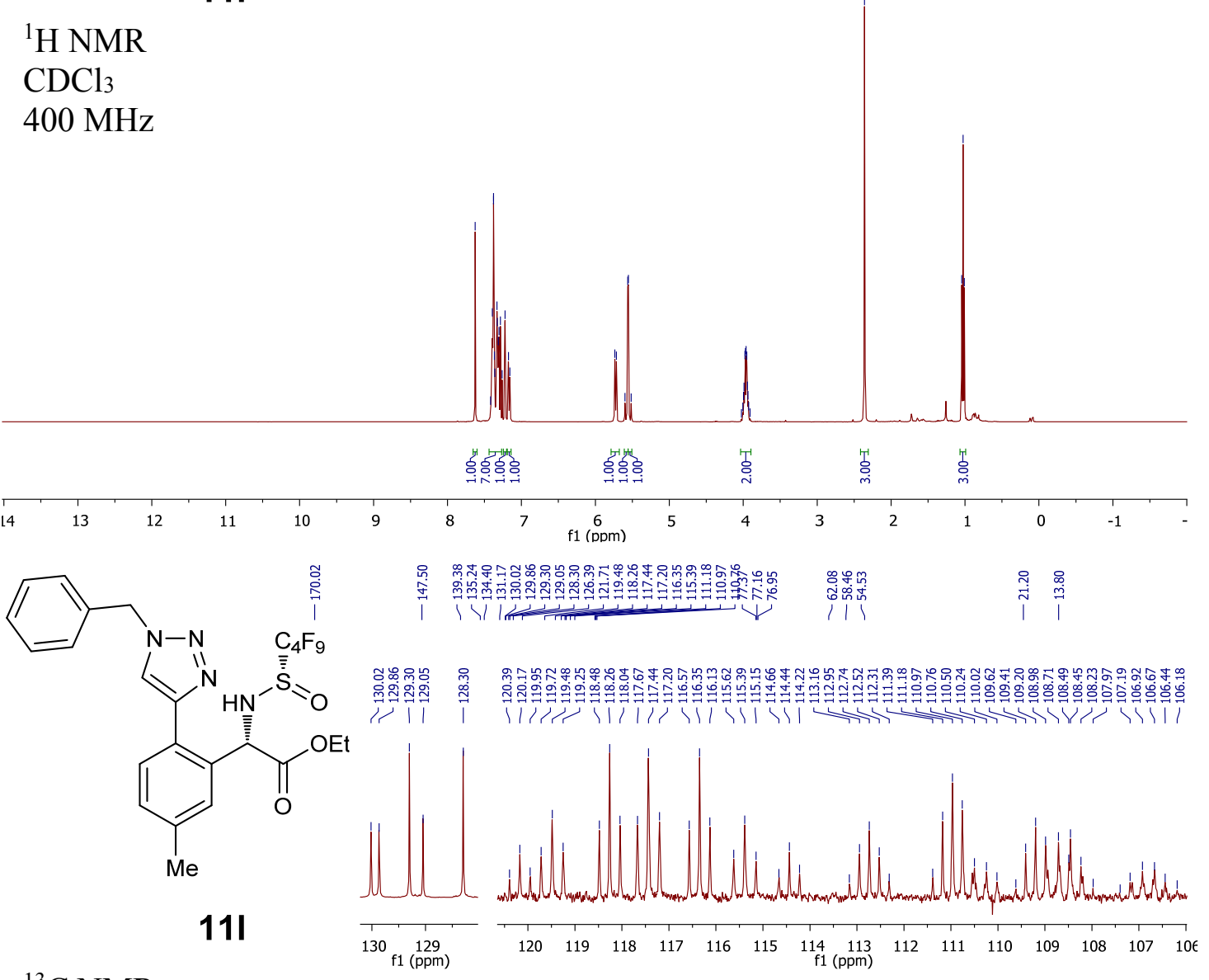

${ }^{13} \mathrm{C}$ NMR

$\mathrm{CDCl}_{3}$

$151 \mathrm{MHz}$

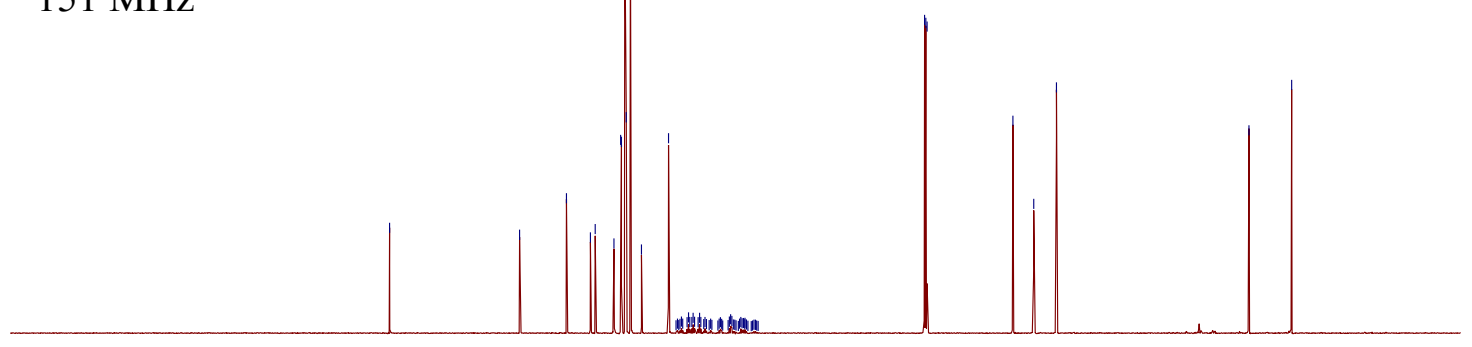

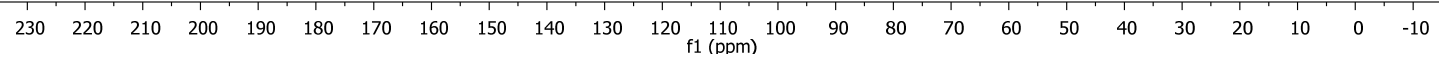




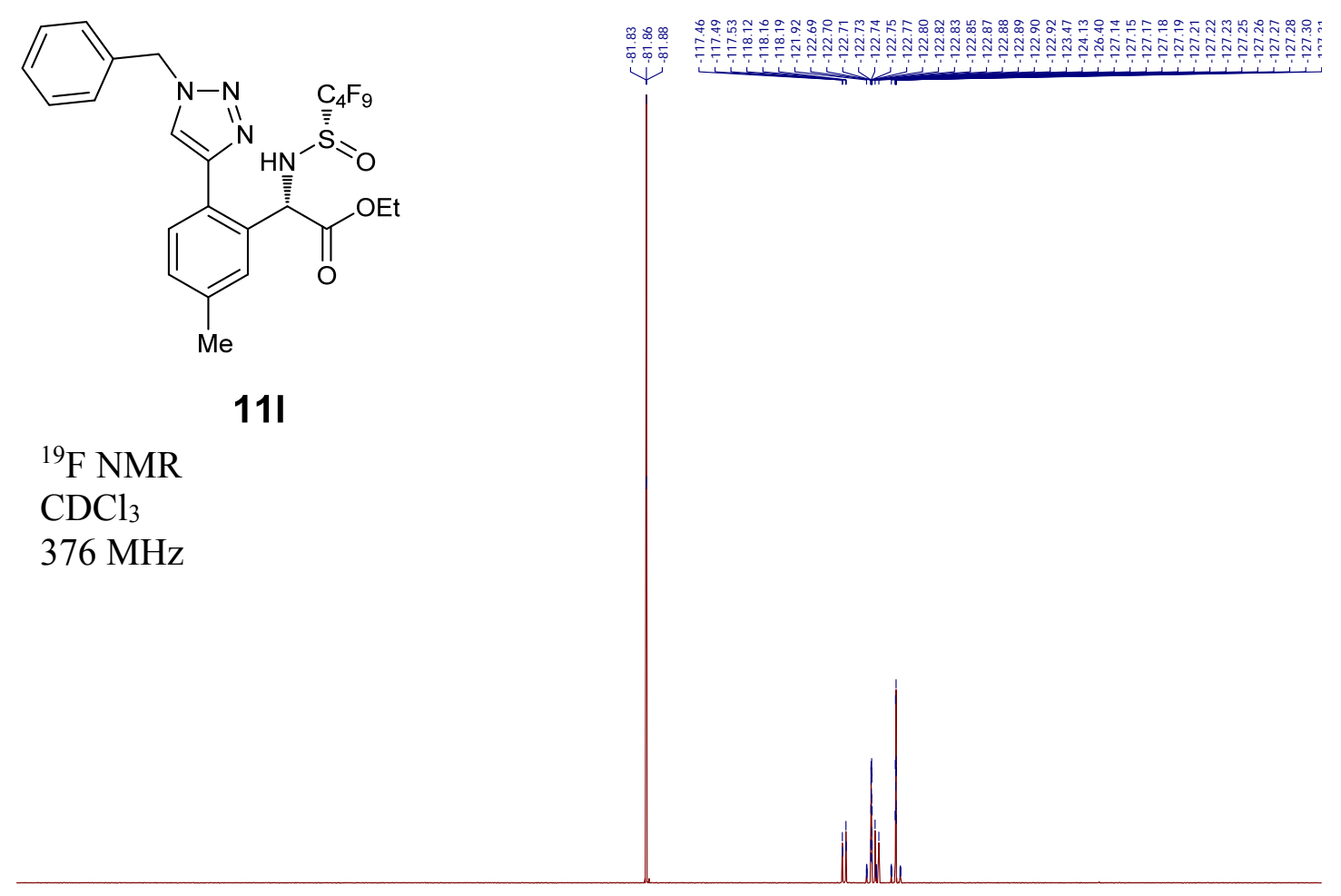

$\begin{array}{llllllllllllllllllllllllllllllll} & 30 & 20 & 10 & 0 & -10 & -20 & -30 & -40 & -50 & -60 & -70 & -80 & -90 & -100 & -110 & -120 & -130 & -140 & -150 & -160 & -170 & -180 & -190 & -200\end{array}$ 

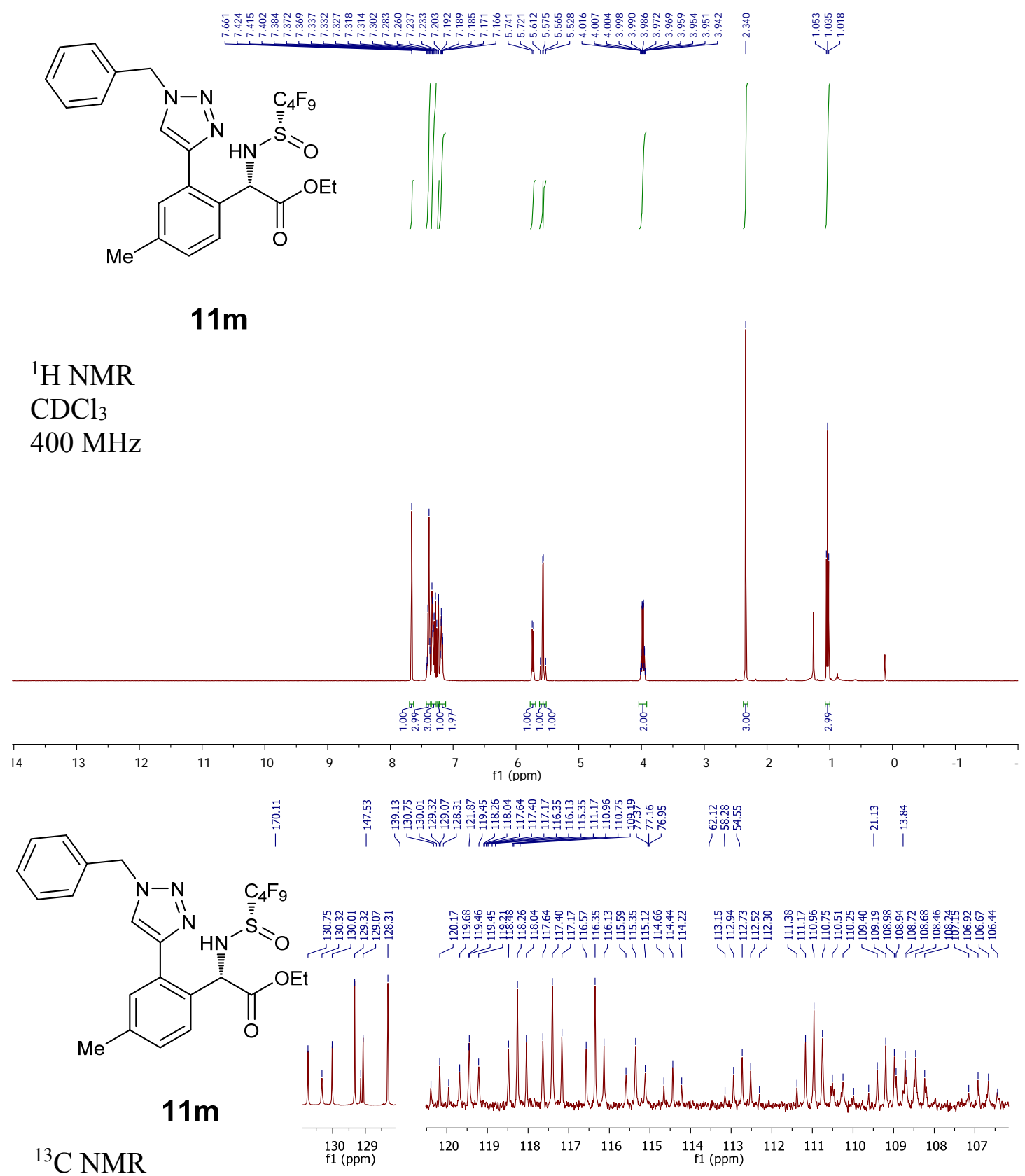

\section{$\mathrm{CDCl}_{3}$ \\ $151 \mathrm{MHz}$}

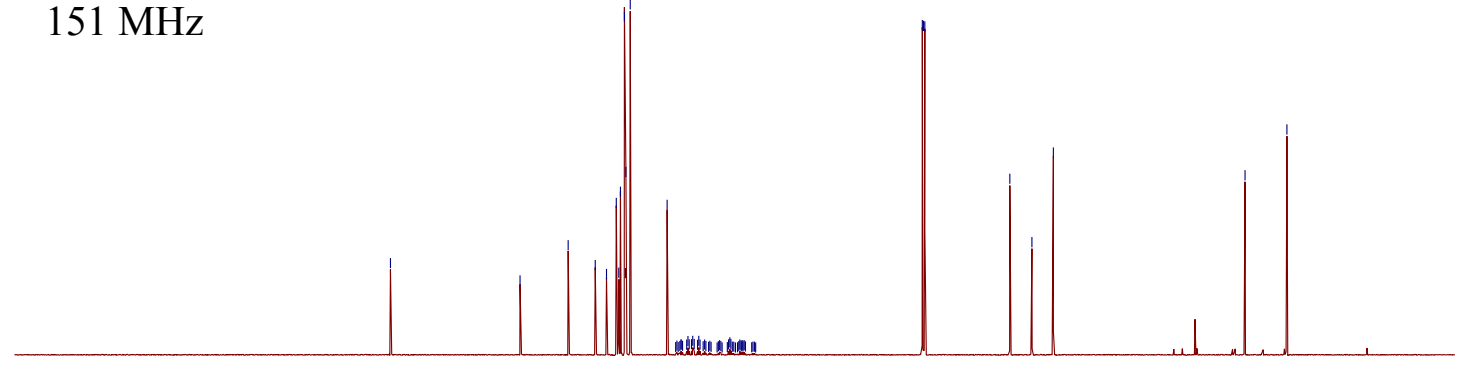

$\begin{array}{lllllllllllllllllllllllll}230 & 220 & 210 & 200 & 190 & 180 & 170 & 160 & 150 & 140 & 130 & 120 & 110 & 100 & 90 & 80 & 70 & 60 & 50 & 40 & 30 & 20 & 10 & 0 & -10\end{array}$ 


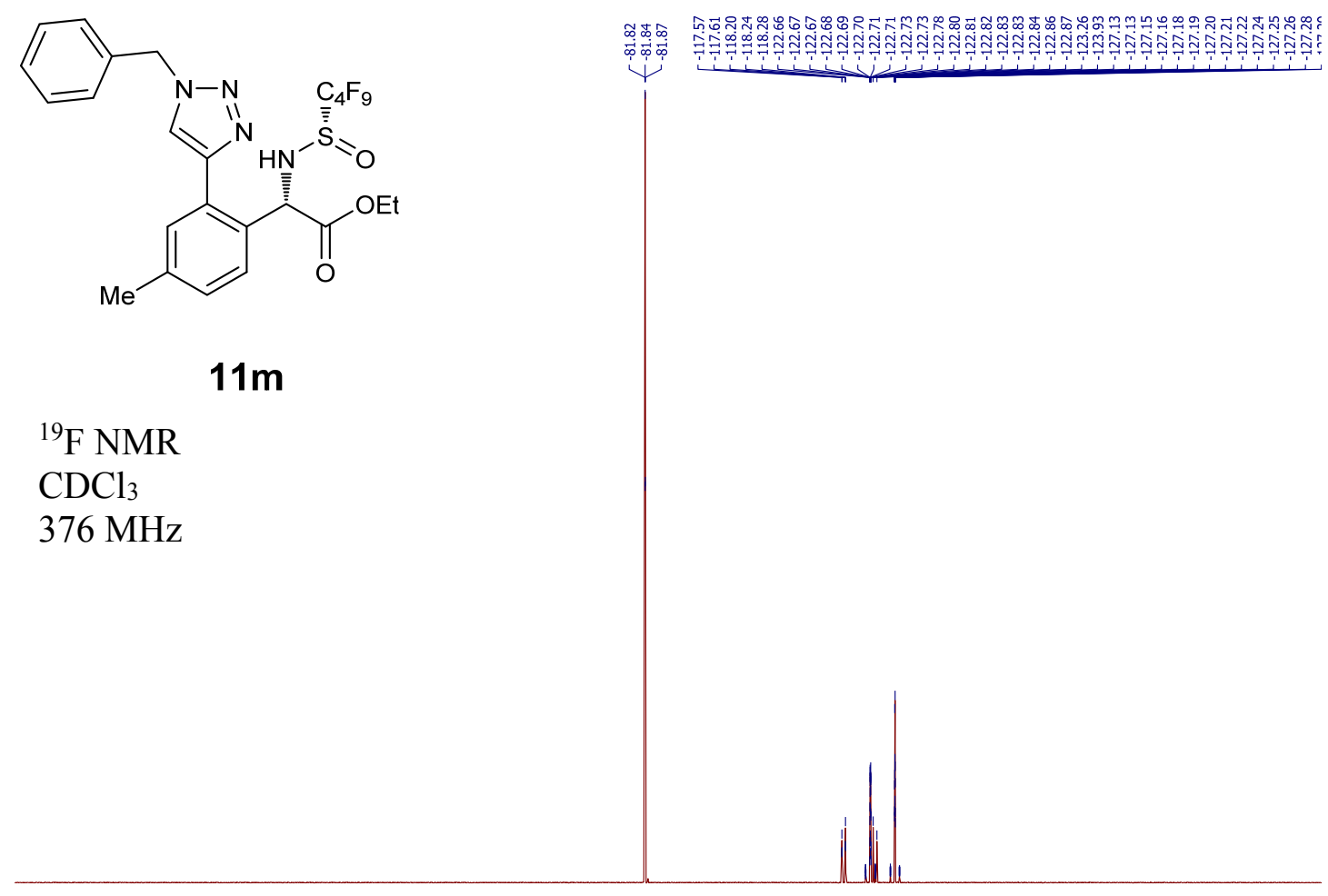

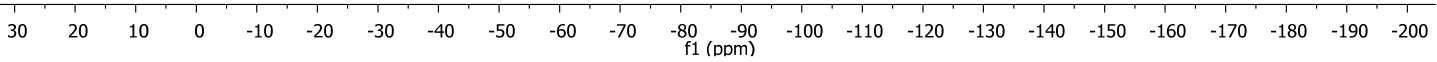


<smiles>CCOC(=O)[C@@H]1CC(C)=CCN1S(=O)C(F)(F)F</smiles>

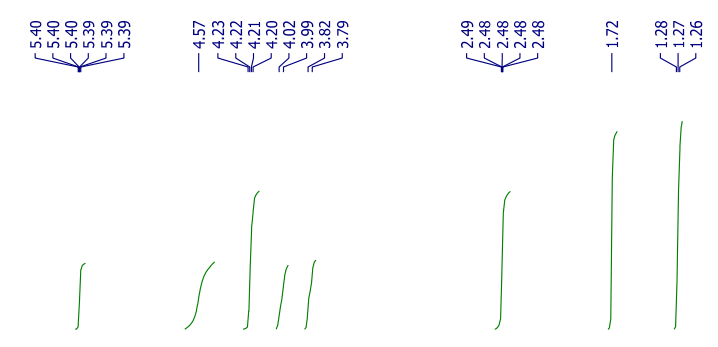

\section{${ }^{1} \mathrm{H}$ NMR \\ $\mathrm{CDCl}_{3}$ \\ $600 \mathrm{MHz}$}
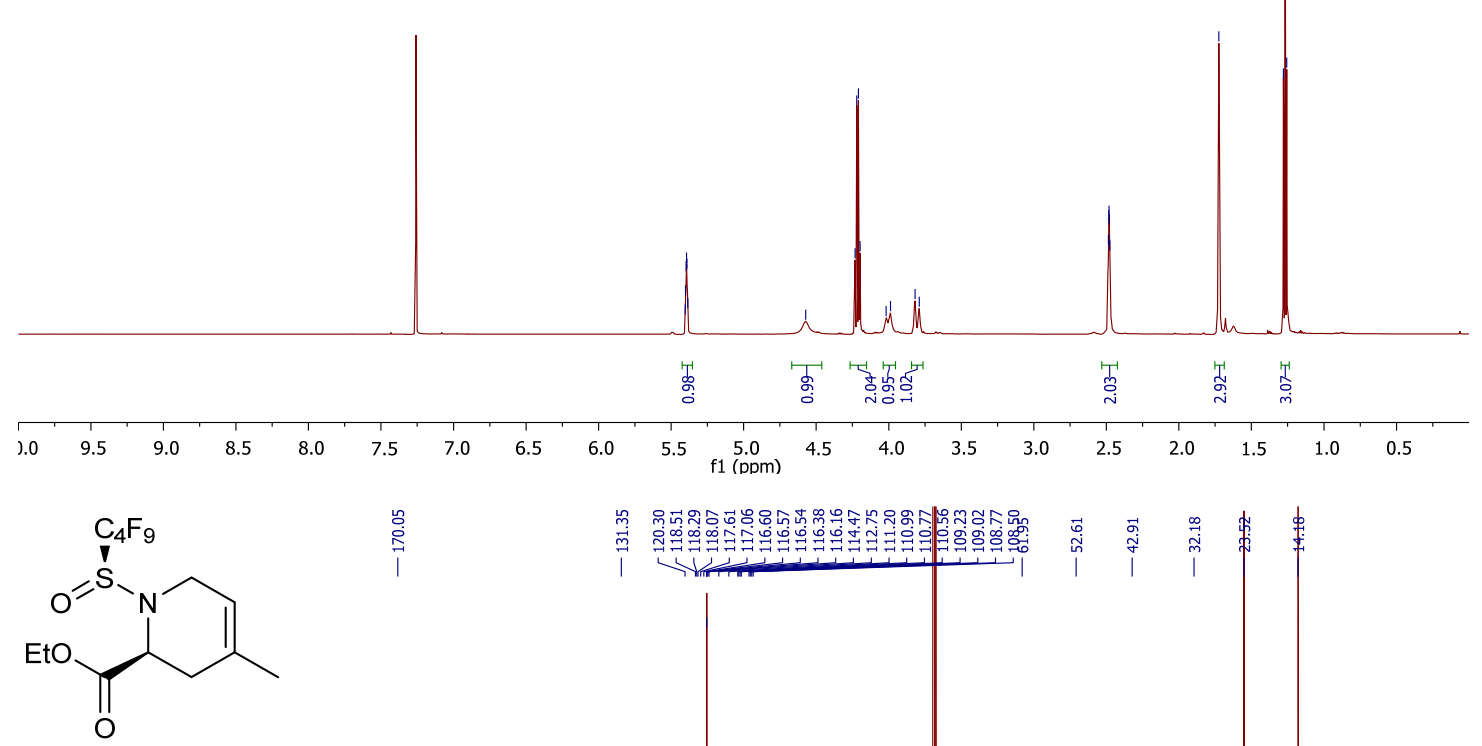

$15 a$

${ }^{13} \mathrm{C}$ NMR

$\mathrm{CDCl}_{3}$

$151 \mathrm{MHz}$

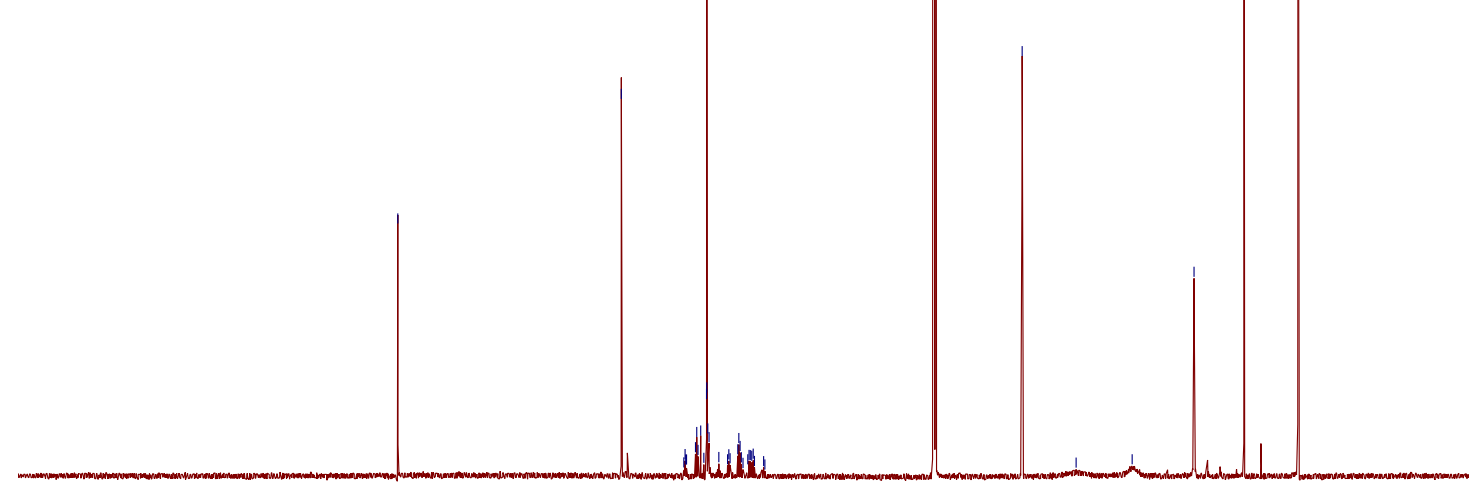

$\begin{array}{llllllllllllllllllllllllll}230 & 220 & 210 & 200 & 190 & 180 & 170 & 160 & 150 & 140 & 130 & 120 & 110 & 100 & 90 & 80 & 70 & 60 & 50 & 40 & 30 & 20 & 10 & 0 & -10\end{array}$ 


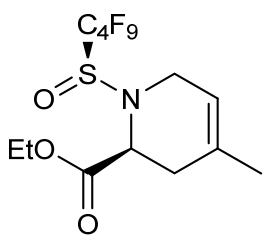

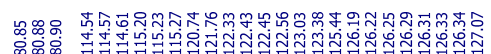

क्ष

$15 a$

${ }^{19} \mathrm{~F}$ NMR

$\mathrm{CDCl}_{3}$

$376 \mathrm{MHz}$

$\begin{array}{lllllllllllllllllllllllllllll}30 & 20 & 10 & 0 & -10 & -20 & -30 & -40 & -50 & -60 & -70 & -80 & -90 & -100 & -110 & -120 & -130 & -140 & -150 & -160 & -170 & -180 & -190 & -200\end{array}$ 
<smiles>CCOC(=O)[C@@H]1CC(C)=C(C)CN1S(=O)C(F)(F)F</smiles>

$15 b$

\section{${ }^{1} \mathrm{H}$ NMR}

$\mathrm{CDCl}_{3}$ $600 \mathrm{MHz}$

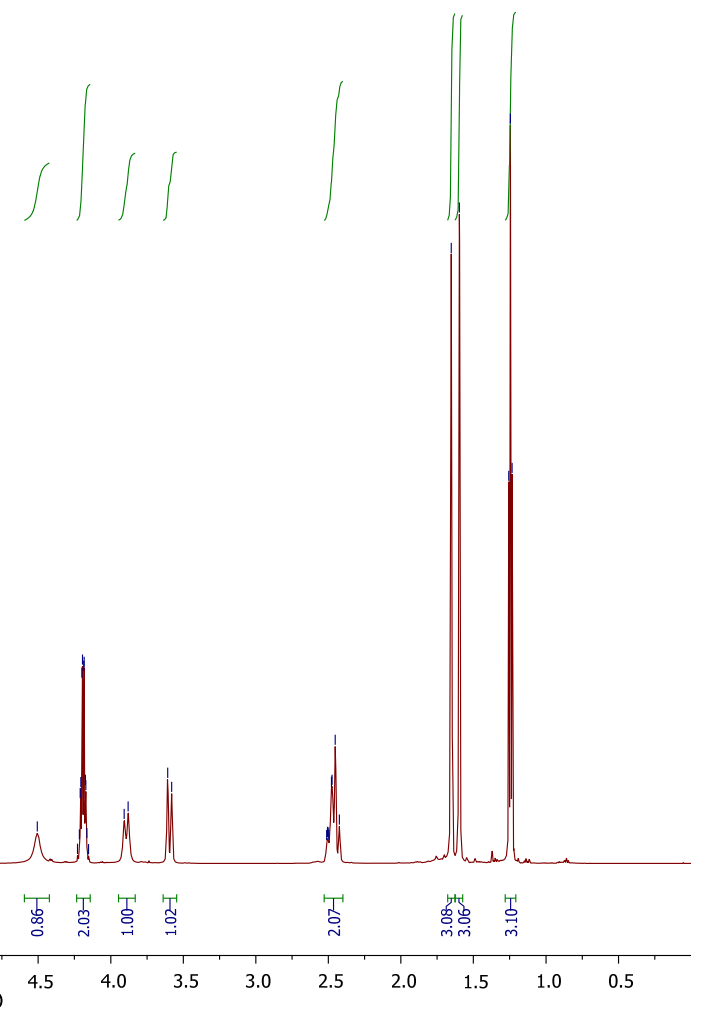

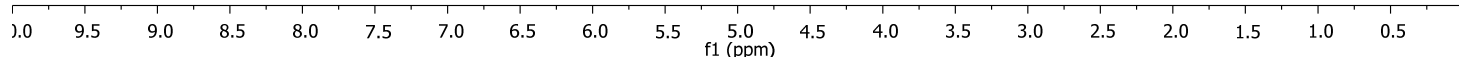

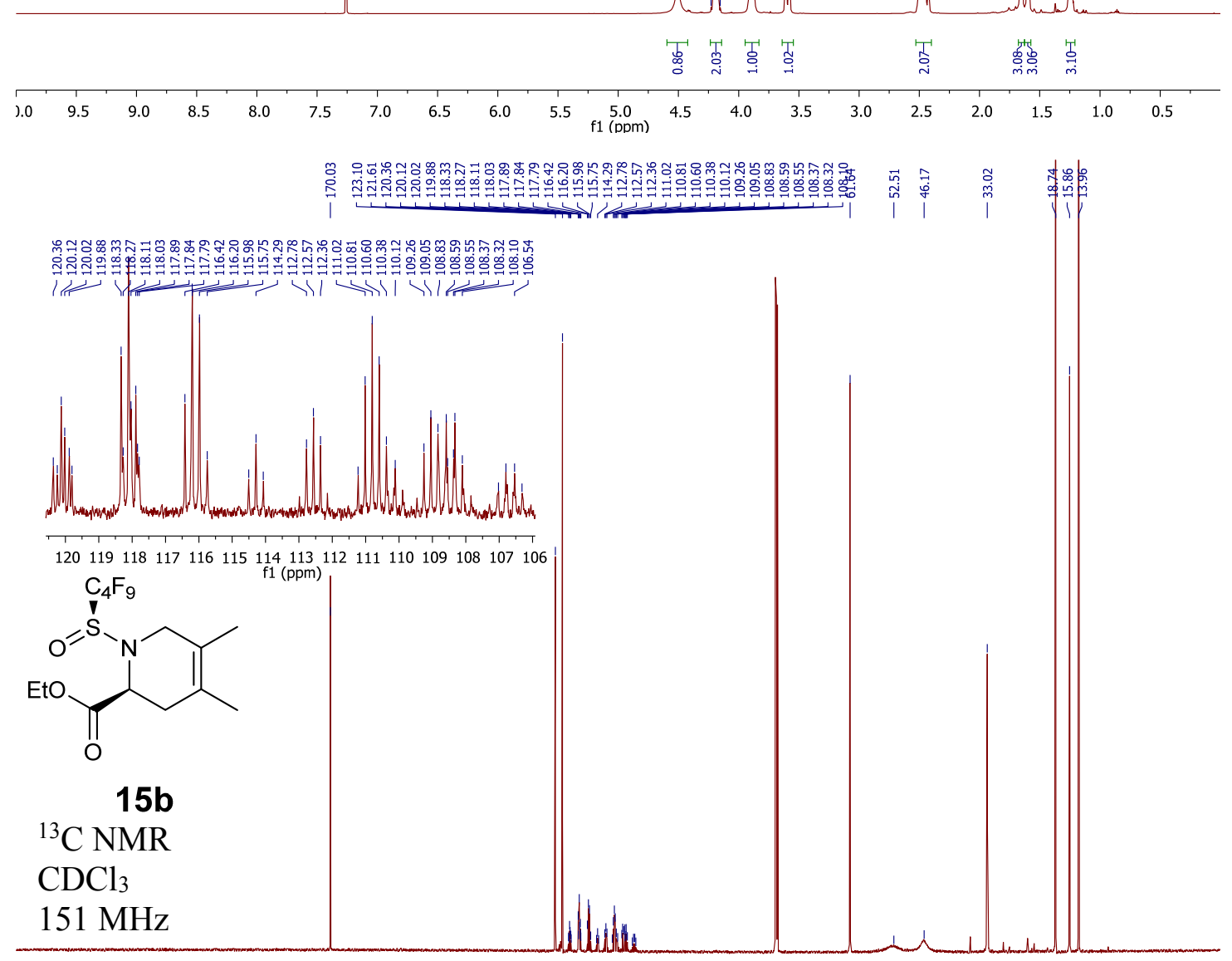

$\begin{array}{llllllllllllllllllllllllllll}230 & 220 & 210 & 200 & 190 & 180 & 170 & 160 & 150 & 140 & 130 & 120 & 110 & 100 & 90 & 80 & 70 & 60 & 50 & 40 & 30 & 20 & 10 & 0 & -10\end{array}$ 


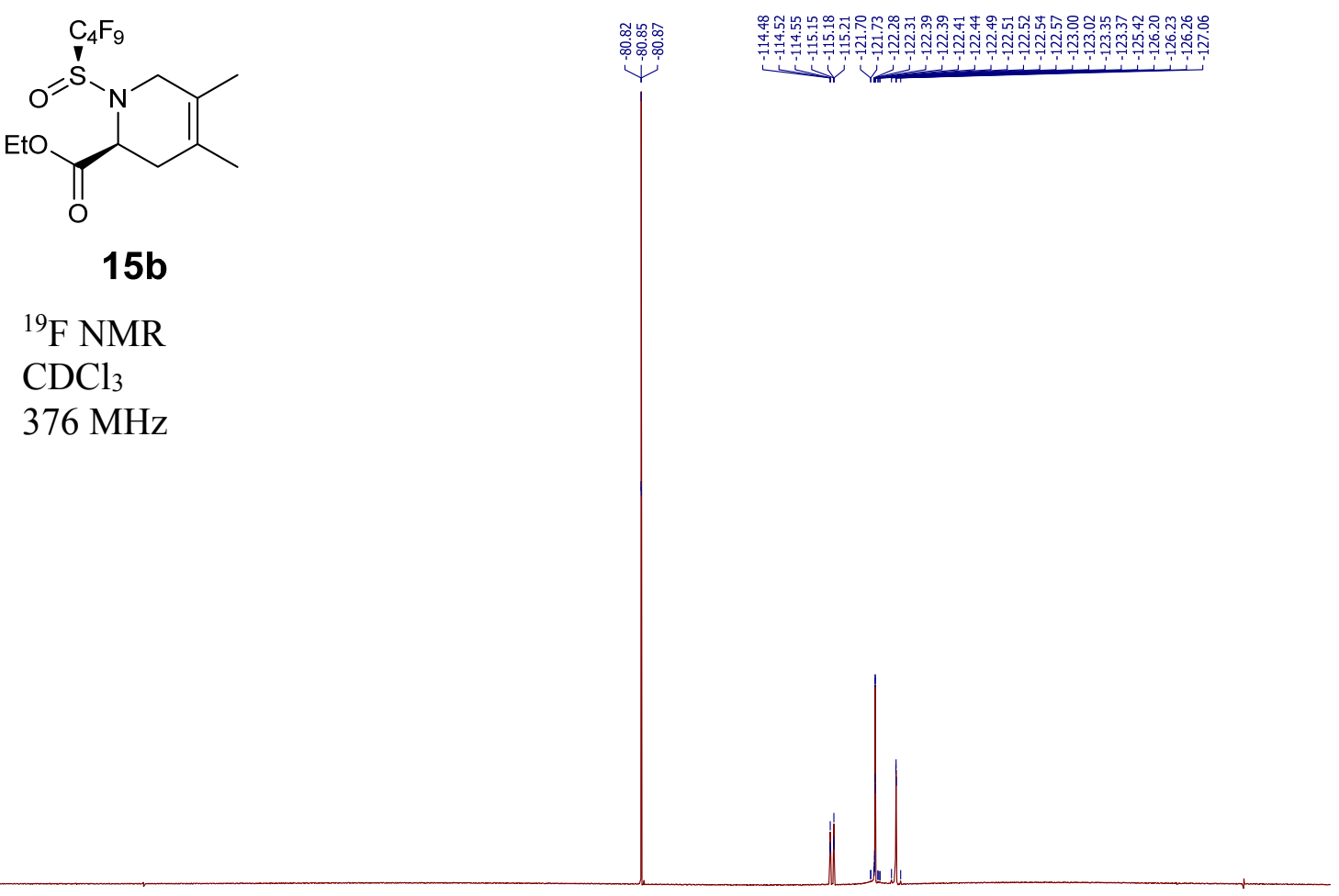

$\begin{array}{lllllllllllllllllllllllllllll}30 & 20 & 10 & 0 & -10 & -20 & -30 & -40 & -50 & -60 & -70 & -80 & -90 & -100 & -110 & -120 & -130 & -140 & -150 & -160 & -170 & -180 & -190 & -200\end{array}$ 

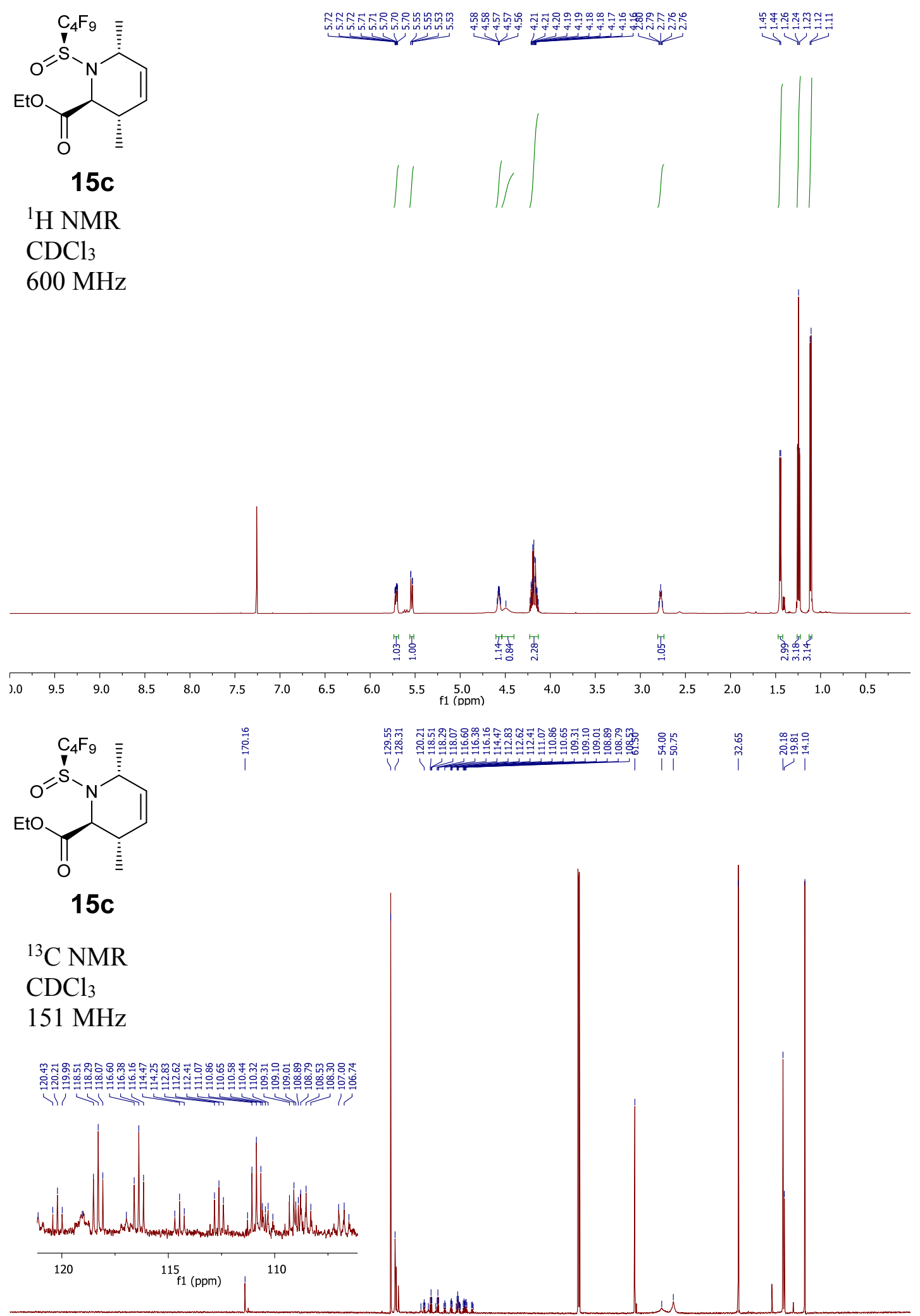

$\begin{array}{lllllllllllllllllllllllllllllllll}230 & 220 & 210 & 200 & 190 & 180 & 170 & 160 & 150 & 140 & 130 & 120 & 110 & 100 & 90 & 80 & 70 & 60 & 50 & 40 & 30 & 20 & 10 & 0 & -10\end{array}$ 

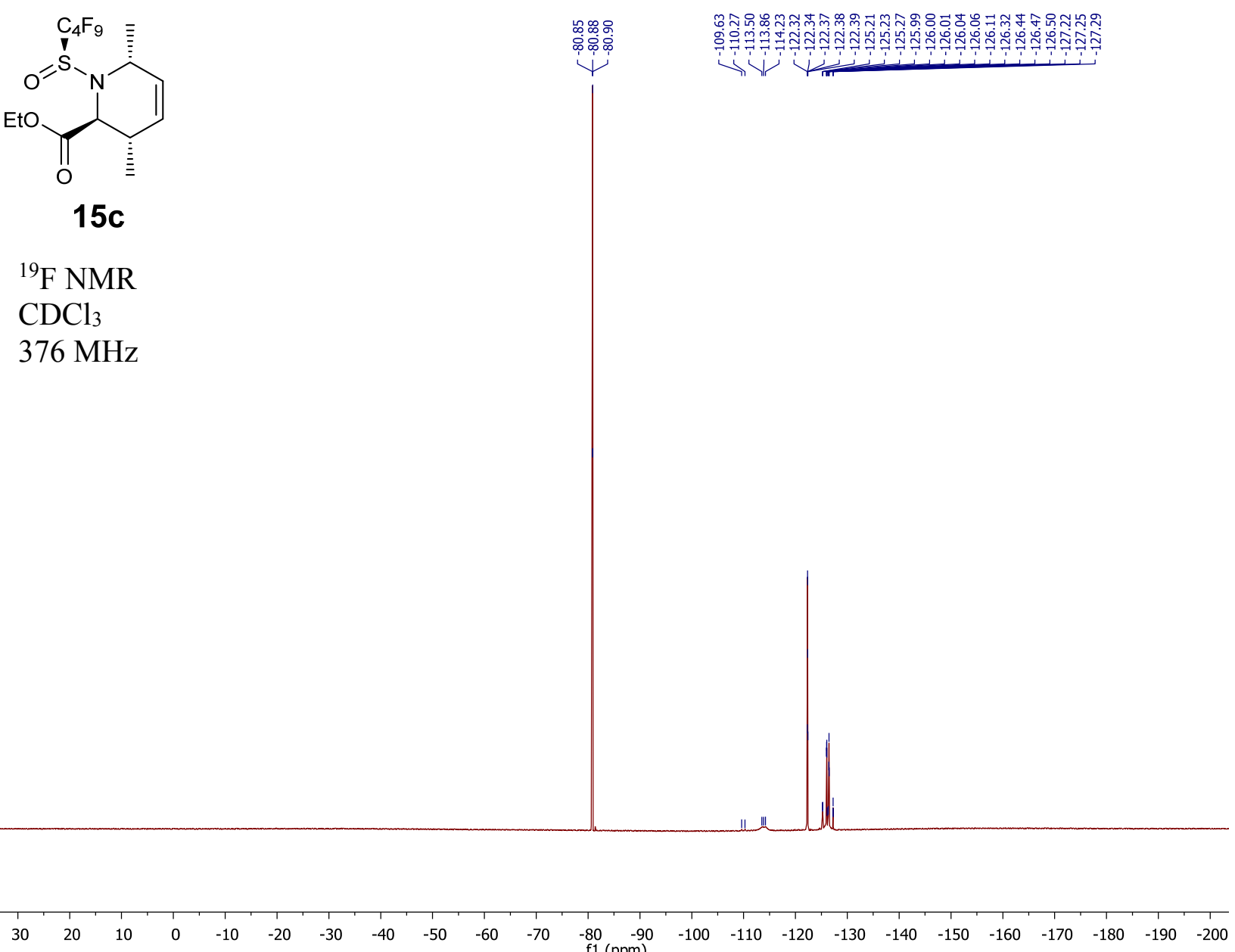

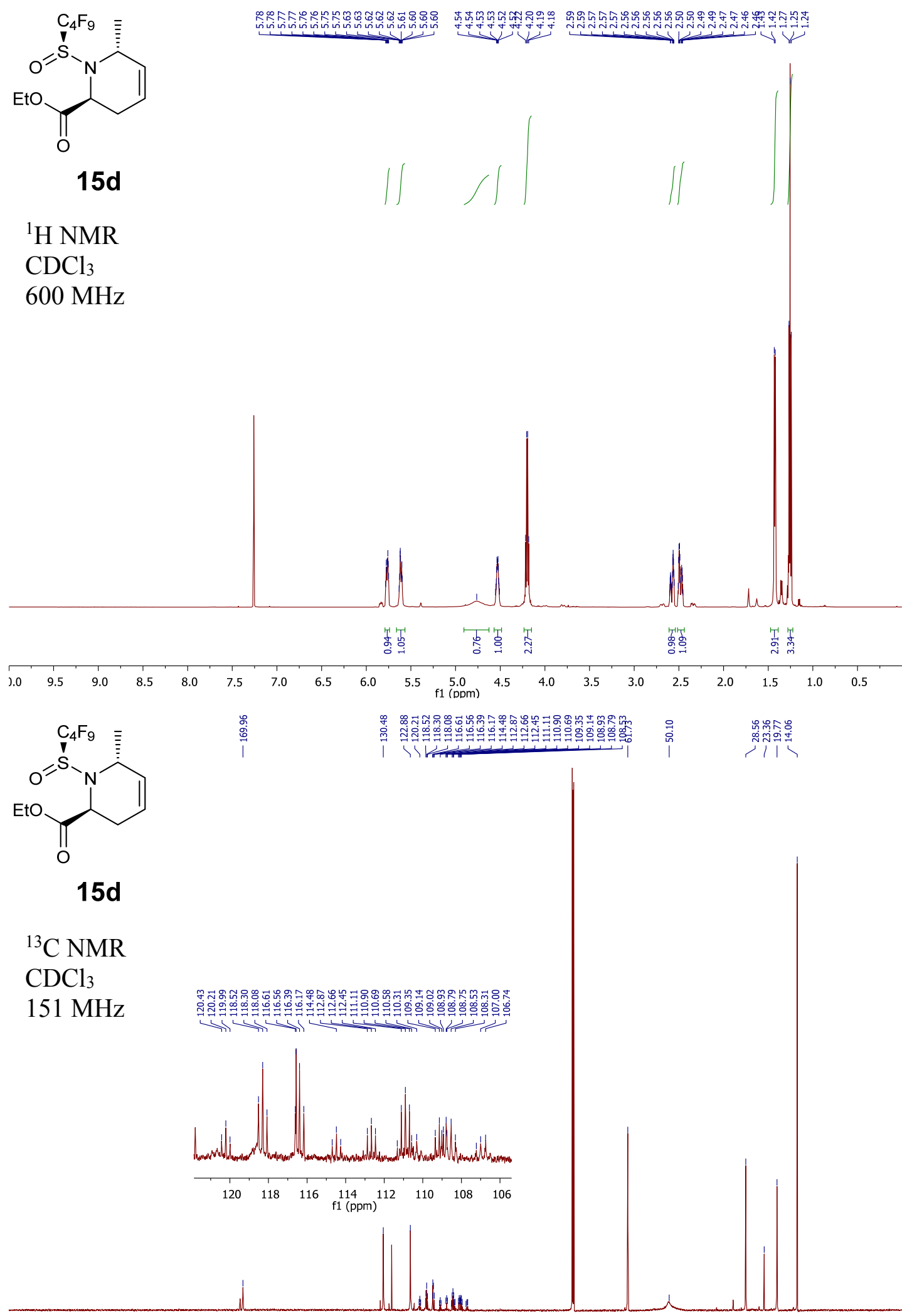

$\begin{array}{llllllllllllllllllllllllll}230 & 220 & 210 & 200 & 190 & 180 & 170 & 160 & 150 & 140 & 130 & 120 & 110 & 100 & 90 & 80 & 70 & 60 & 50 & 40 & 30 & 20 & 10 & 0 & -10\end{array}$ 


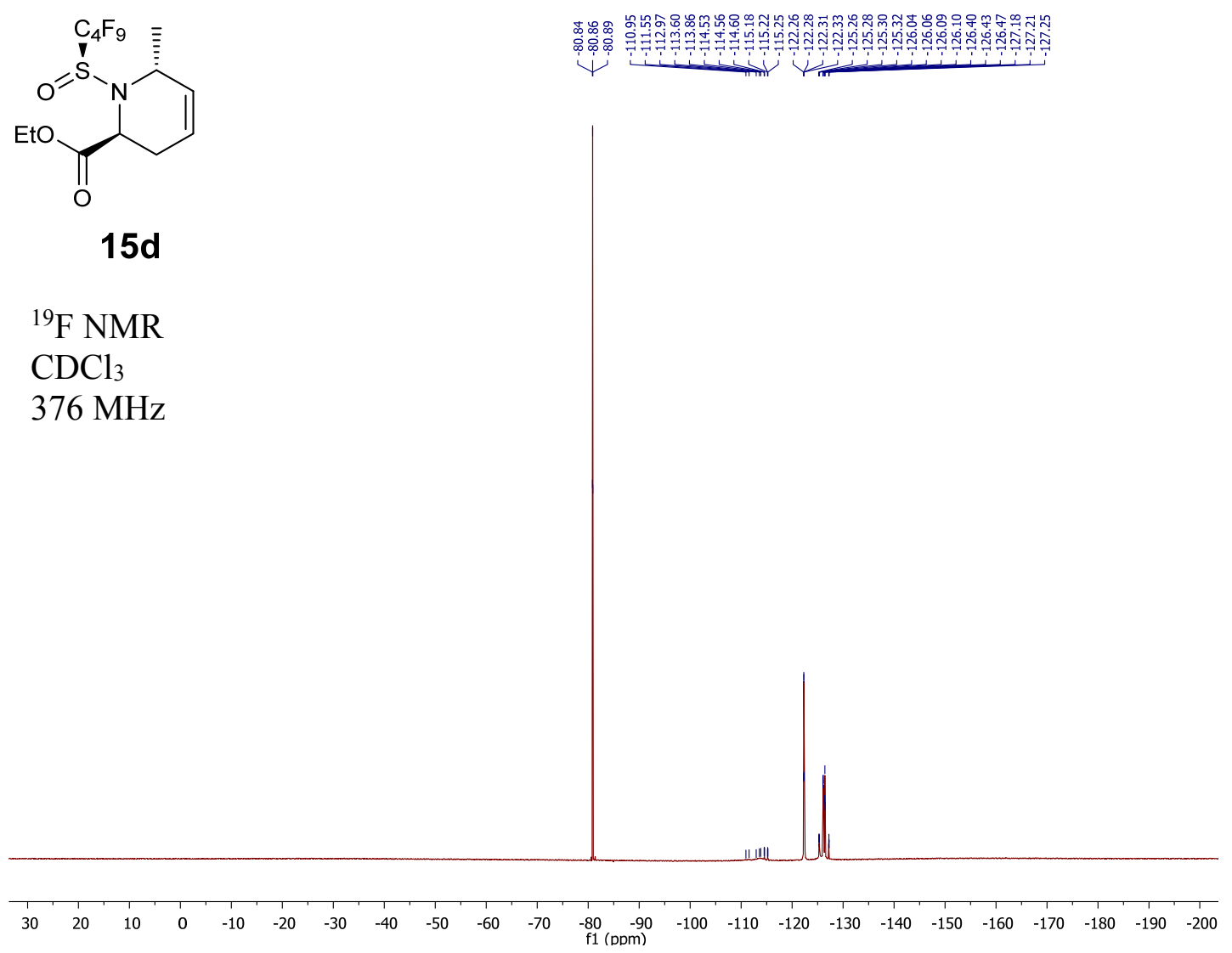



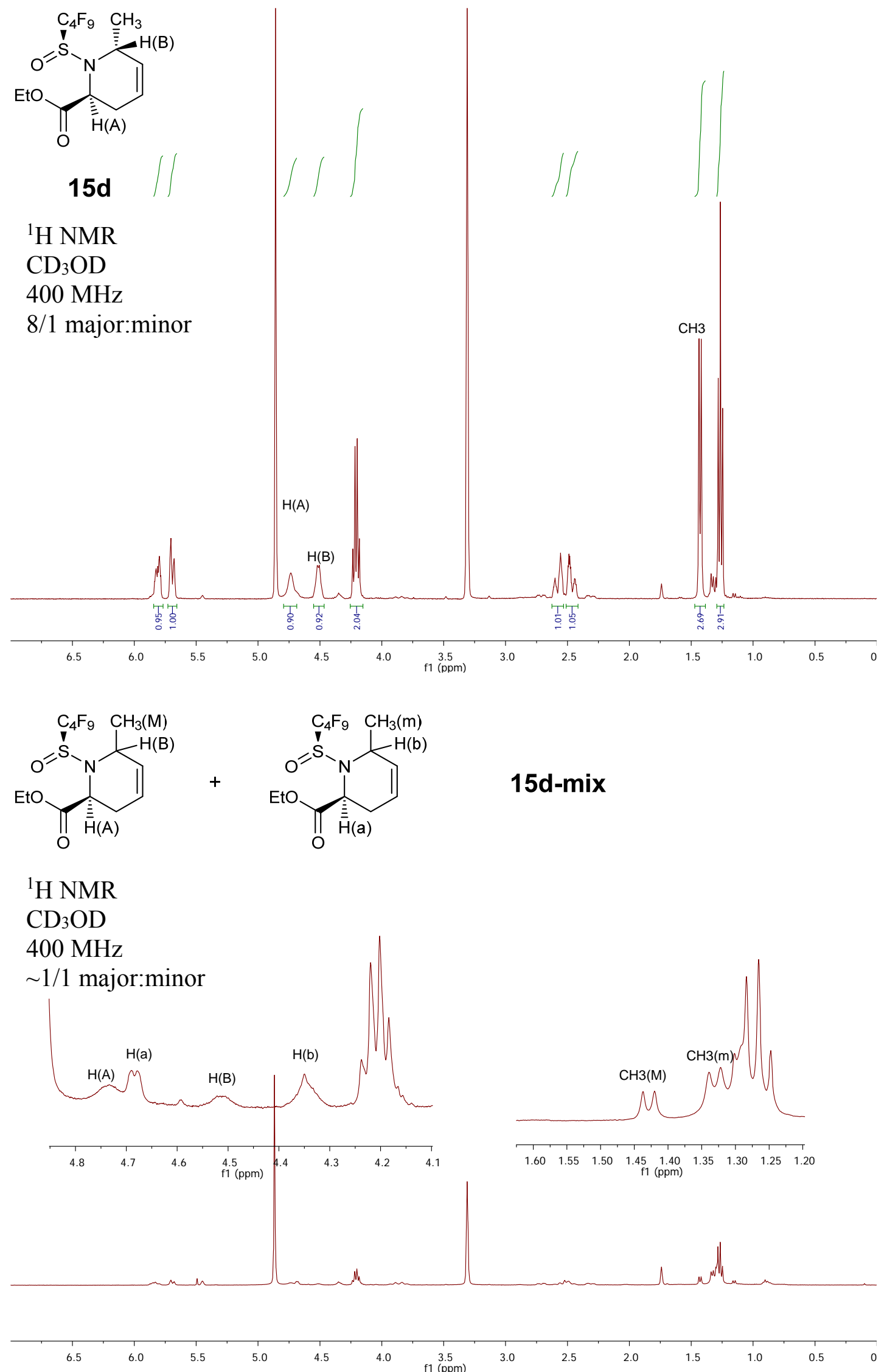

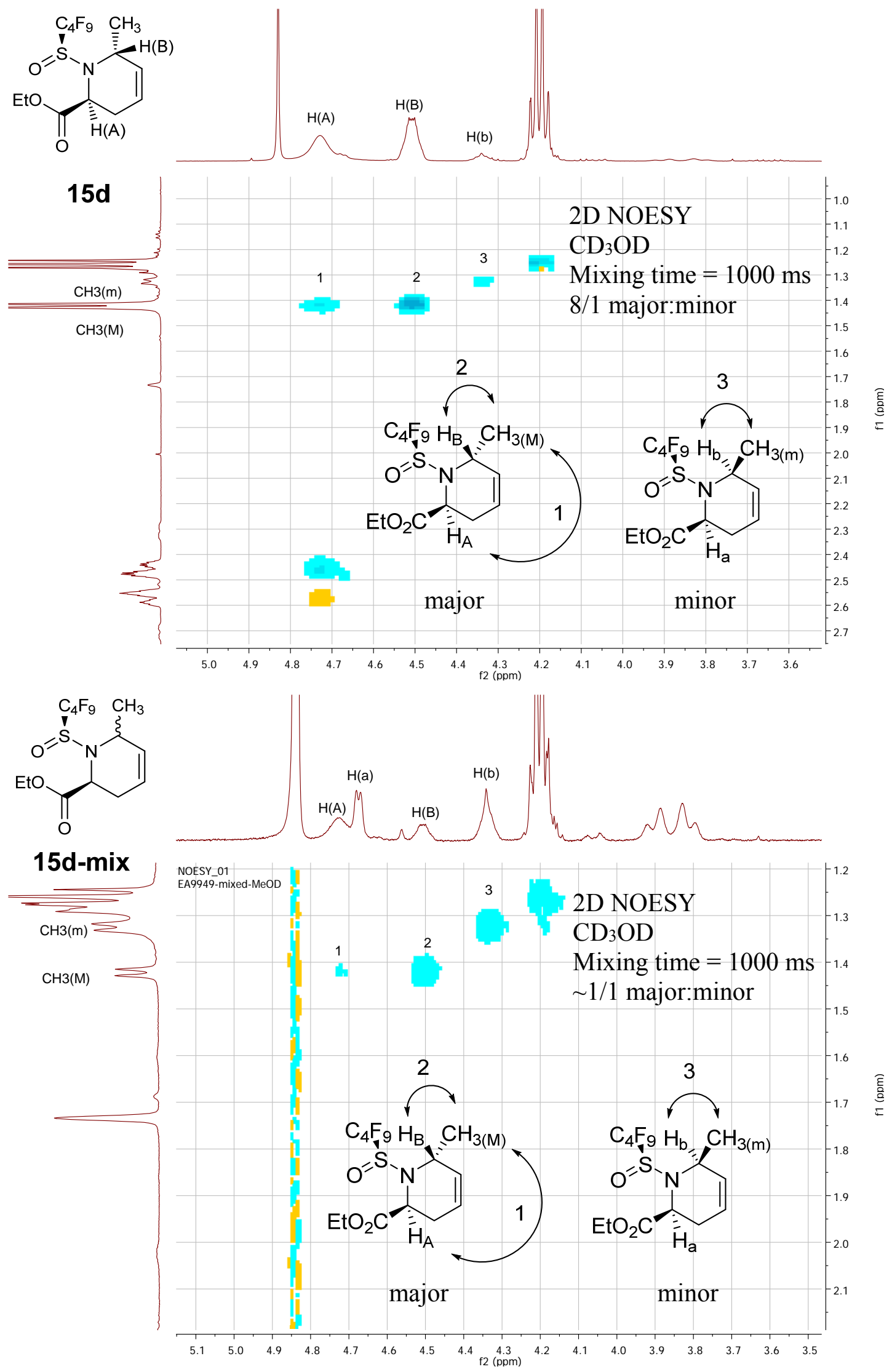


\section{HPLC Data}

Method: Chiralpak IB column, 10\% ethanol and 90\% hexanes, $230 \mathrm{~nm}$
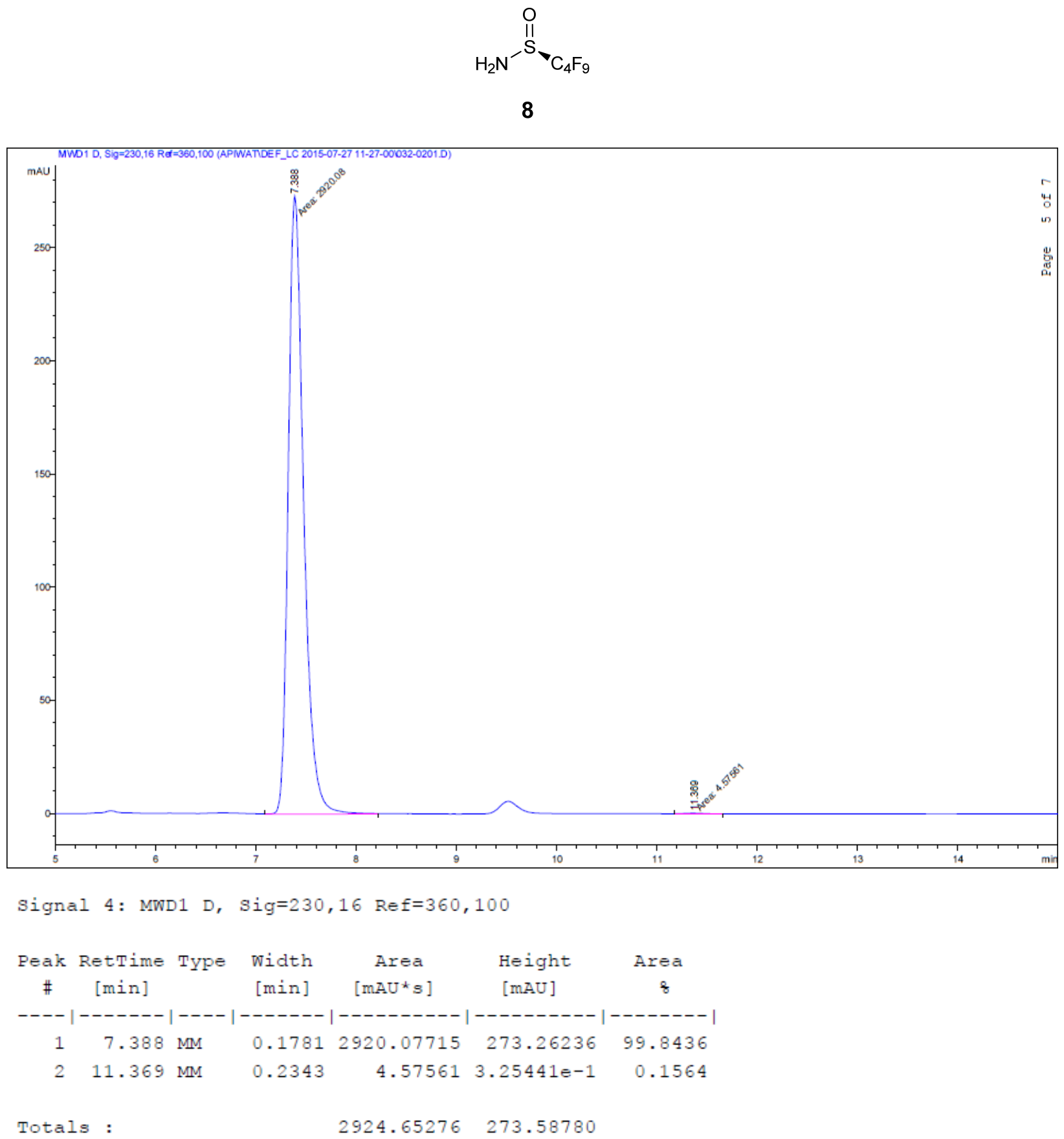


$$
\stackrel{\stackrel{O}{I I}}{\mathrm{H}_{2} \mathrm{~N}^{-S}}{ }^{-} \mathrm{C}_{4} \mathrm{~F}_{9}
$$

(士)-8

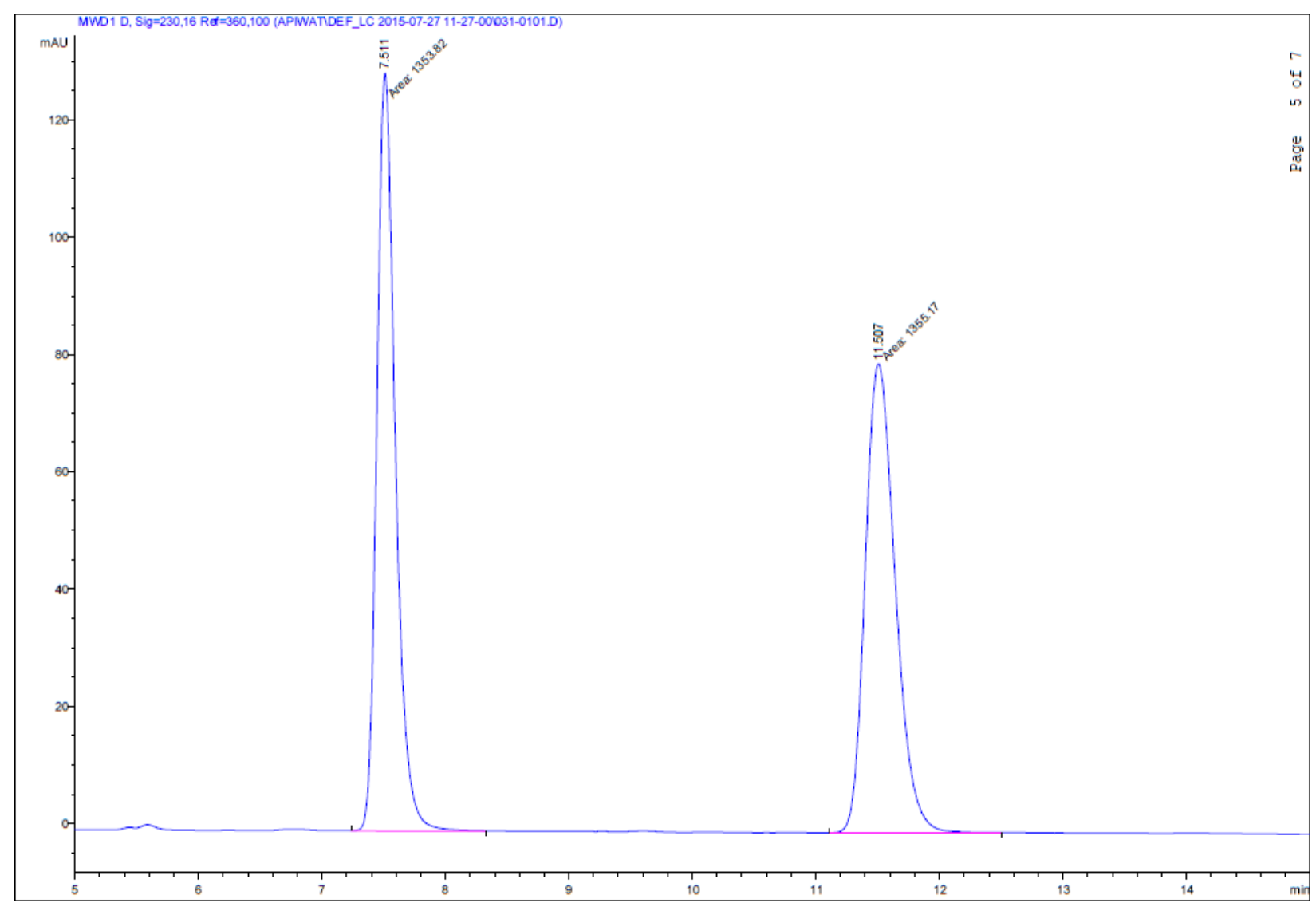

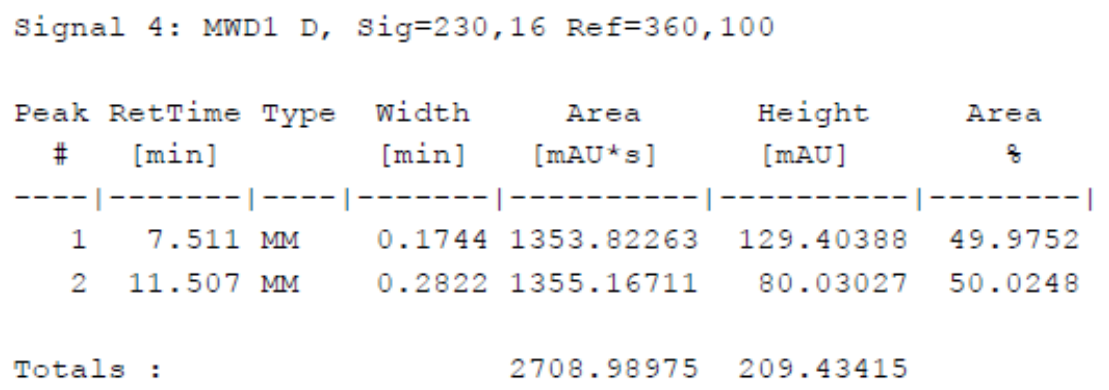


Method: Microsorb silica column, 15\% isopropanol and 85\% hexanes, $230 \mathrm{~nm}$

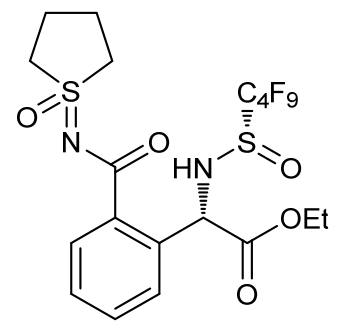

$11 d$

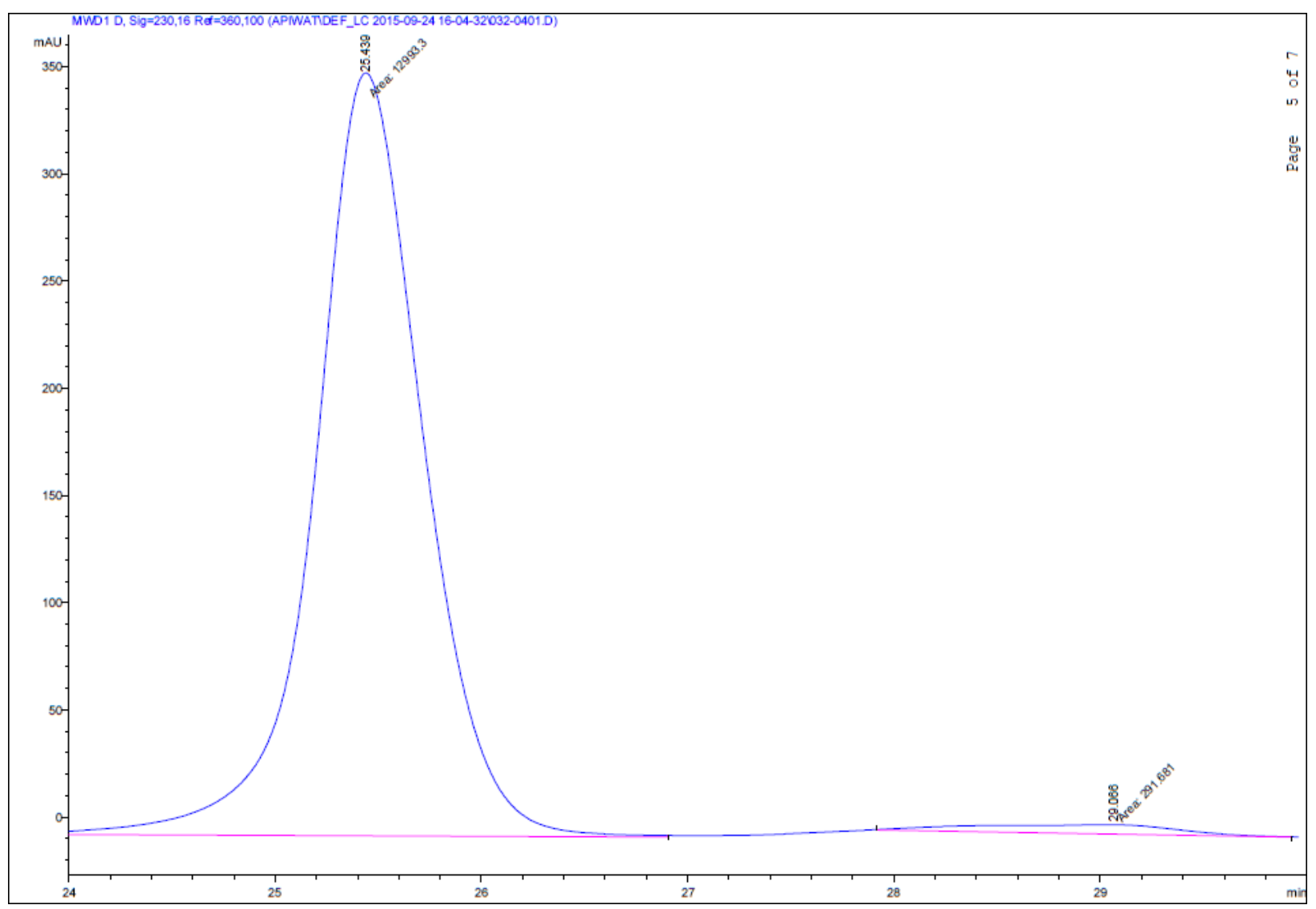

Signal 4: MWD1 D, Sig=230,16 Ref=360,100

\begin{tabular}{|c|c|c|c|c|c|c|}
\hline $\begin{array}{c}\text { Peak } \\
\#\end{array}$ & $\begin{array}{c}\text { RetTime } \\
\text { [min] }\end{array}$ & Type & $\begin{array}{l}\text { Width } \\
\text { [min] }\end{array}$ & $\begin{array}{c}\text { Area } \\
{\left[\mathrm{mAU}{ }^{\star} \mathrm{s}\right]}\end{array}$ & $\begin{array}{l}\text { Height } \\
{[\mathrm{mAU}]}\end{array}$ & $\begin{array}{c}\text { Area } \\
\&\end{array}$ \\
\hline 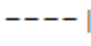 & ------ & --- & $------\mid$ & |--------- & --------- & ------- \\
\hline 1 & 25.439 & MM & 0.6091 & $1.29933 e 4$ & 355.54047 & 97.8044 \\
\hline 2 & 29.066 & $\mathrm{MM}$ & 1.0994 & 291.68118 & 4.42173 & 2.1956 \\
\hline Total & $\mathrm{s}:$ & & & $1.32850 e 4$ & 359.96220 & \\
\hline
\end{tabular}




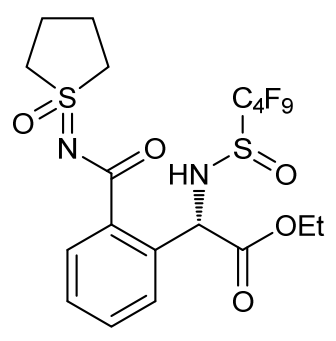

11d-mix (from 11d)

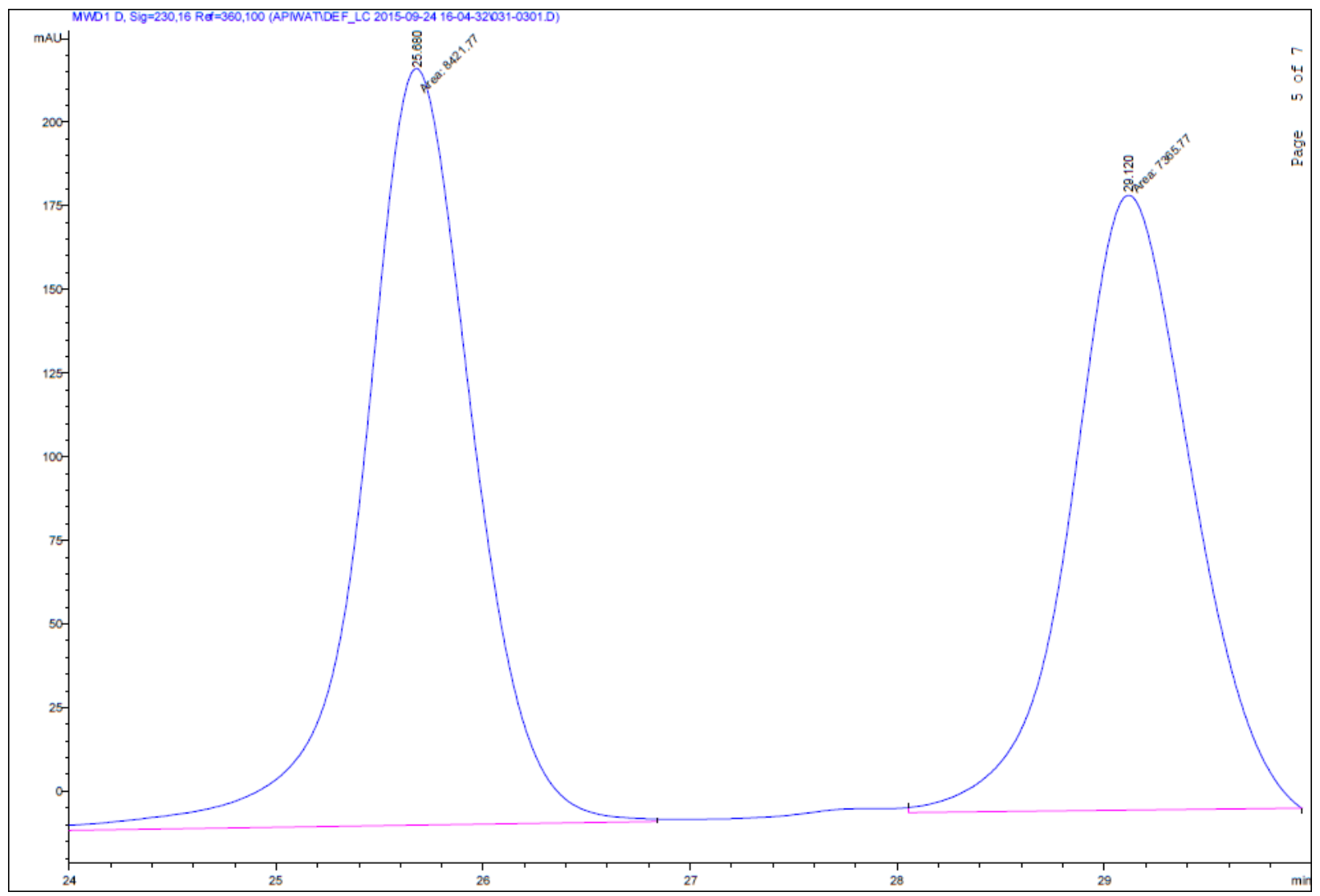

Signal 4: MWD1 D, Sig=230,16 Ref=360,100

\begin{tabular}{|c|c|c|c|c|c|c|}
\hline $\begin{array}{c}\text { eak } \\
\#\end{array}$ & $\begin{array}{c}\text { RetTime } \\
\text { [min] }\end{array}$ & Type & $\begin{array}{l}\text { Width } \\
\text { [min] }\end{array}$ & $\begin{array}{c}\text { Area } \\
{\left[\mathrm{mAU}^{\star} \mathrm{s}\right]}\end{array}$ & $\begin{array}{l}\text { Height } \\
{[\mathrm{mAU}]}\end{array}$ & $\begin{array}{c}\text { Area } \\
\&\end{array}$ \\
\hline & & & & -------- & ----- & --- \\
\hline 1 & & MM & & 8421.76563 & 226.2 & 3444 \\
\hline 2 & 20 & MM & 78 & 7365.76807 & 183.81911 & 46.6556 \\
\hline
\end{tabular}

Totals : $\quad 1.57875 e 4 \quad 410.03230$ 
Method: Microsorb silica column with 2\% ethanol and 98\% hexanes

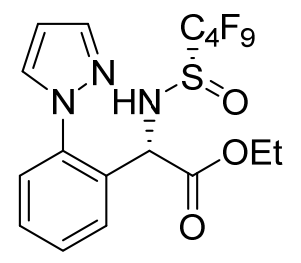

$11 \mathrm{e}$

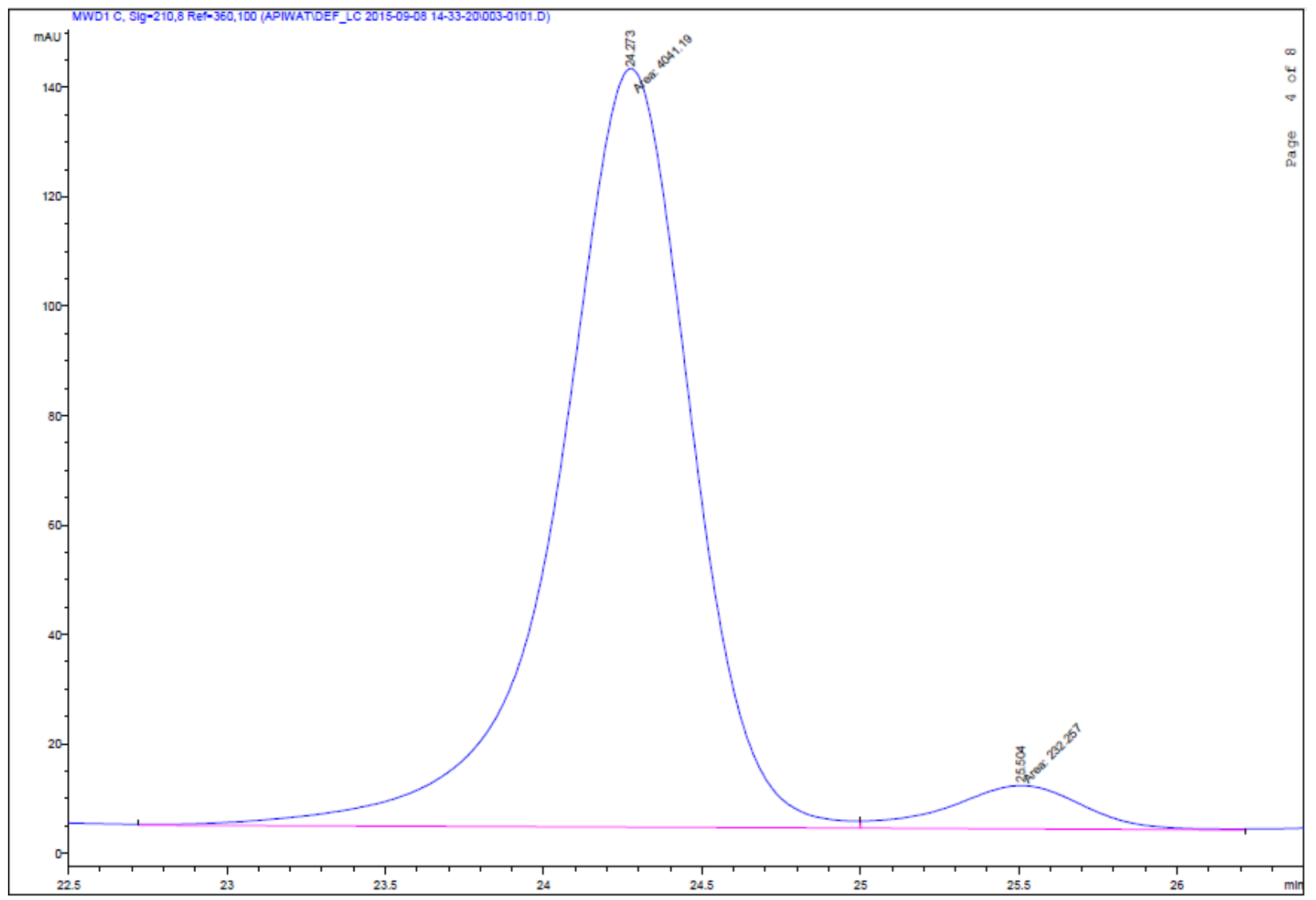

Signal 3: MWD1 C, Sig=210,8 Ref $=360,100$

\begin{tabular}{|c|c|c|c|c|c|c|}
\hline $\begin{array}{c}\text { Peak } \\
\quad \#\end{array}$ & $\begin{array}{c}\text { RetTime } \\
\text { [min] }\end{array}$ & Type & $\begin{array}{l}\text { Width } \\
\text { [min] }\end{array}$ & $\begin{array}{c}\text { Area } \\
{\left[\mathrm{mAU}^{*} \mathrm{~s}\right]}\end{array}$ & $\begin{array}{l}\text { Height } \\
{[\mathrm{mAU}]}\end{array}$ & $\begin{array}{c}\text { Area } \\
\frac{8}{8}\end{array}$ \\
\hline \multicolumn{7}{|c|}{$----|-------|----|-------|---------||----------|--------|$} \\
\hline 1 & 24.273 & $\mathrm{MF}$ & 0.4853 & 4041.18652 & 138.79001 & 94.5651 \\
\hline 2 & 25.504 & FM & 0.4873 & 232.25742 & 7.94361 & 5.4349 \\
\hline Total & is : & & & 4273.44394 & 146.73362 & \\
\hline
\end{tabular}




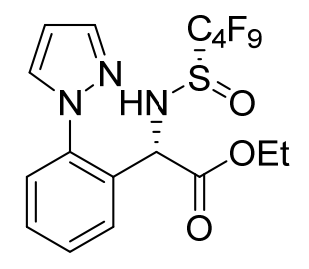

\section{1e-mix (from 11e)}

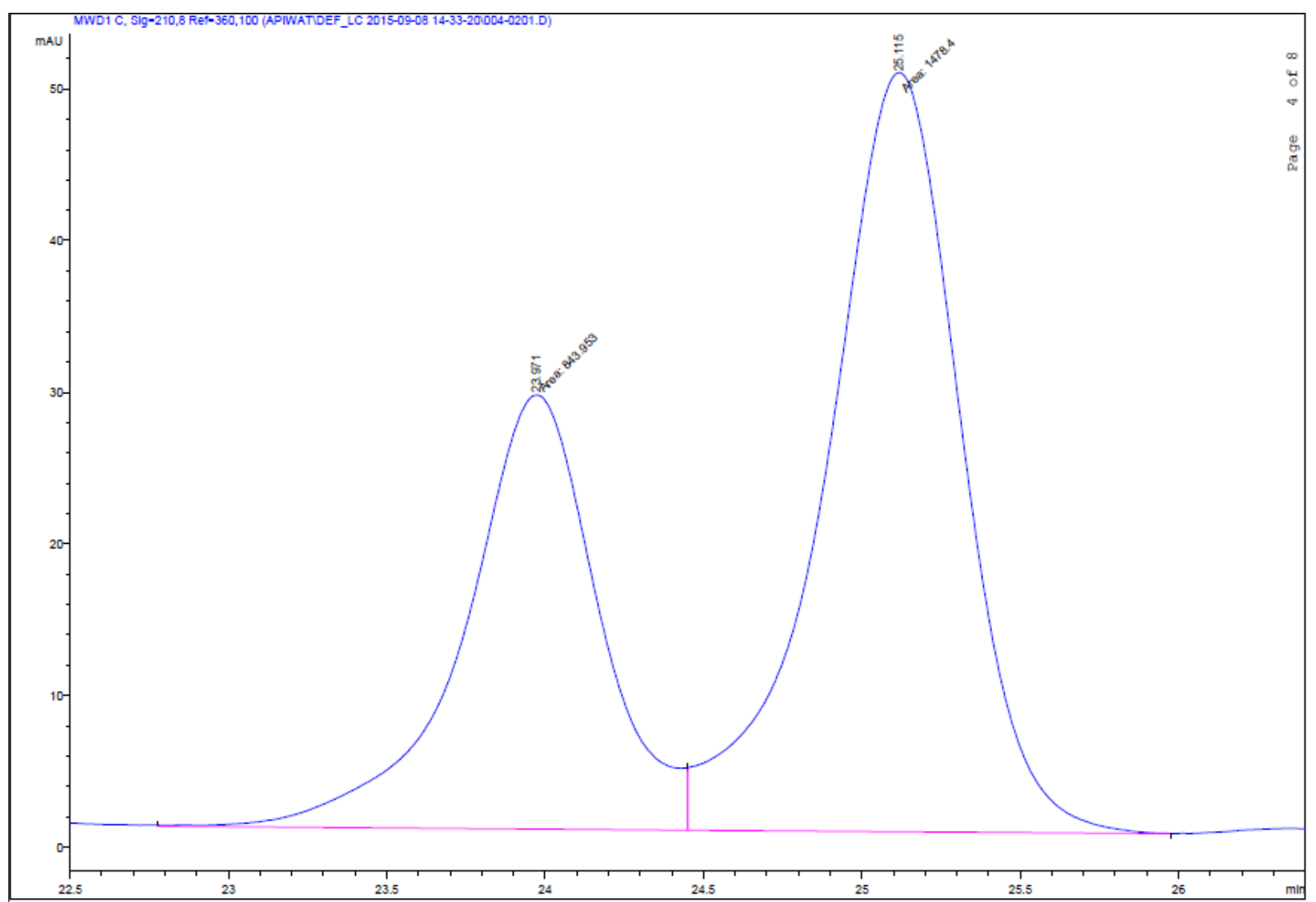

Signal 3: MWD1 C, Sig=210,8 Ref=360,100

\begin{tabular}{|c|c|c|c|c|c|c|}
\hline $\begin{array}{c}\text { Peak } \\
\quad \#\end{array}$ & $\begin{array}{c}\text { RetTime } \\
\text { [min] }\end{array}$ & Type & $\begin{array}{l}\text { Width } \\
\text { [min] }\end{array}$ & $\begin{array}{c}\text { Area } \\
{\left[\mathrm{mAU}^{*} \mathrm{~s}\right]}\end{array}$ & $\begin{array}{l}\text { Height } \\
{[\mathrm{mAU}]}\end{array}$ & $\begin{array}{c}\text { Area } \\
8\end{array}$ \\
\hline & & & & & & \\
\hline 1 & 23.971 & $\mathrm{MF}$ & 0.4912 & 843.95325 & 28.63390 & 36.3405 \\
\hline 2 & 25.115 & FM & 4921 & 1478.39514 & 0.07388 & 6595 \\
\hline
\end{tabular}

$\begin{array}{llll}\text { Totals : } & 2322.34839 & 78.70778\end{array}$ 
Method: Microsorb silica column with 2\% isopropanol and 98\% hexanes

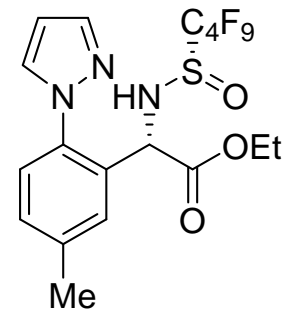

$11 f$

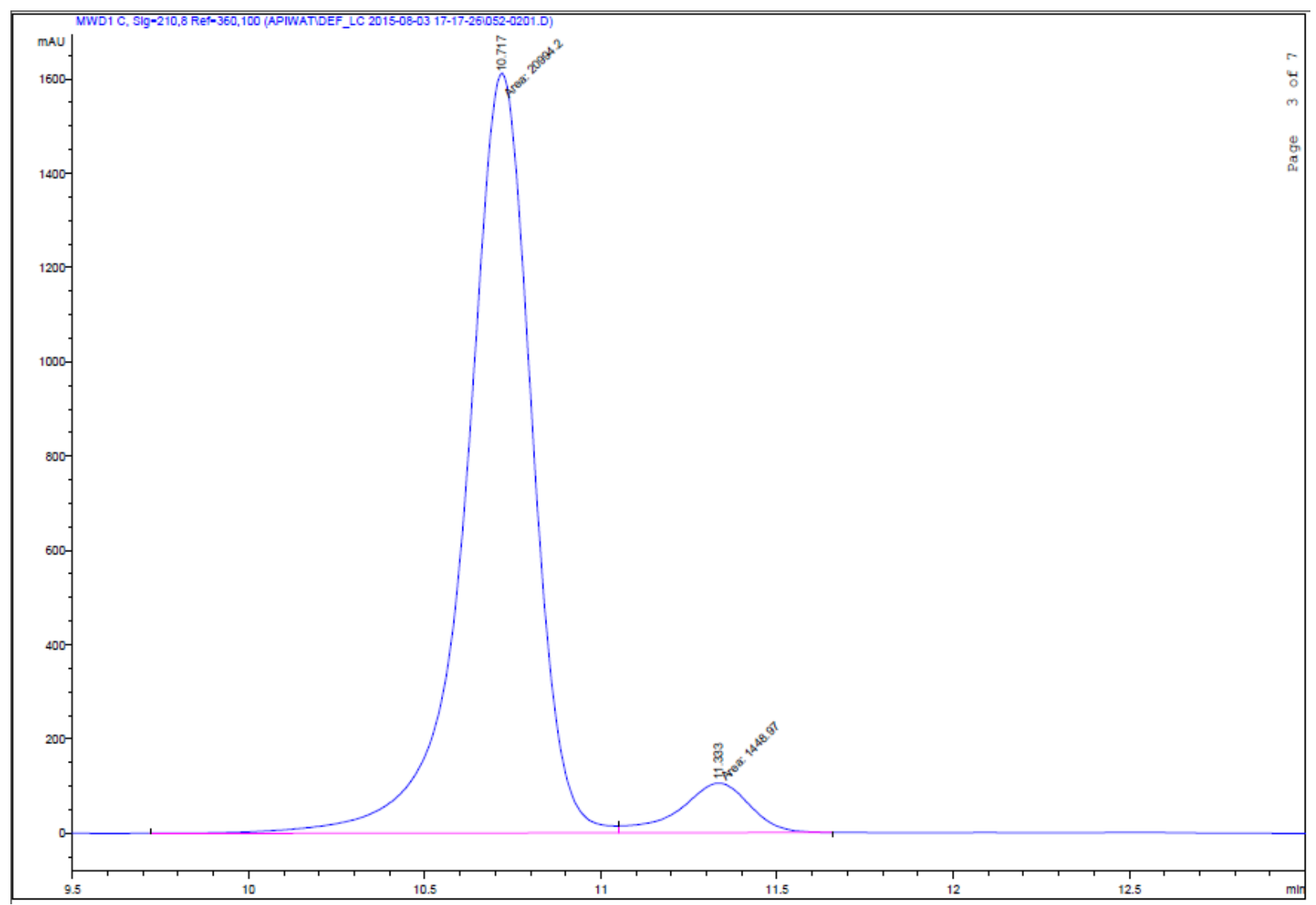

Signal 2: MWD1 C, Sig=210,8 Ref $=360,100$

\begin{tabular}{|c|c|c|c|c|c|c|}
\hline $\begin{array}{c}\text { Peak } \\
\text { \# }\end{array}$ & $\begin{array}{c}\text { RetTime } \\
\text { [min] }\end{array}$ & Type & $\begin{array}{l}\text { Width } \\
{[\text { min] }}\end{array}$ & $\begin{array}{c}\text { Area } \\
{\left[\mathrm{mAU}^{*} \mathrm{~s}\right]}\end{array}$ & $\begin{array}{l}\text { Height } \\
{[\mathrm{mAU}]}\end{array}$ & $\begin{array}{c}\text { Area } \\
\quad \%\end{array}$ \\
\hline & & & & -ー-ー-ー-ー-- & $----------\mid$ & -----1 \\
\hline 1 & 10.717 & MF & & $2.09942 e 4$ & 1612.02808 & 5438 \\
\hline 2 & 11.333 & FM & .2294 & 1448.97485 & 105.29061 & 6.4562 \\
\hline
\end{tabular}

$\begin{array}{lll}\text { Totals : } & 2.24432 \mathrm{e} 4 & 1717.31869\end{array}$ 


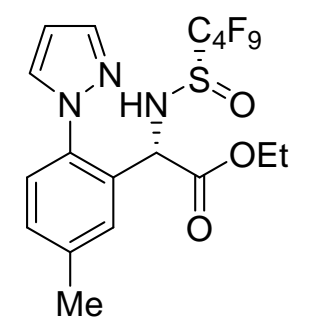

11f-mix (from 11f)

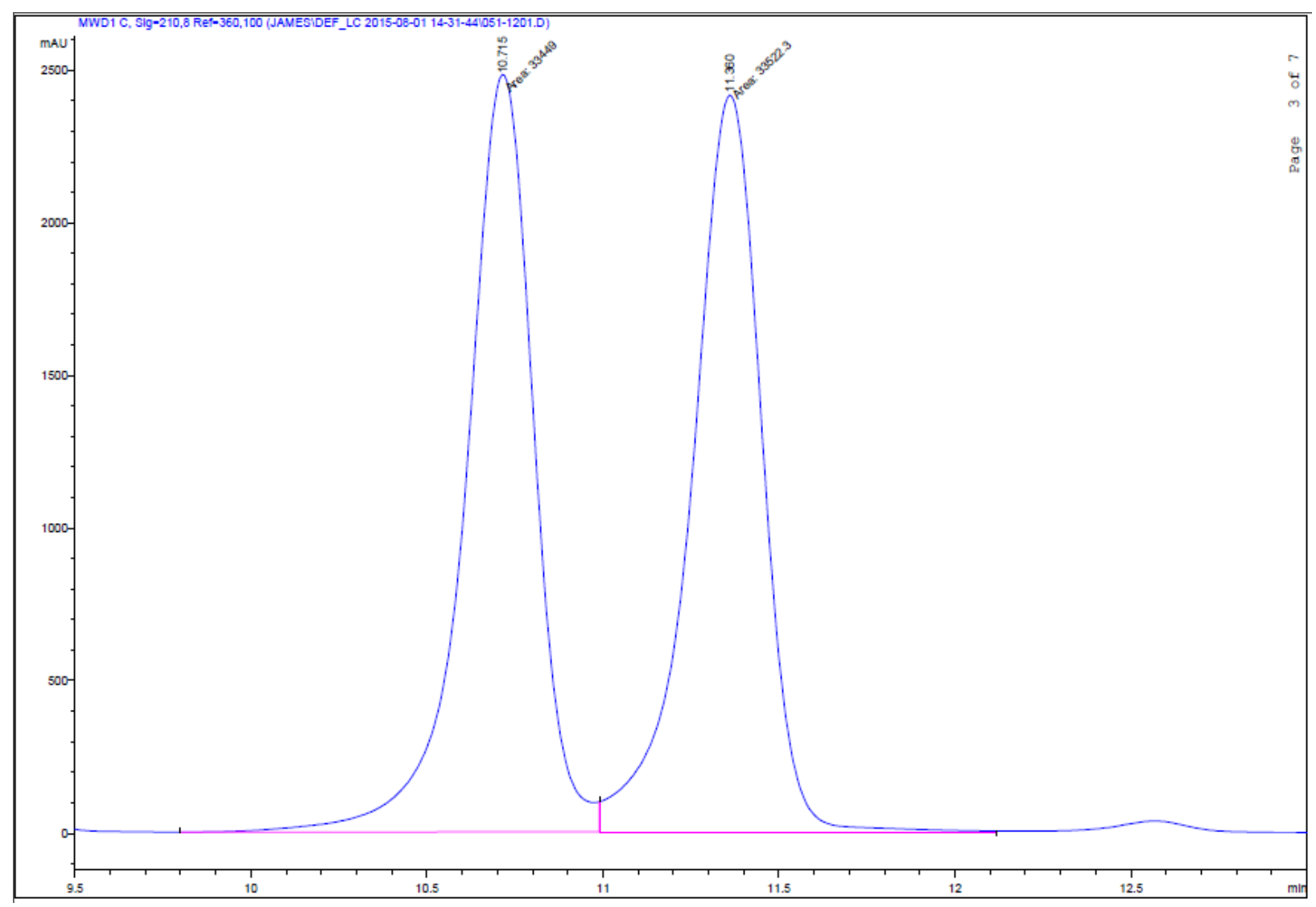

Signal 2: MWD1 C, Sig=210,8 Ref=360,100

\begin{tabular}{|c|c|c|c|c|c|c|}
\hline $\begin{array}{c}\text { Peak } \\
\quad \#\end{array}$ & $\begin{array}{c}\text { RetTime } \\
\text { [min] }\end{array}$ & Type & $\begin{array}{l}\text { Width } \\
\text { [min] }\end{array}$ & $\begin{array}{c}\text { Area } \\
{\left[\mathrm{mAU}^{\star} \mathrm{s}\right]}\end{array}$ & $\begin{array}{l}\text { Height } \\
{[\mathrm{mAU}]}\end{array}$ & $\begin{array}{c}\text { Area } \\
\frac{8}{8}\end{array}$ \\
\hline \multicolumn{7}{|c|}{$----|-------|----|-------|----------|----------|--------\mid$} \\
\hline 1 & 10.715 & $\mathrm{MF}$ & 0.2245 & $3.34490 e 4$ & 2483.30396 & 49.9453 \\
\hline 2 & 11.360 & FM & 0.2314 & $3.35223 e 4$ & 2414.77783 & 50.0547 \\
\hline . & Ls : & & & $6.69713 e 4$ & .08179 & \\
\hline
\end{tabular}


Method: Microsorb silica column with 3\% isopropanol and 97\% hexanes

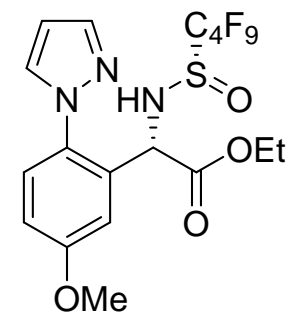

$11 \mathrm{~g}$

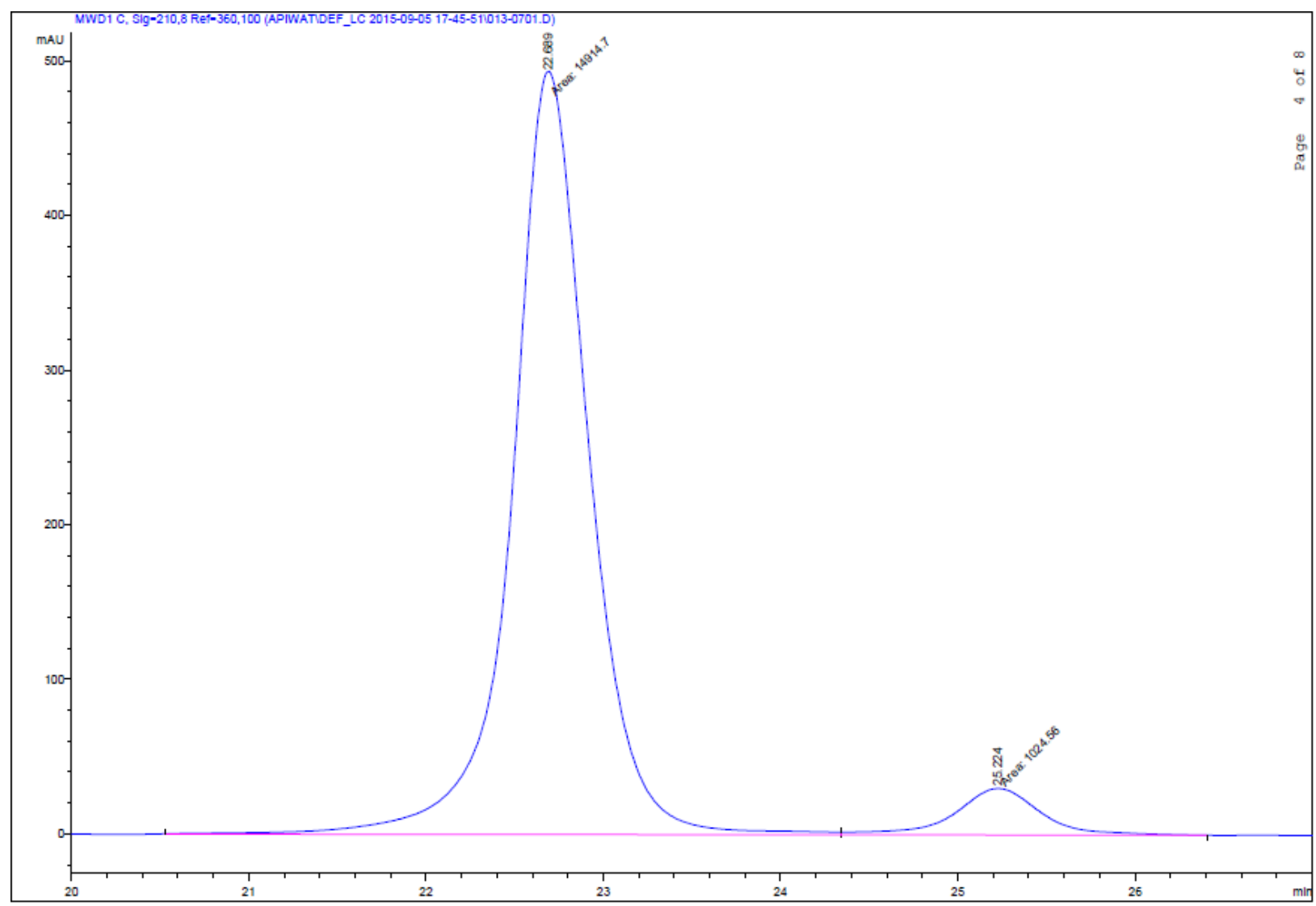

Signal 3: MWD1 C, Sig=210,8 Ref $=360,100$

\begin{tabular}{|c|c|c|c|c|c|c|}
\hline $\begin{array}{c}\text { Peak } \\
\#\end{array}$ & $\begin{array}{c}\text { RetTime } \\
\text { [min] }\end{array}$ & Type & $\begin{array}{l}\text { Width } \\
\text { [min] }\end{array}$ & $\begin{array}{c}\text { Area } \\
{\left[\mathrm{mAU}^{*} \mathrm{~s}\right]}\end{array}$ & $\begin{array}{l}\text { Height } \\
\text { [mAU] }\end{array}$ & $\begin{array}{c}\text { Area } \\
\text { \% }\end{array}$ \\
\hline \multicolumn{7}{|c|}{$----|-------|----|-------|----------|----------|--------\mid$} \\
\hline 1 & 22.689 & $\mathrm{MF}$ & 0.5036 & $1.49147 e 4$ & 493.59485 & 93.5721 \\
\hline 2 & 25.224 & FM & 0.5656 & 1024.55957 & 30.19225 & 6.4279 \\
\hline Total & ls : & & & $1.59392 \mathrm{e} 4$ & 523.78709 & \\
\hline
\end{tabular}




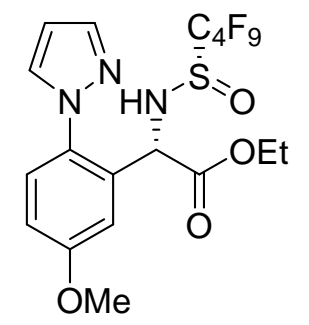

11g-mix (from 11g)

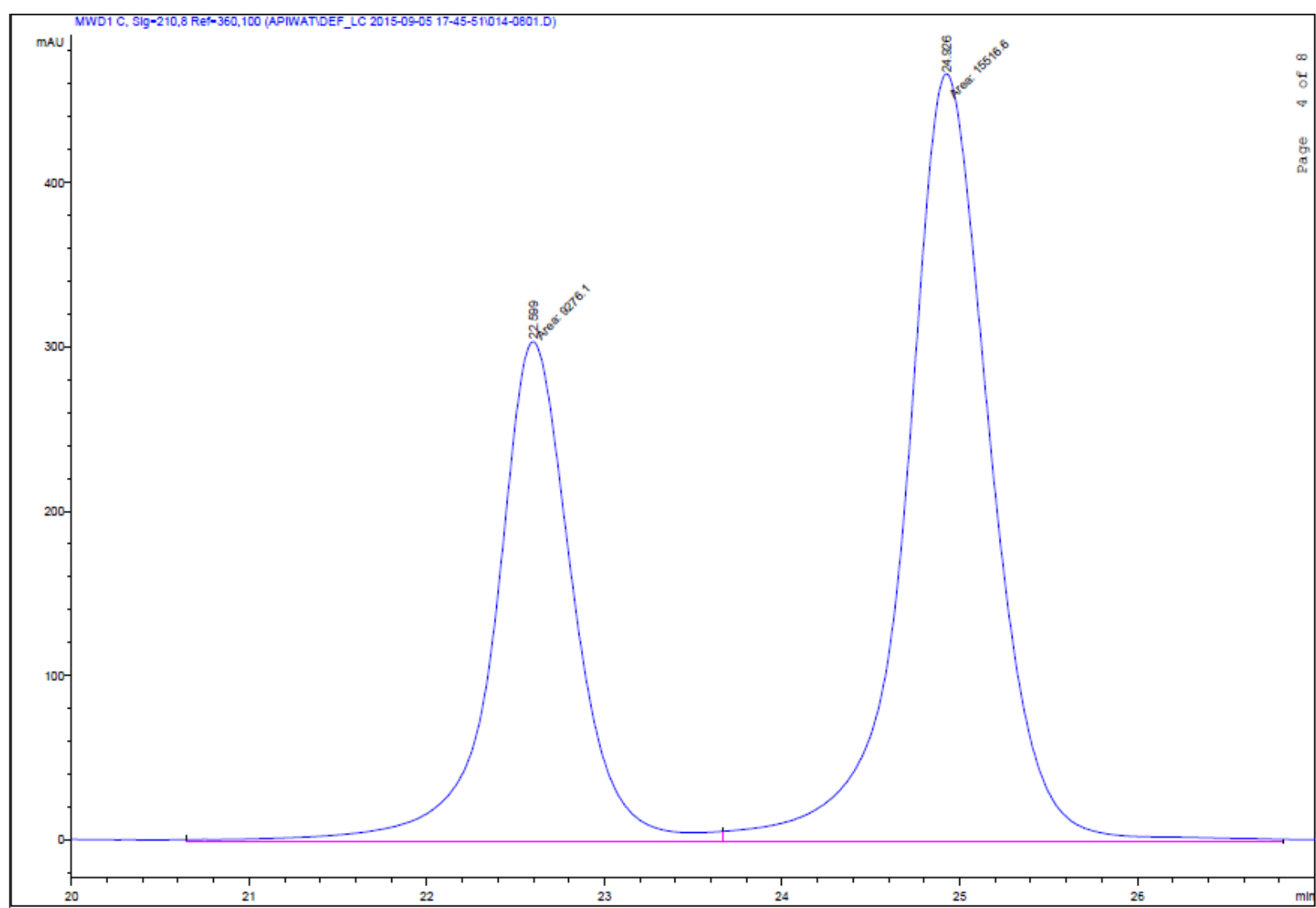

Signal 3: MWD1 C, Sig=210, 8 Ref $=360,100$

\begin{tabular}{|c|c|c|c|c|c|c|}
\hline $\begin{array}{c}\text { Peak } \\
\quad \#\end{array}$ & $\begin{array}{c}\text { RetTime } \\
\text { [min] }\end{array}$ & Type & $\begin{array}{l}\text { Width } \\
\text { [min] }\end{array}$ & $\begin{array}{c}\text { Area } \\
{\left[\mathrm{mAU}^{*} \mathrm{~S}\right]}\end{array}$ & $\begin{array}{l}\text { Height } \\
{[\mathrm{mAU}]}\end{array}$ & $\begin{array}{c}\text { Area } \\
\frac{\circ}{\delta}\end{array}$ \\
\hline \multicolumn{7}{|c|}{$----|-------|----|-------|---------||----------|--------|$} \\
\hline 1 & 22.599 & $\mathrm{MF}$ & 0.5094 & 9276.09961 & 303.52060 & 37.4146 \\
\hline 2 & 24.926 & FM & 0.5544 & $1.55166 \mathrm{e} 4$ & 466.46173 & 62.5854 \\
\hline Tota. & $1 \mathrm{~s}:$ & & & $2.47927 e 4$ & 769.98233 & \\
\hline
\end{tabular}


Method: Microsorb silica column with 3\% isopropanol and 97\% hexanes

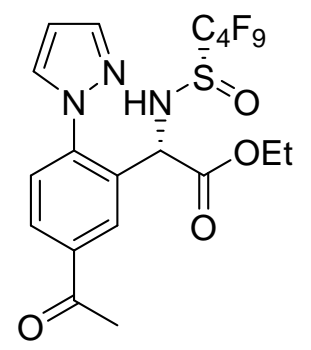

$11 \mathrm{~h}$

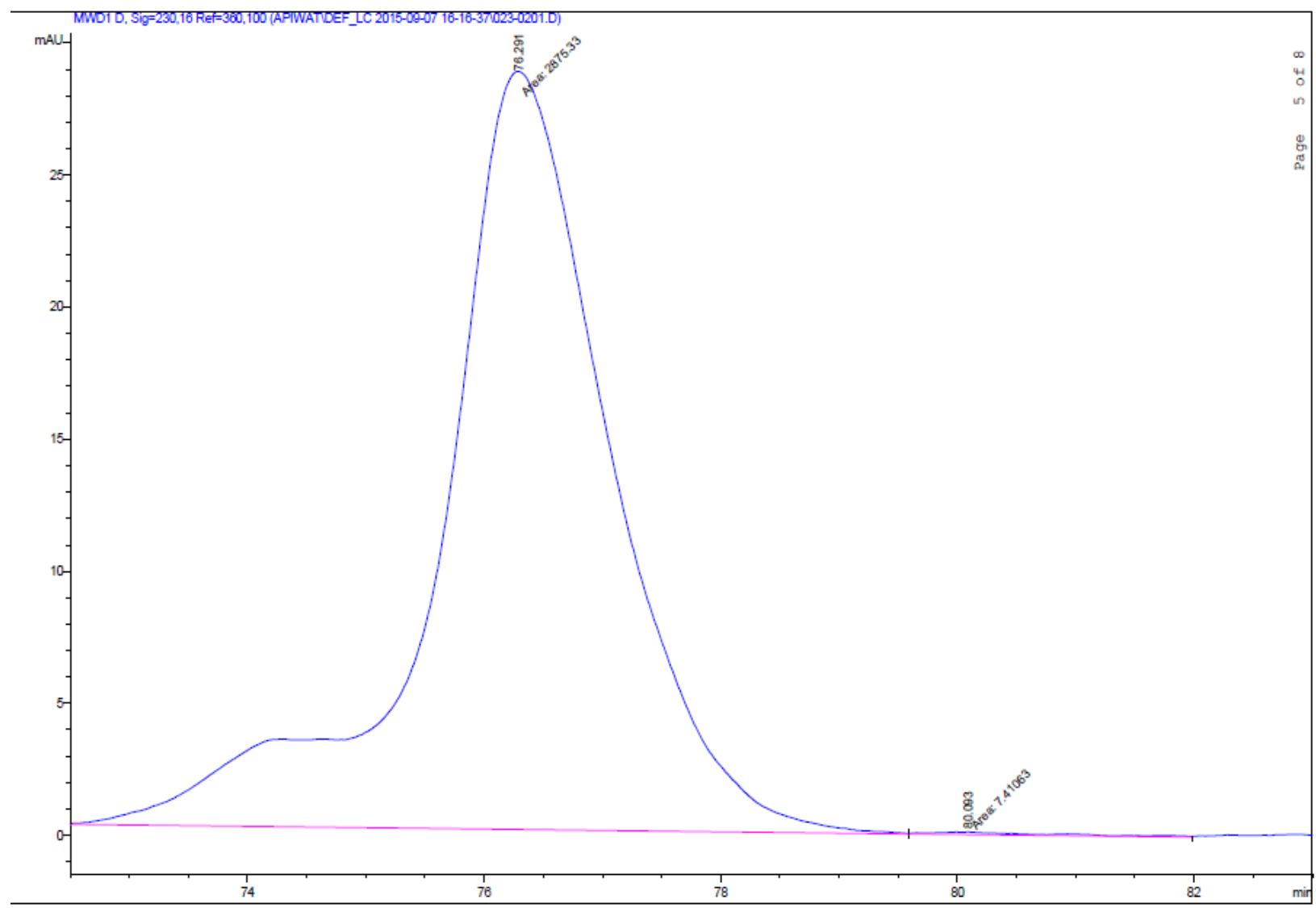

Signal 4: MWD1 D, Sig=230,16 Ref=360,100

\begin{tabular}{|c|c|c|c|c|c|c|}
\hline $\begin{array}{c}\text { Peak } \\
\#\end{array}$ & $\begin{array}{c}\text { RetTime } \\
\text { [min] }\end{array}$ & Type & $\begin{array}{c}\text { Width } \\
\text { [min] }\end{array}$ & $\begin{array}{c}\text { Area } \\
{\left[\mathrm{mAU}^{*} \mathrm{~S}\right]}\end{array}$ & $\begin{array}{l}\text { Height } \\
{[\mathrm{mAU}]}\end{array}$ & $\begin{array}{c}\text { Area } \\
\%\end{array}$ \\
\hline & & & ----- & $\mid----------$ & $|----------|$ & $--------\mid$ \\
\hline 1 & 76.291 & $\mathrm{MF}$ & 1.6701 & 2875.33423 & 28.69366 & 99.7429 \\
\hline 2 & 80.093 & FM & 1.1822 & 7.41063 & $1.04473 e-1$ & 0.2571 \\
\hline
\end{tabular}

Totals : $\quad 2882.74486 \quad 28.79814$ 


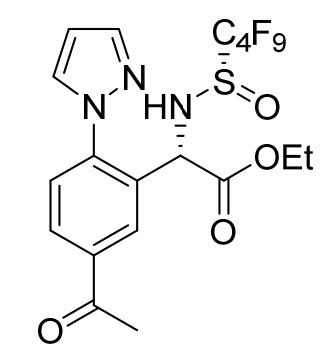

11h-mix (from 11h)

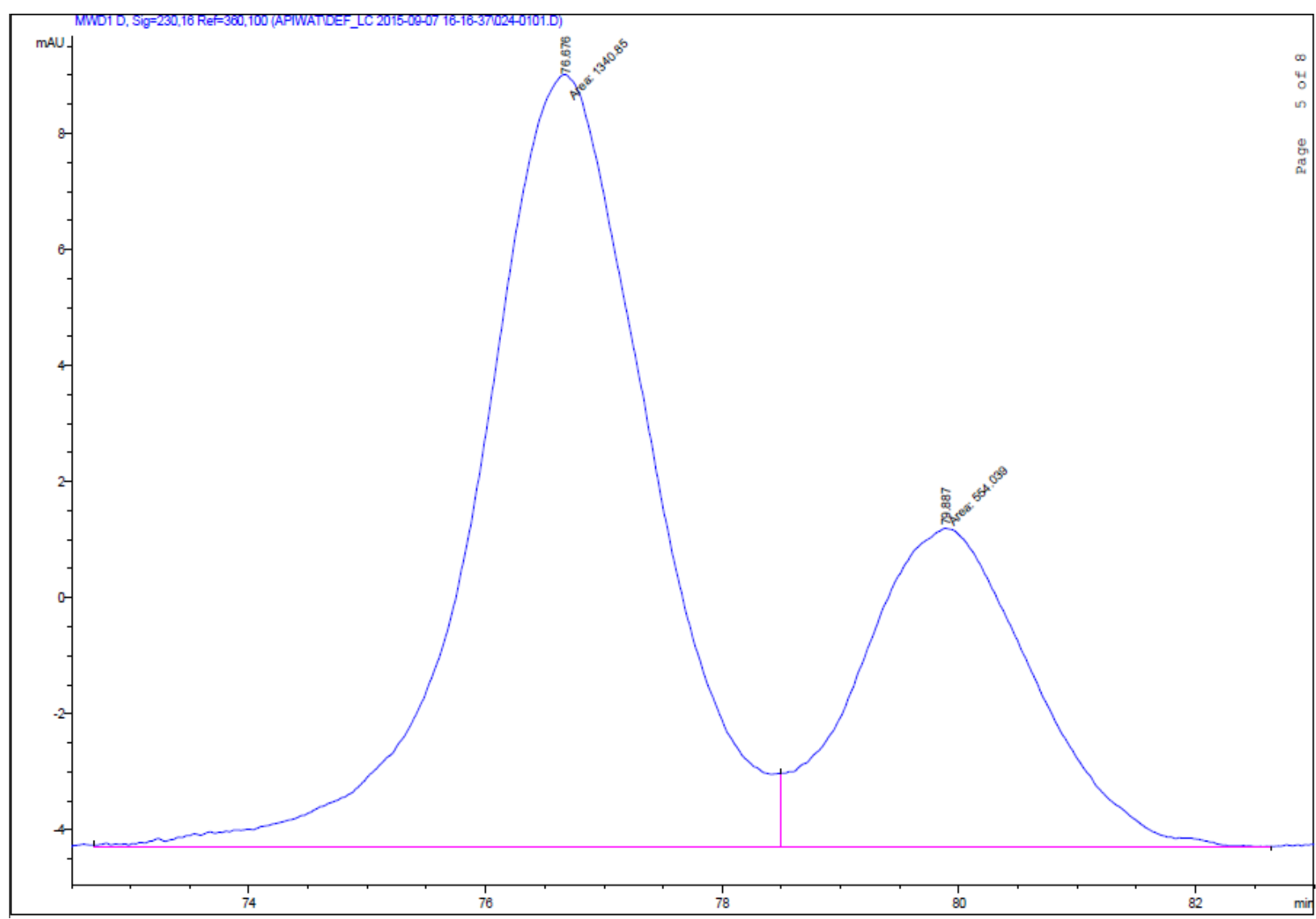

Signal 4: MWD1 D, Sig=230,16 Ref=360,100

\begin{tabular}{|c|c|c|c|c|c|c|}
\hline $\begin{array}{c}\text { Peak } \\
\#\end{array}$ & $\begin{array}{c}\text { RetTime } \\
\text { [min] }\end{array}$ & Type & $\begin{array}{l}\text { Width } \\
\text { [min] }\end{array}$ & $\begin{array}{c}\text { Area } \\
{\left[\mathrm{mAU}^{*} \mathrm{~s}\right]}\end{array}$ & $\begin{array}{l}\text { Height } \\
{[\mathrm{mAU}]}\end{array}$ & $\begin{array}{c}\text { Area } \\
\%\end{array}$ \\
\hline \multicolumn{7}{|c|}{$----|-------|----|-------|----------|----------|--------\mid$} \\
\hline 1 & 76.676 & $\mathrm{MF}$ & 1.6809 & 1340.84985 & 13.29531 & 70.7614 \\
\hline 2 & 79.887 & FM & 1.6861 & 554.03931 & 5.47658 & 29.2386 \\
\hline btal & : & & & 1894.88916 & 7189 & \\
\hline
\end{tabular}


Method: Microsorb silica column with 2\% isopropanol and 98\% hexanes<smiles>CCOC(=O)[C@H](NS(=O)C(F)(F)F)c1ccc(C)cc1-n1cccn1</smiles>

$11 \mathbf{i}$

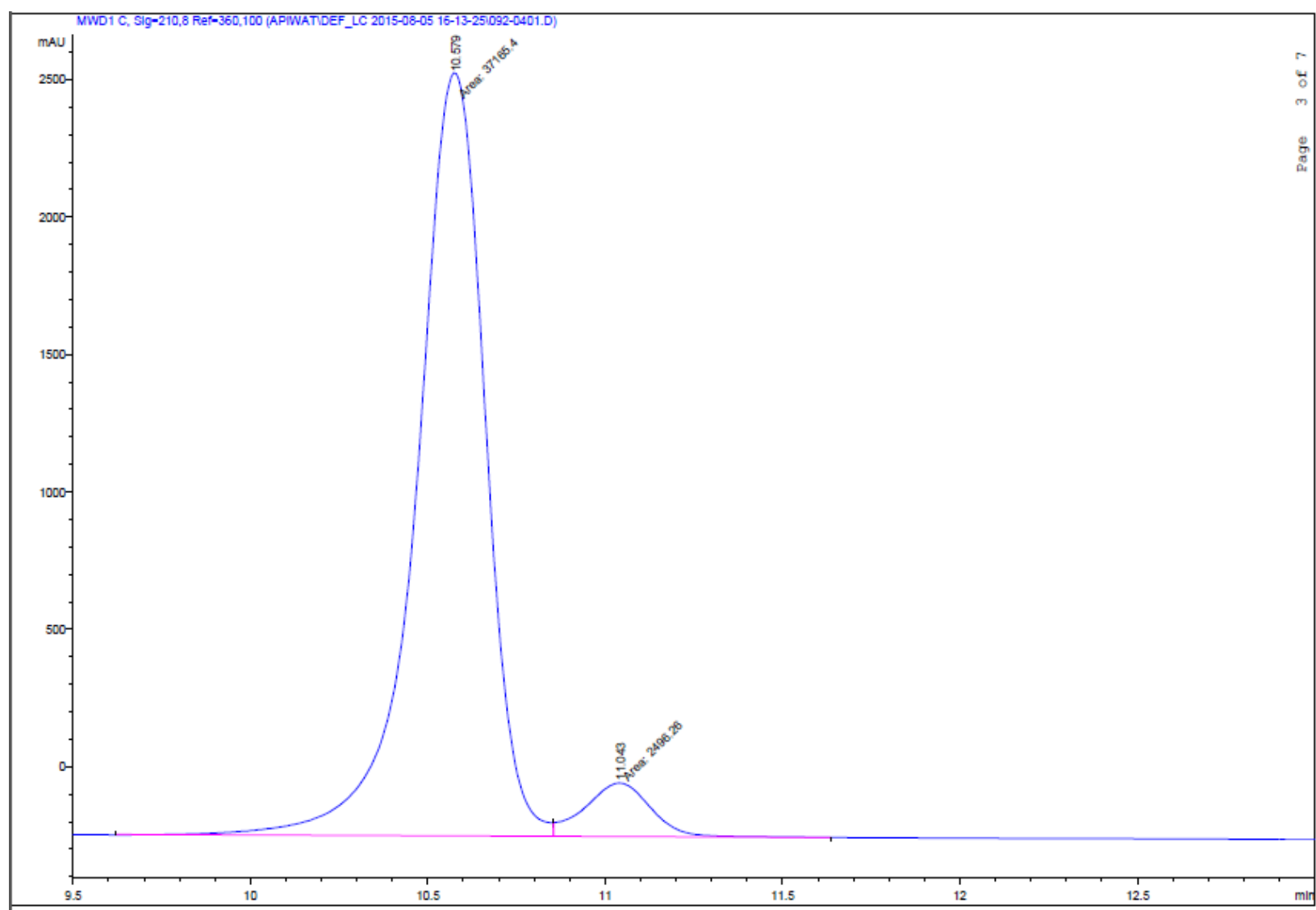

Signal 2: MWD1 C, Sig=210,8 Ref $=360,100$

\begin{tabular}{|c|c|c|c|c|c|c|}
\hline $\begin{array}{c}\text { eak } \\
\#\end{array}$ & $\begin{array}{c}\text { RetTime } \\
\text { [min] }\end{array}$ & Type & $\begin{array}{l}\text { Width } \\
{[\mathrm{min}]}\end{array}$ & $\begin{array}{c}\text { Area } \\
{\left[\mathrm{mAU}^{*} \mathrm{~S}\right]}\end{array}$ & $\begin{array}{l}\text { Height } \\
{[\mathrm{mAU}]}\end{array}$ & $\begin{array}{c}\text { Area } \\
\frac{8}{8}\end{array}$ \\
\hline & & & & & & \\
\hline 1 & & & & $3.71654 \mathrm{e} 4$ & 2777.01245 & 061 \\
\hline ? & 043 & & 39 & 2496.26221 & 194.46129 & .2939 \\
\hline
\end{tabular}

Totals :

$3.96617 e 4 \quad 2971.47374$ 


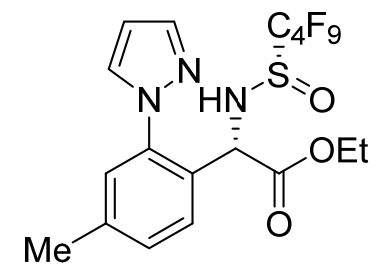

11i-mix (from 11i)

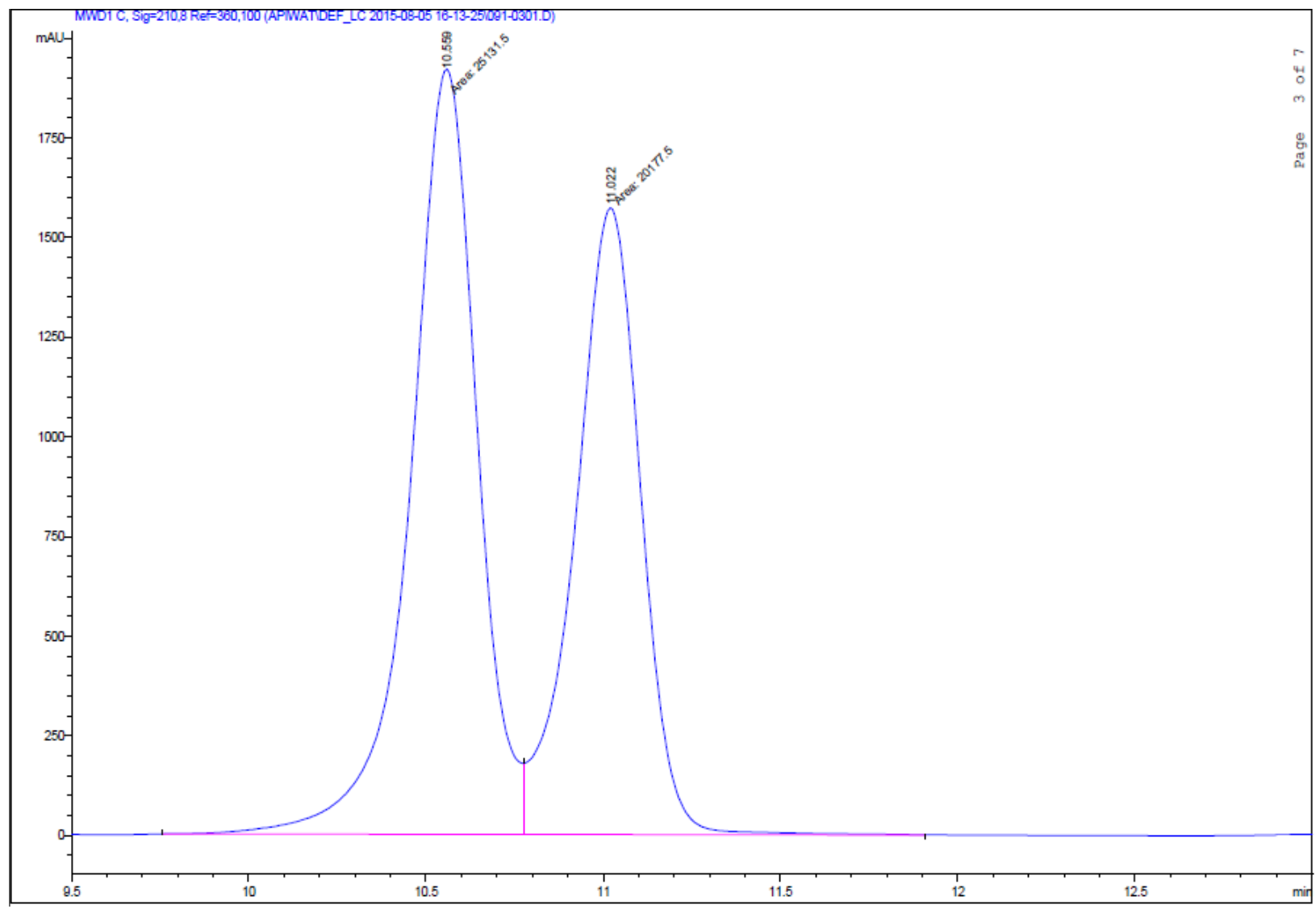

Signal 2: MWD1 C, Sig=210,8 Ref=360,100

\begin{tabular}{|c|c|c|c|c|c|c|}
\hline $\begin{array}{c}\text { Peak } \\
\#\end{array}$ & $\begin{array}{c}\text { RetTime } \\
\text { [min] }\end{array}$ & Type & $\begin{array}{l}\text { Width } \\
\text { [min] }\end{array}$ & $\begin{array}{c}\text { Area } \\
{\left[\mathrm{mAU}^{*} \mathrm{~s}\right]}\end{array}$ & $\begin{array}{l}\text { Height } \\
{[\mathrm{mAU}]}\end{array}$ & $\begin{array}{c}\text { Area } \\
\%\end{array}$ \\
\hline & & & & | --------- & $\mid-------$ & -------- \\
\hline 1 & 10.559 & $\mathrm{MF}$ & 0.2181 & $2.51315 e 4$ & 1920.30078 & 55.4669 \\
\hline 2 & 11.022 & $\mathrm{FM}$ & 0.2138 & $2.01775 e 4$ & 1572.66968 & 44.5331 \\
\hline & & & & $4.53090 \mathrm{e} 4$ & 3492.97046 & \\
\hline
\end{tabular}


Method: Microsorb silica column with 3\% isopropanol and 97\% hexanes

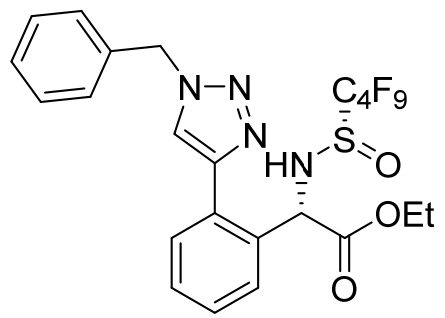

$11 \mathbf{j}$

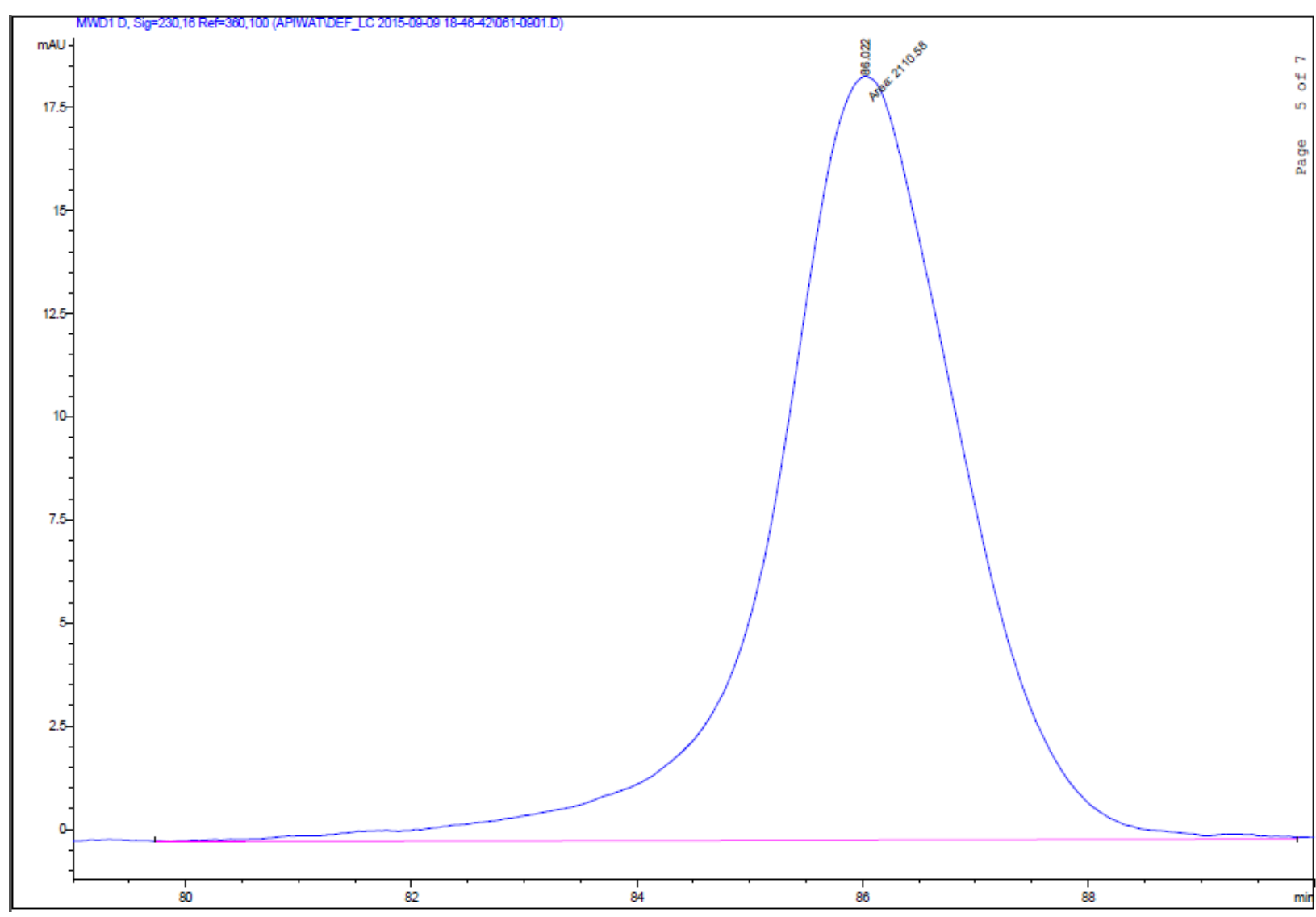

Signal 4: MWD1 D, Sig=230,16 Ref=360,100

\begin{tabular}{|c|c|c|c|c|c|c|}
\hline $\begin{array}{c}\text { Peak } \\
\quad \#\end{array}$ & $\begin{array}{c}\text { RetTime } \\
\text { [min] }\end{array}$ & Type & $\begin{array}{l}\text { Width } \\
\text { [min] }\end{array}$ & $\begin{array}{c}\text { Area } \\
{\left[\mathrm{mAU}^{*} \mathrm{~s}\right]}\end{array}$ & $\begin{array}{l}\text { Height } \\
{[\mathrm{mAU}]}\end{array}$ & $\begin{array}{c}\text { Area } \\
8\end{array}$ \\
\hline--- & | ------- & |-- & $-------\mid$ & $|----------|$ & $---------\mid$ & $|--------|$ \\
\hline 1 & 86.022 & MM & 1.9003 & 2110.58203 & 18.51105 & 100.0000 \\
\hline Tota & $1 \mathrm{~s}:$ & & & 2110.58203 & 18.51105 & \\
\hline
\end{tabular}




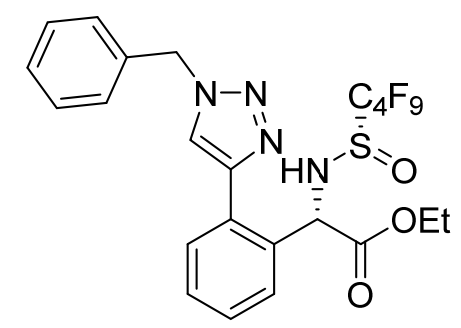

11j-mix (from 11j)

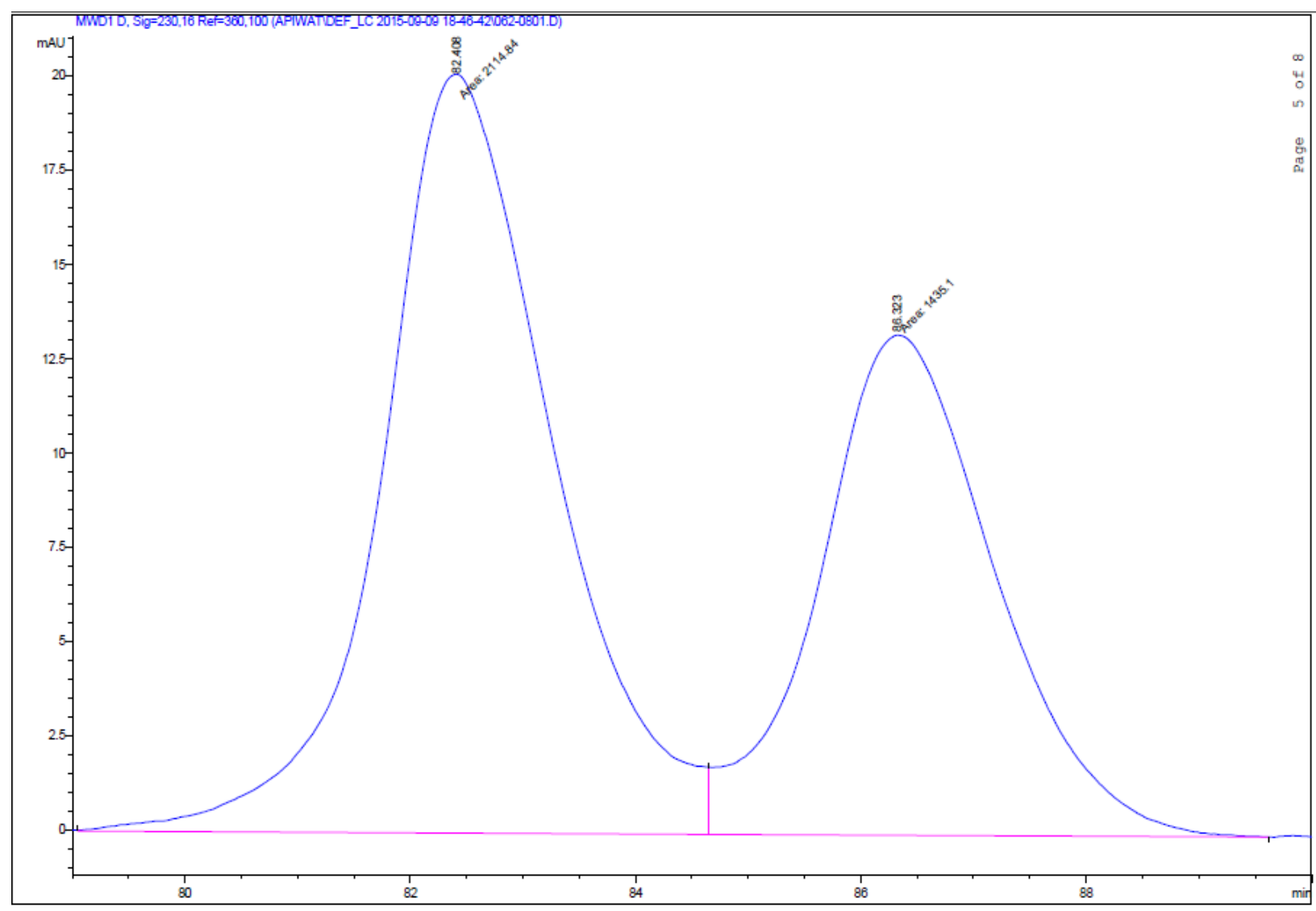

Signal 4: MWD1 D, Sig=230,16 Ref=360,100

\begin{tabular}{|c|c|c|c|c|c|c|}
\hline $\begin{array}{c}\text { Peak } \\
\quad \#\end{array}$ & $\begin{array}{c}\text { RetTime } \\
\text { [min] }\end{array}$ & Type & $\begin{array}{l}\text { Width } \\
\text { [min] }\end{array}$ & $\begin{array}{c}\text { Area } \\
{\left[\mathrm{mAU}^{*} \mathrm{~s}\right]}\end{array}$ & $\begin{array}{l}\text { Height } \\
\text { [mAU] }\end{array}$ & $\begin{array}{c}\text { Area } \\
\frac{8}{6}\end{array}$ \\
\hline \multicolumn{7}{|c|}{$----|-------|----|-------|----------|----------|--------\mid$} \\
\hline 1 & 82.408 & MF & 1.7516 & 2114.83960 & 20.12297 & 59.5739 \\
\hline 2 & 86.323 & FM & 1.8036 & 1435.10156 & 13.26181 & 40.4261 \\
\hline Tota: & ls : & & & 3549.94116 & 33.38479 & \\
\hline
\end{tabular}


Method: Chiralpak IB with 5\% isopropanol and 95\% hexanes

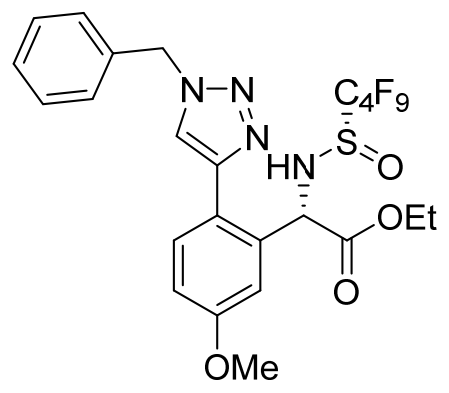

\section{$11 \mathrm{k}$}

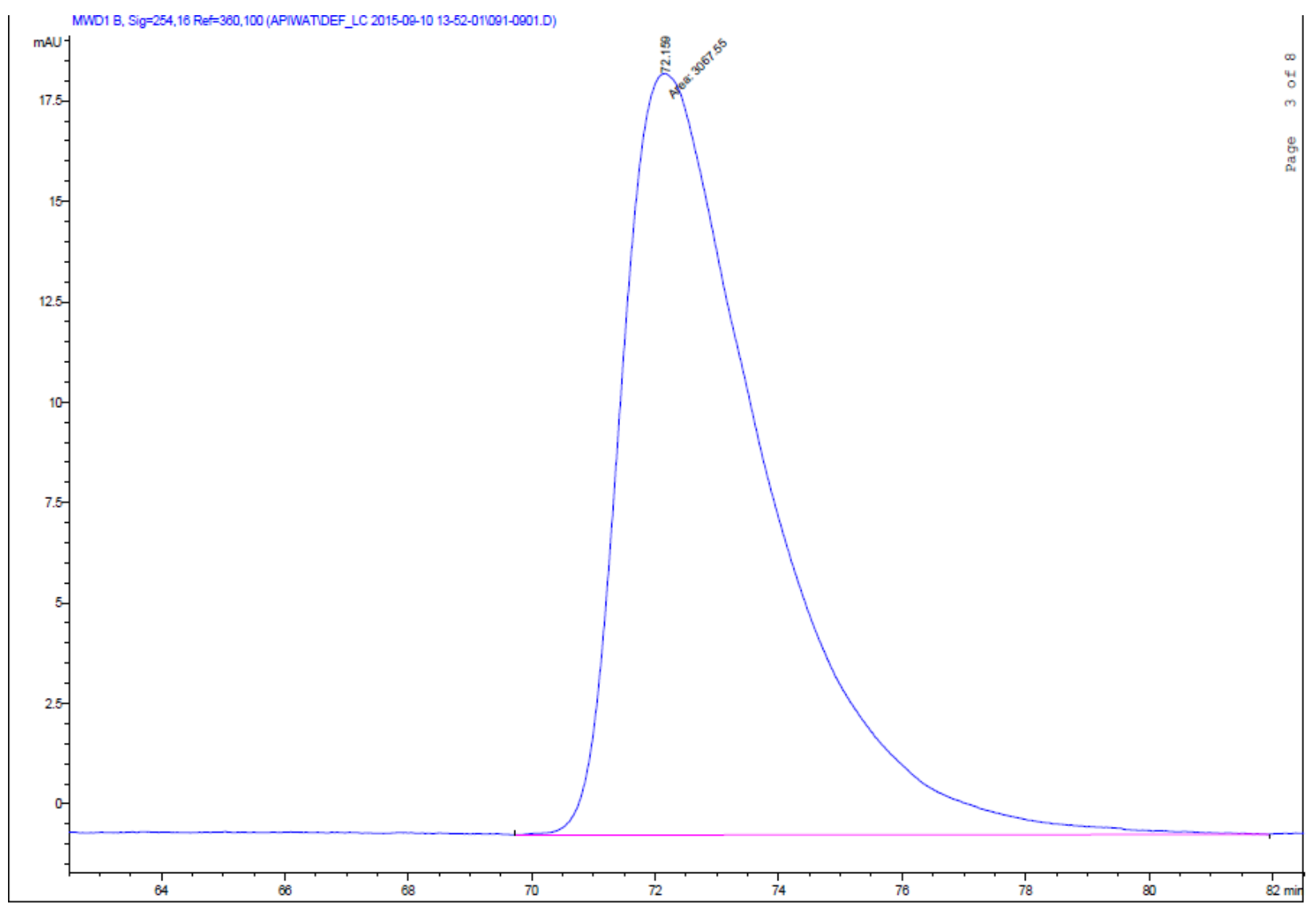

Signal 2: MWD1 B, Sig=254,16 Ref=360,100

\begin{tabular}{|c|c|c|c|c|c|c|}
\hline $\begin{array}{c}\text { Peak } \\
\#\end{array}$ & RetTime & Type & $\begin{array}{l}\text { Width } \\
\text { [min] }\end{array}$ & $\begin{array}{c}\text { Area } \\
{\left[\mathrm{mAU}^{*} \mathrm{~S}\right]}\end{array}$ & Height & $\begin{array}{c}\text { Area } \\
\%\end{array}$ \\
\hline & ------ & 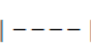 & $-------\mid$ & $-----------\mid$ & $---------\mid$ & $--------\mid$ \\
\hline 1 & 72.159 & MM & 2.6985 & 3067.55200 & 18.94575 & 100.0000 \\
\hline Total & : & & & 3067.55200 & 18.94575 & \\
\hline
\end{tabular}




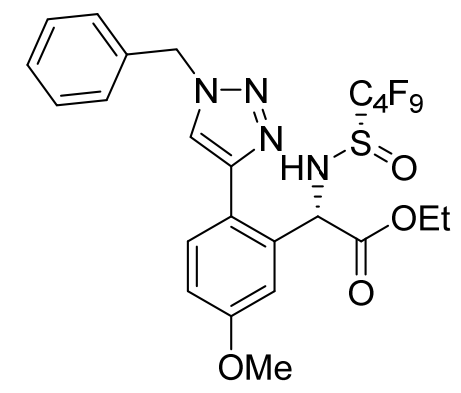

11k-mix (from 11k)

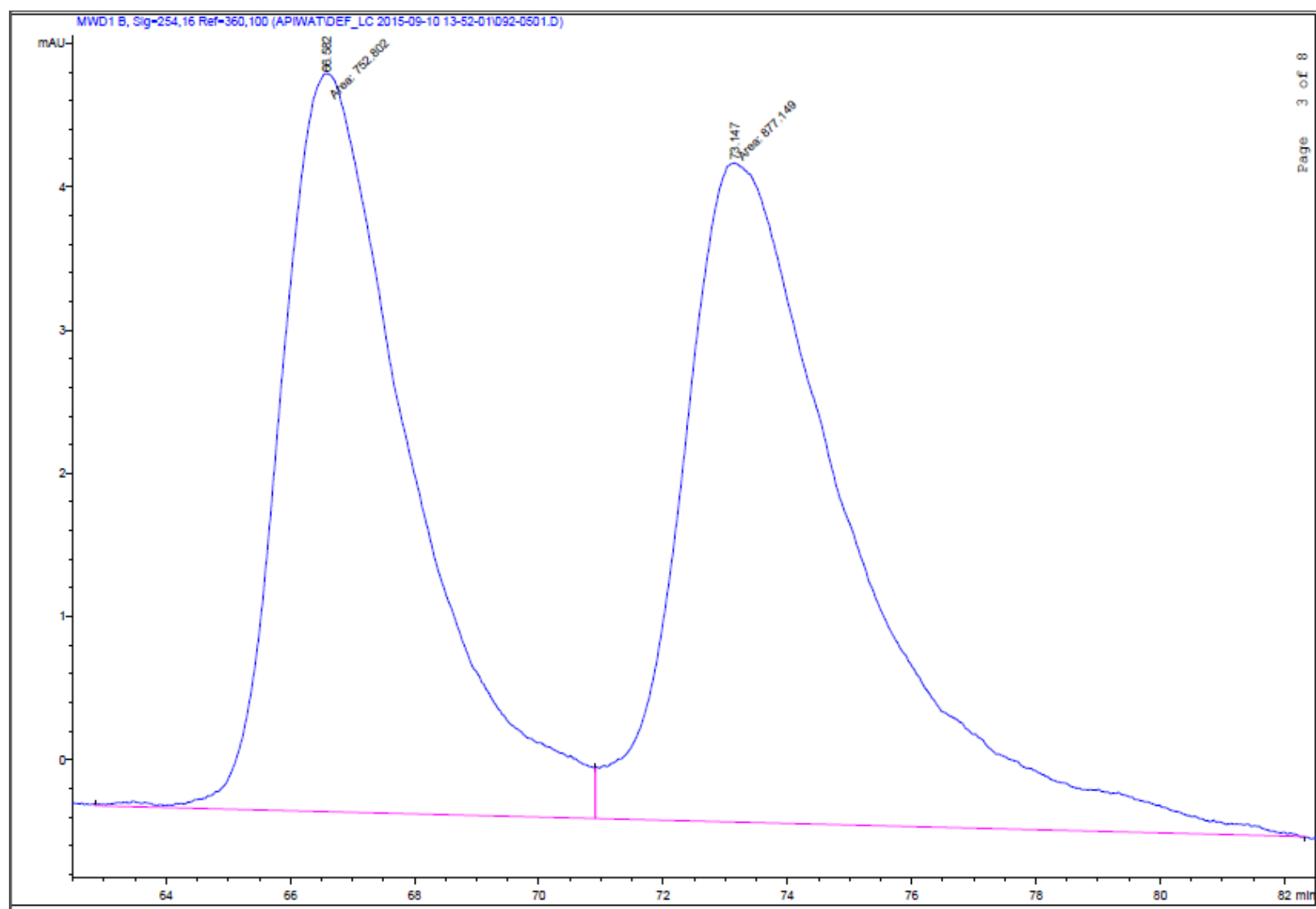

Signal 2: MWD1 B, Sig=254,16 Ref=360,100

\begin{tabular}{|c|c|c|c|c|c|c|}
\hline $\begin{array}{c}\text { Peak } \\
\quad \#\end{array}$ & $\begin{array}{c}\text { RetTime } \\
\text { [min] }\end{array}$ & Type & $\begin{array}{l}\text { Width } \\
\text { [min] }\end{array}$ & $\begin{array}{c}\text { Area } \\
{\left[\mathrm{mAU}^{*} \mathrm{~s}\right]}\end{array}$ & $\begin{array}{l}\text { Height } \\
{[\mathrm{mAU}]}\end{array}$ & $\begin{array}{c}\text { Area } \\
\frac{8}{8}\end{array}$ \\
\hline & ------ & I & ------- & $----------\mid$ & -------- & $--------\mid$ \\
\hline 1 & 66.582 & $\mathrm{MF}$ & 2.4340 & 752.80157 & 5.15475 & 46.1855 \\
\hline 2 & 73.147 & FM & 3.1757 & 877.14929 & 4.60344 & 53.8145 \\
\hline Total & $S:$ & & & 1629.95087 & 9.75820 & \\
\hline
\end{tabular}


Method: Microsorb silica column with 5\% isopropanol and 95\% hexanes

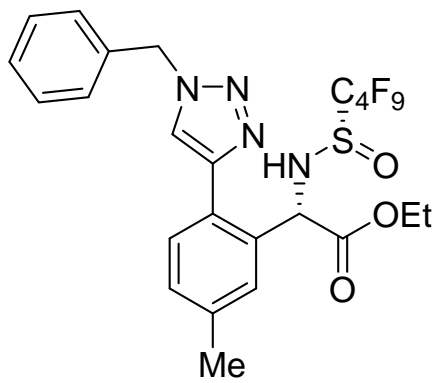

111

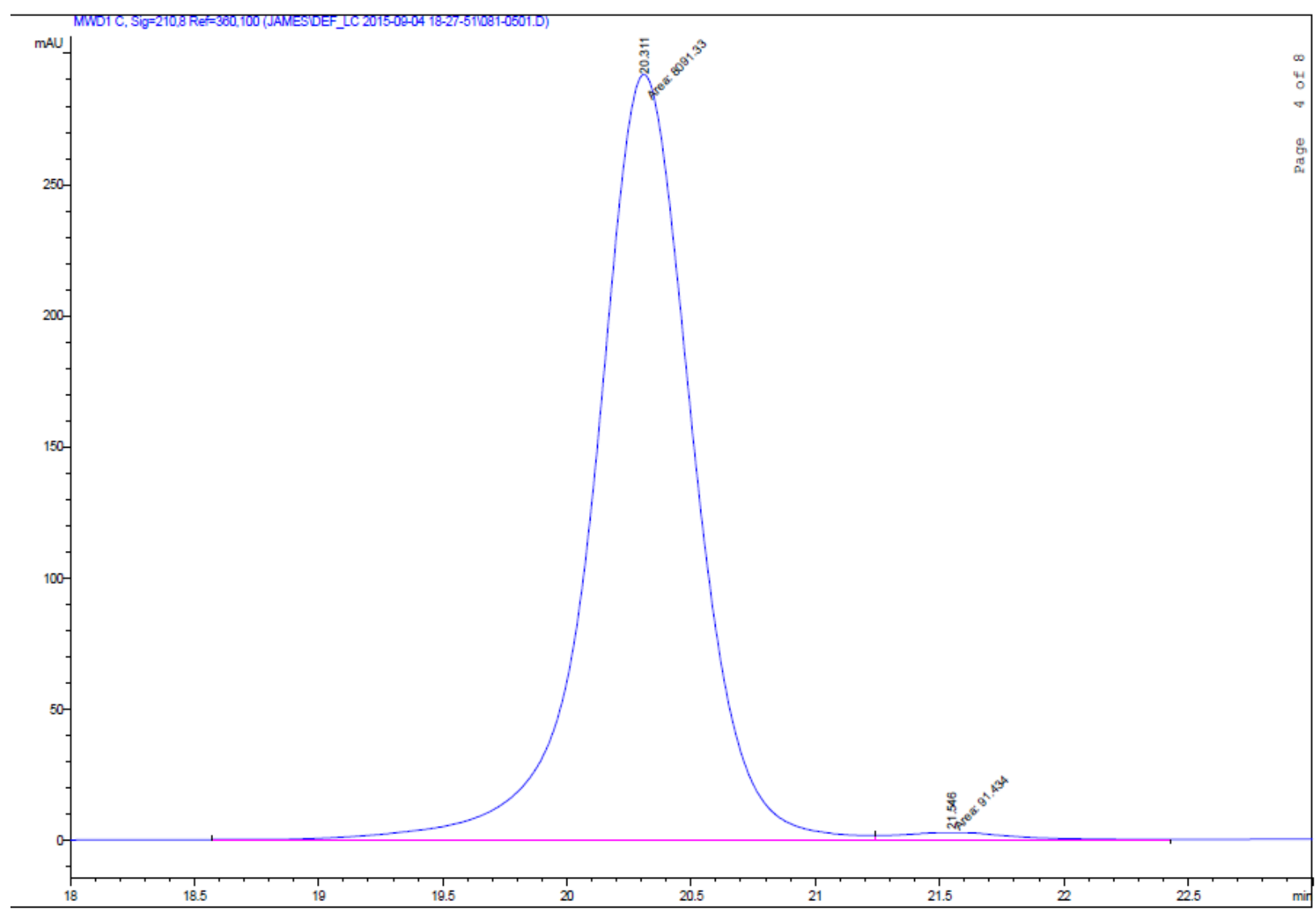

Signal 3: MWD1 C, Sig $=210,8$ Ref $=360,100$

Peak RetTime Type Width Area Height Area

\# $[\mathrm{min}] \quad[\mathrm{min}] \quad\left[\mathrm{mAU}^{*} \mathrm{~S}\right] \quad[\mathrm{mAU}] \quad-$

$----|------|----|------|--------1---------\mid-------1$

$1 \quad 20.311 \mathrm{MF} \quad 0.4622 \quad 8091.32910 \quad 291.76617 \quad 98.8826$

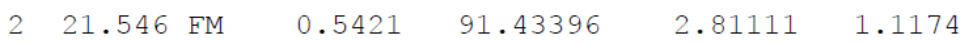

Totals : $\quad 8182.76306 \quad 294.57729$ 


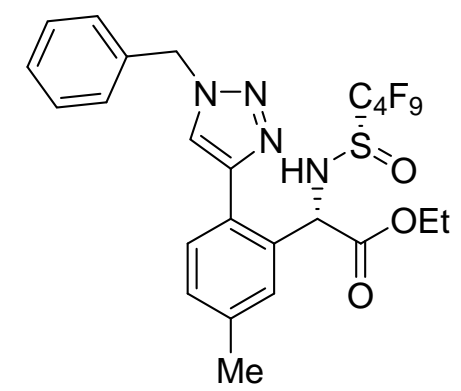

111-mix (from 11I)

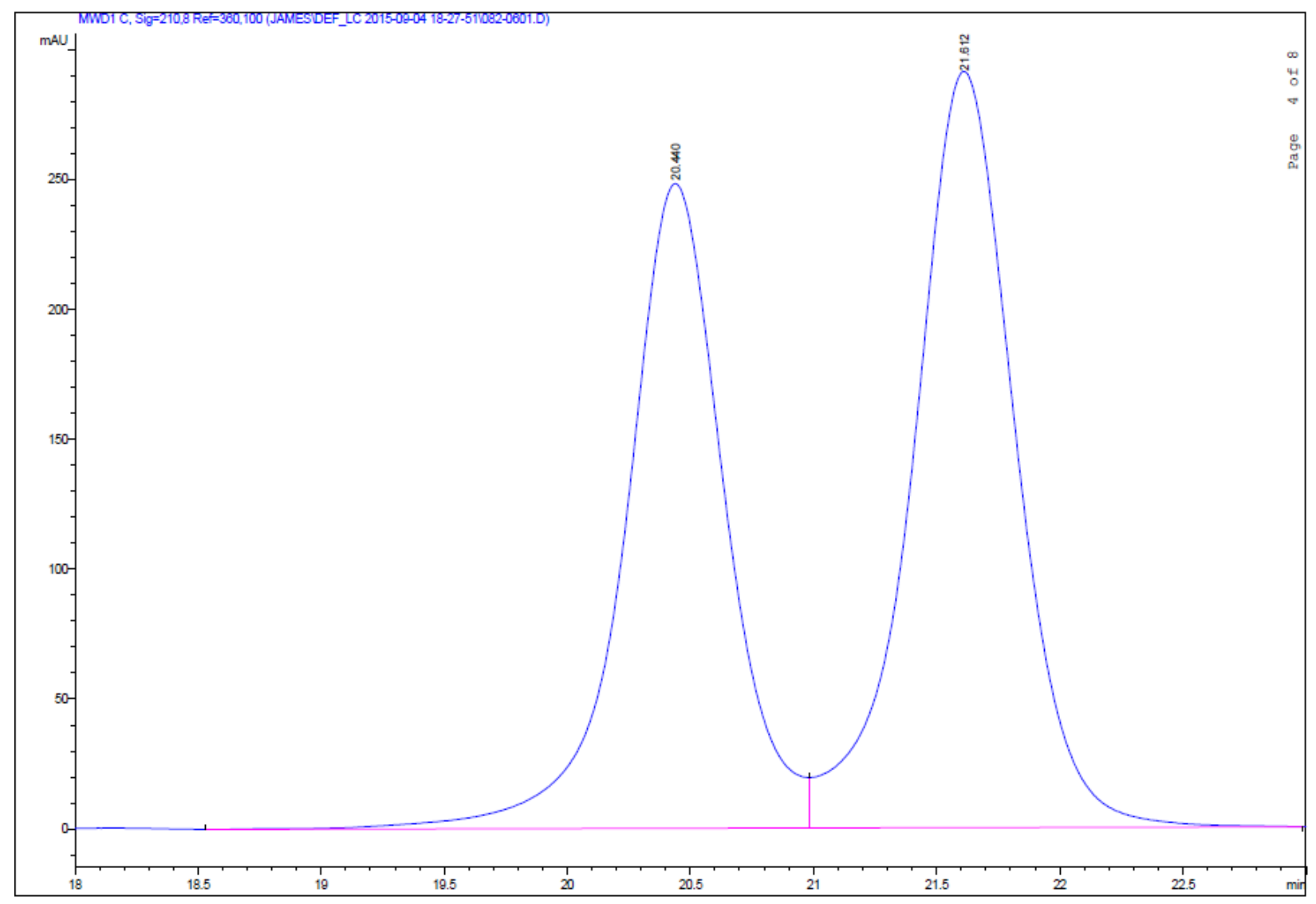

Signal 3: MWD1 C, Sig=210,8 $\operatorname{Ref}=360,100$

\begin{tabular}{|c|c|c|c|c|c|c|}
\hline $\begin{array}{c}\text { Peak } \\
\text { \# }\end{array}$ & $\begin{array}{c}\text { RetTime } \\
\text { [min] }\end{array}$ & Type & $\begin{array}{l}\text { Width } \\
\text { [min] }\end{array}$ & $\begin{array}{c}\text { Area } \\
{\left[\mathrm{mAU}^{\star} \mathrm{s}\right]}\end{array}$ & $\begin{array}{l}\text { Height } \\
\text { [mAU] }\end{array}$ & $\begin{array}{c}\text { Area } \\
\frac{8}{8}\end{array}$ \\
\hline & & & & & & \\
\hline 1 & 20.440 & $\mathrm{VV}$ & 0.4196 & 6964.66650 & 248.00560 & 45.2935 \\
\hline 2 & 21.612 & VB & 0.4353 & 8412.07910 & 290.94504 & 54.7065 \\
\hline Total & Ls : & & & $1.53767 \mathrm{e} 4$ & 538.95064 & \\
\hline
\end{tabular}


Method: Microsorb silica column with 5\% isopropanol and 95\% hexanes
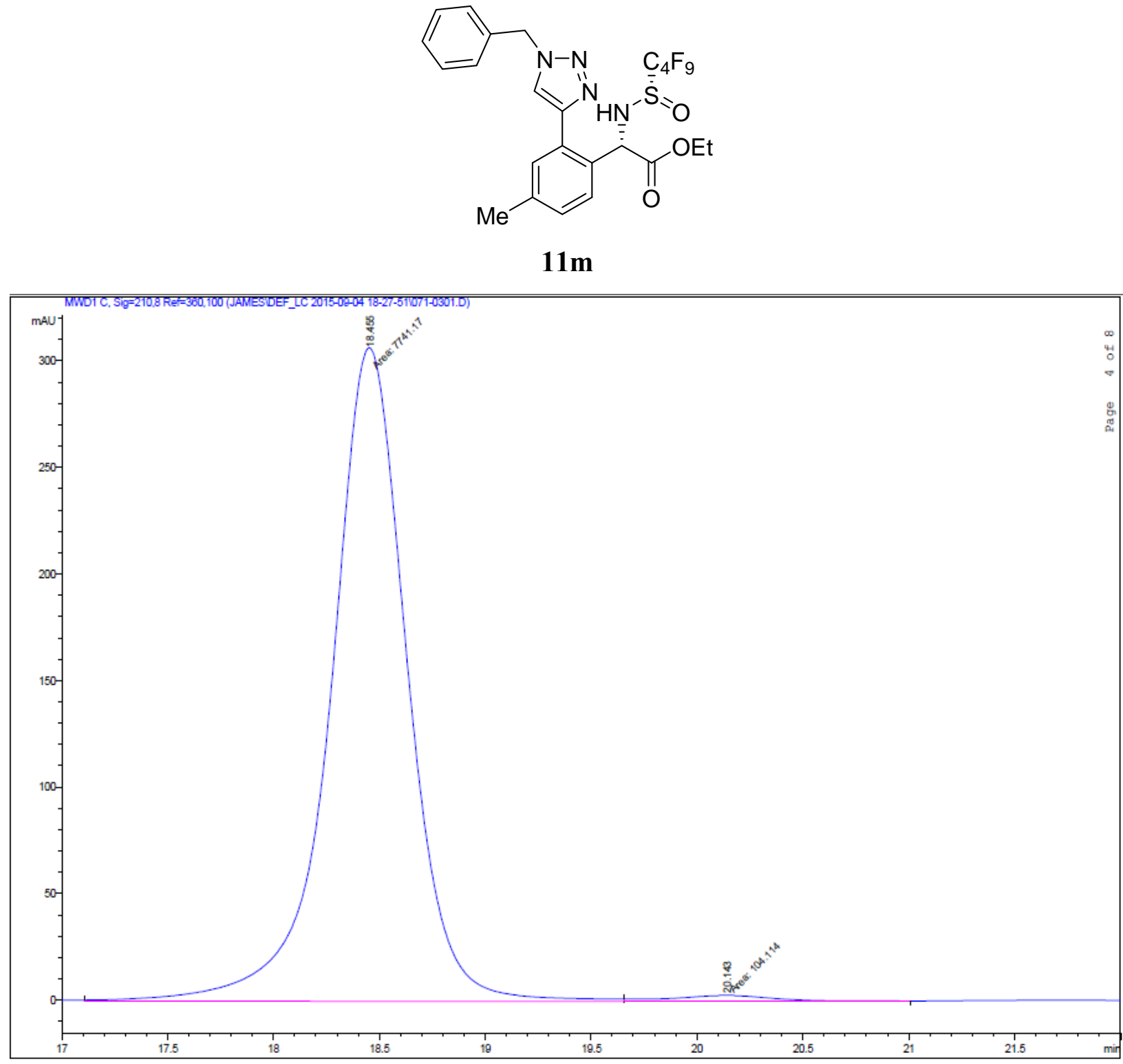

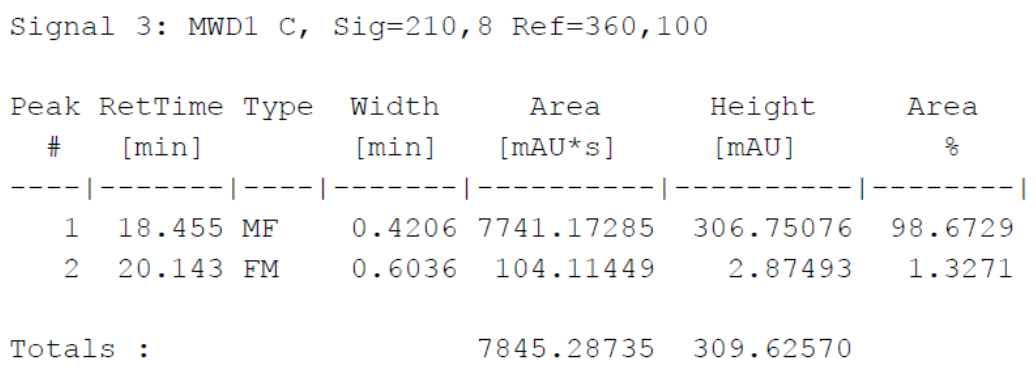




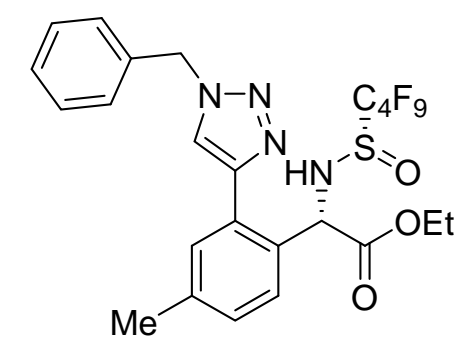

11m-mix (from 11m)

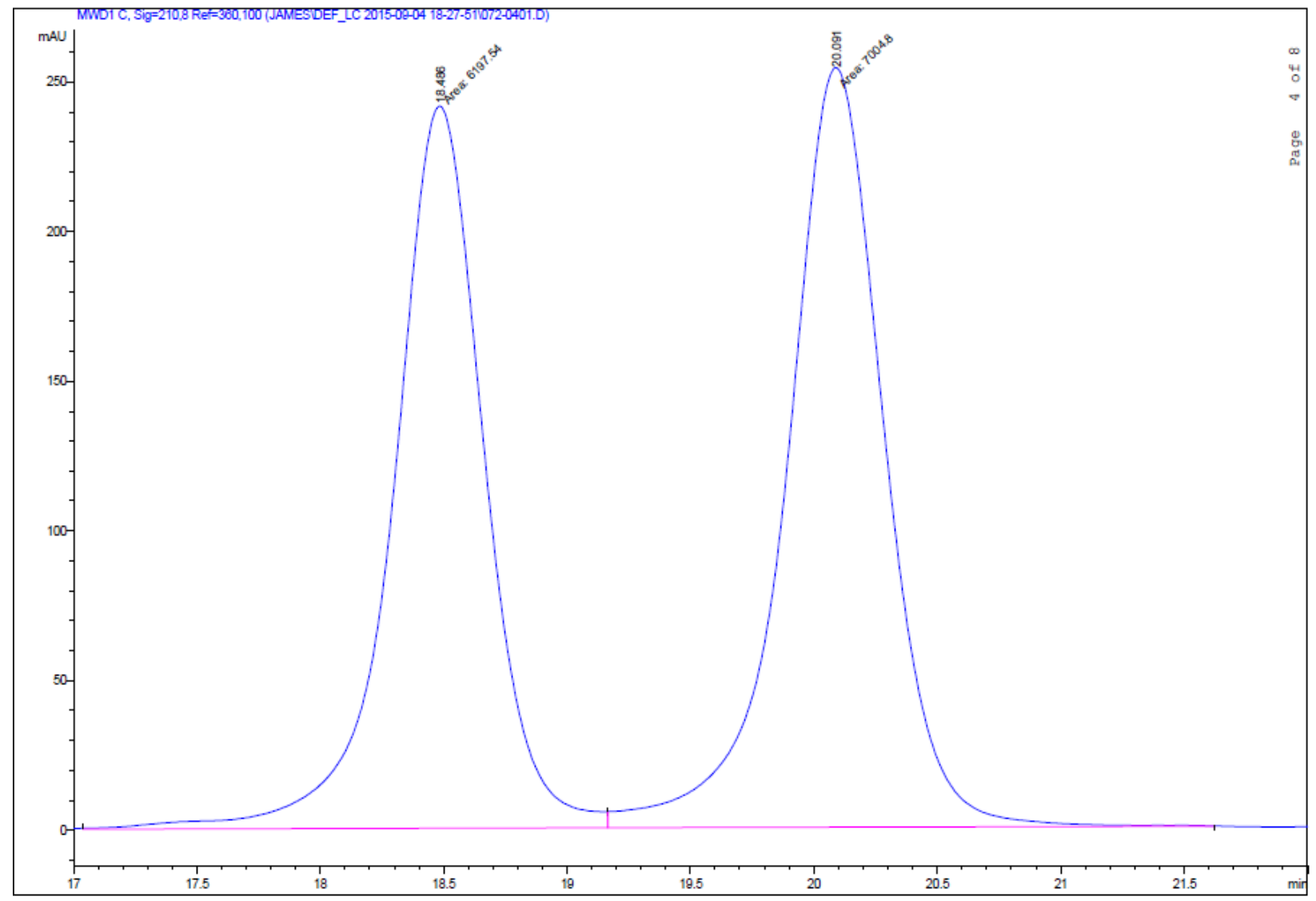

Signal 3: MWD1 C, Sig=210,8 Ref $=360,100$

\begin{tabular}{|c|c|c|c|c|c|c|}
\hline $\begin{array}{c}\text { Peak } \\
\#\end{array}$ & $\begin{array}{c}\text { RetTime } \\
\text { [min] }\end{array}$ & Type & $\begin{array}{l}\text { Width } \\
\text { [min] }\end{array}$ & $\begin{array}{c}\text { Area } \\
{\left[\mathrm{mAU}^{*} \mathrm{~S}\right]}\end{array}$ & $\begin{array}{l}\text { Height } \\
\text { [mAU] }\end{array}$ & $\begin{array}{c}\text { Area } \\
\quad 8\end{array}$ \\
\hline \multicolumn{7}{|c|}{$----|-------|----|-------|----------|----------|--------\mid$} \\
\hline 1 & 18.486 & $\mathrm{MF}$ & 0.4280 & 6197.53662 & 241.34331 & 46.9427 \\
\hline 2 & 20.091 & FM & 0.4601 & 7004.80127 & 253.76945 & 53.0573 \\
\hline Tota & LS : & & & $1.32023 \mathrm{e} 4$ & 495.11276 & \\
\hline
\end{tabular}


Method: Microsorb silica column, 1\% isopropanol and 99\% hexanes, $230 \mathrm{~nm}$

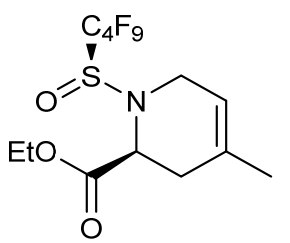

$15 a$

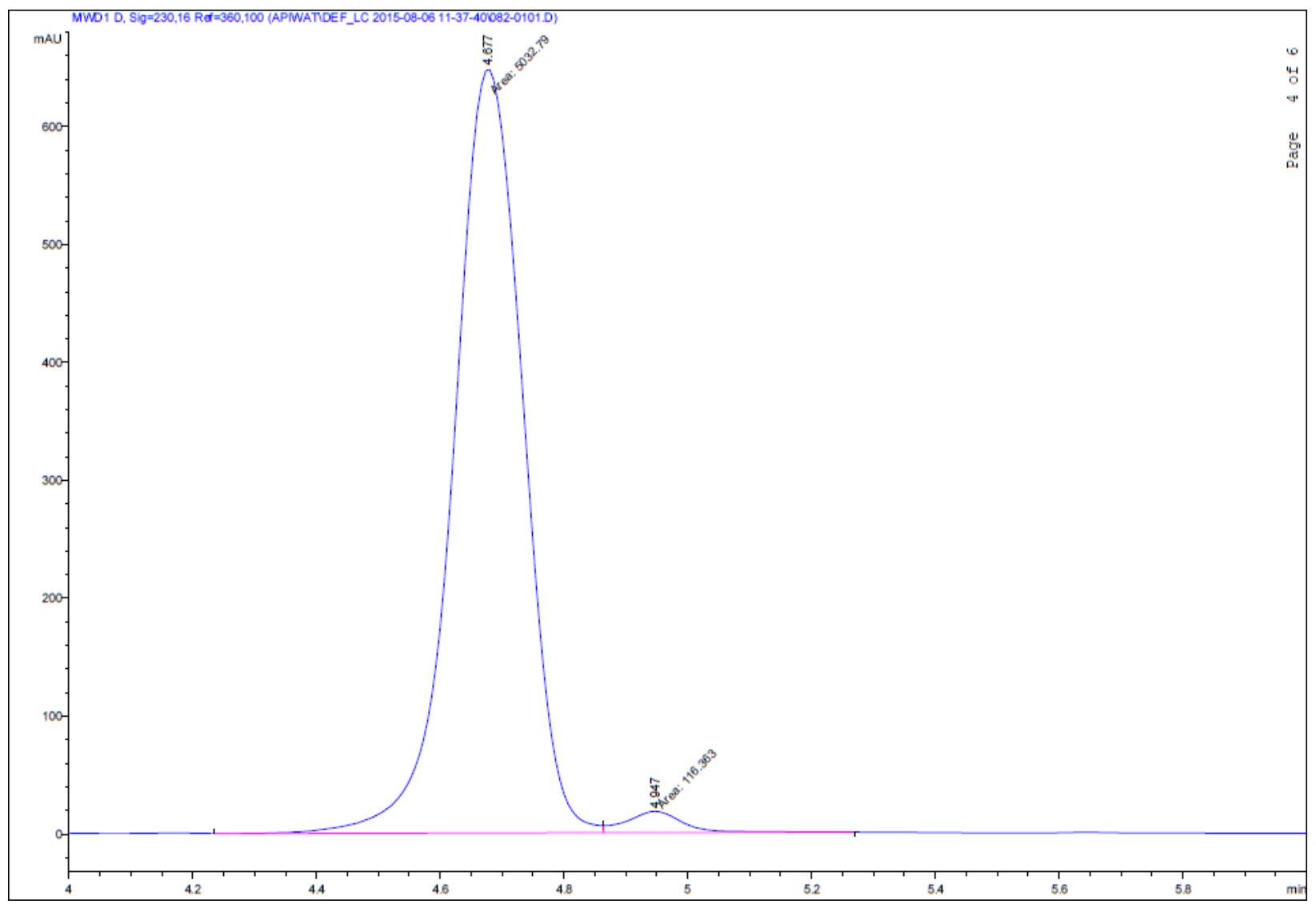

Signal 3: MWD1 D, Sig=230,16 Ref=360,100

\begin{tabular}{|c|c|c|c|c|c|c|}
\hline $\begin{array}{c}\text { Peak } \\
\#\end{array}$ & $\begin{array}{c}\text { RetTime } \\
\text { [min] }\end{array}$ & Type & $\begin{array}{l}\text { Width } \\
\text { [min] }\end{array}$ & $\begin{array}{c}\text { Area } \\
{\left[\mathrm{mAU}^{\star} \mathrm{s}\right]}\end{array}$ & $\begin{array}{l}\text { Height } \\
\text { [mAU] }\end{array}$ & $\begin{array}{c}\text { Area } \\
\&\end{array}$ \\
\hline 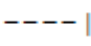 & ------- & & ------ & $|----------|$ & ---------- & $--------\mid$ \\
\hline 1 & 4.677 & MF & 0.1293 & 5032.78711 & 648.76239 & 97.7402 \\
\hline 2 & 4.947 & FM & 0.1072 & 116.36285 & 18.08619 & 2.2598 \\
\hline Total & Ls : & & & 5149.14996 & 666.84858 & \\
\hline
\end{tabular}




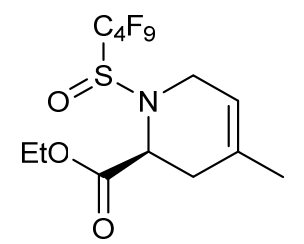

15a-mix (from 15a)

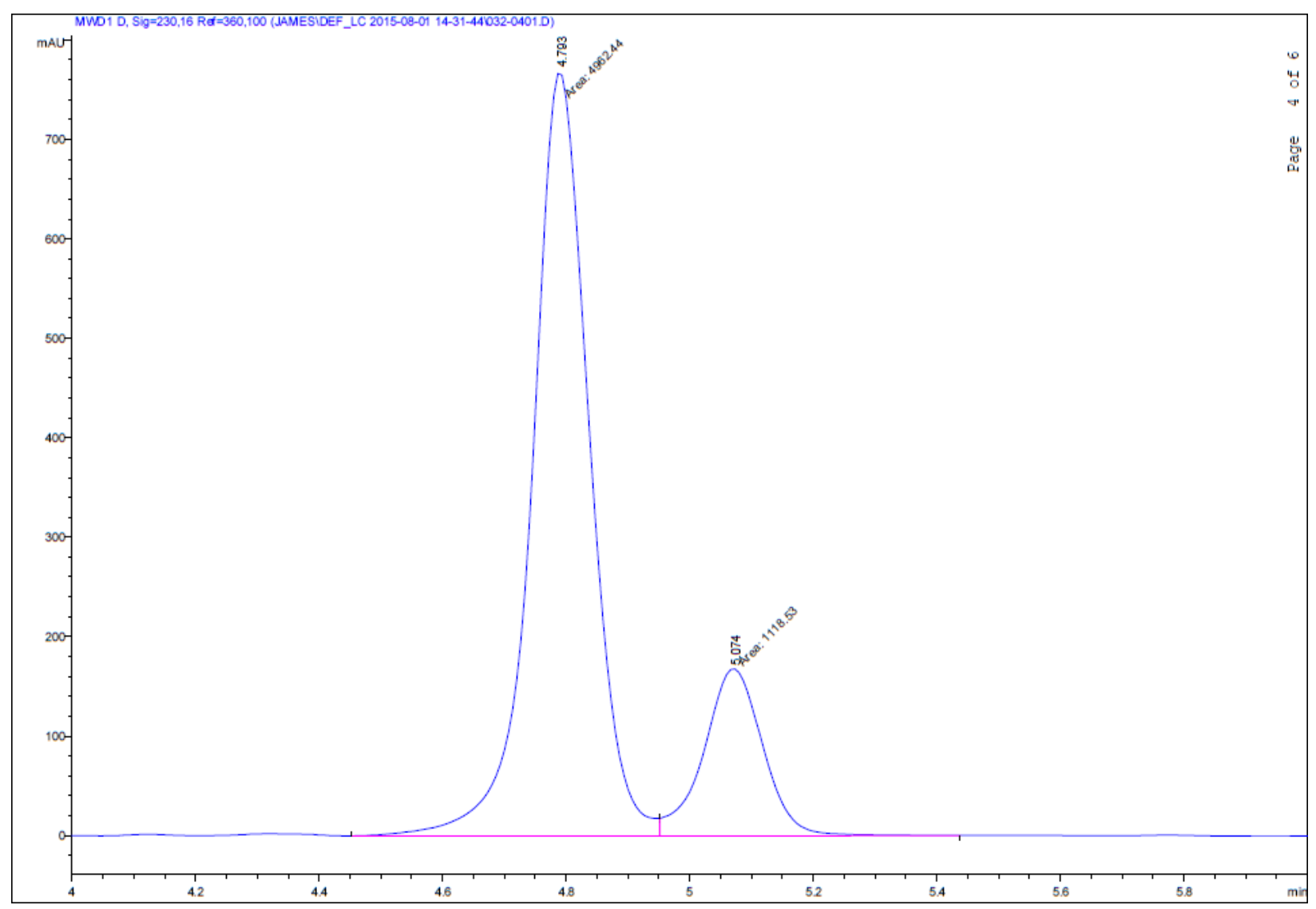

Signal 3: MWD1 D, Sig=230,16 Ref=360,100

\begin{tabular}{|c|c|c|c|c|c|c|}
\hline $\begin{array}{c}\text { Peak } \\
\#\end{array}$ & $\begin{array}{c}\text { RetTime } \\
\text { [min] }\end{array}$ & Type & $\begin{array}{l}\text { Width } \\
\text { [min] }\end{array}$ & $\begin{array}{c}\text { Area } \\
{\left[\mathrm{mAU}{ }^{\star} \mathrm{s}\right]}\end{array}$ & $\begin{array}{l}\text { Height } \\
\text { [mAU] }\end{array}$ & $\begin{array}{c}\text { Area } \\
\&\end{array}$ \\
\hline-- & ------ & - & ------- & | ---------- & --------- & $-------\mid$ \\
\hline 1 & 4.793 & MF & 0.1074 & 4962.43799 & 770.06647 & 81.6060 \\
\hline 2 & 5.074 & FM & 0.1106 & 1118.53247 & 168.48982 & 18.3940 \\
\hline Total & : & & & 6080.97046 & 938.55629 & \\
\hline
\end{tabular}


Method: Microsorb silica column, 1\% isopropanol and 99\% hexanes, $230 \mathrm{~nm}$<smiles>CCOC(=O)[C@@H]1CC(C)=C(C)CN1S(=O)(=O)C(F)(F)F</smiles>

$15 b$

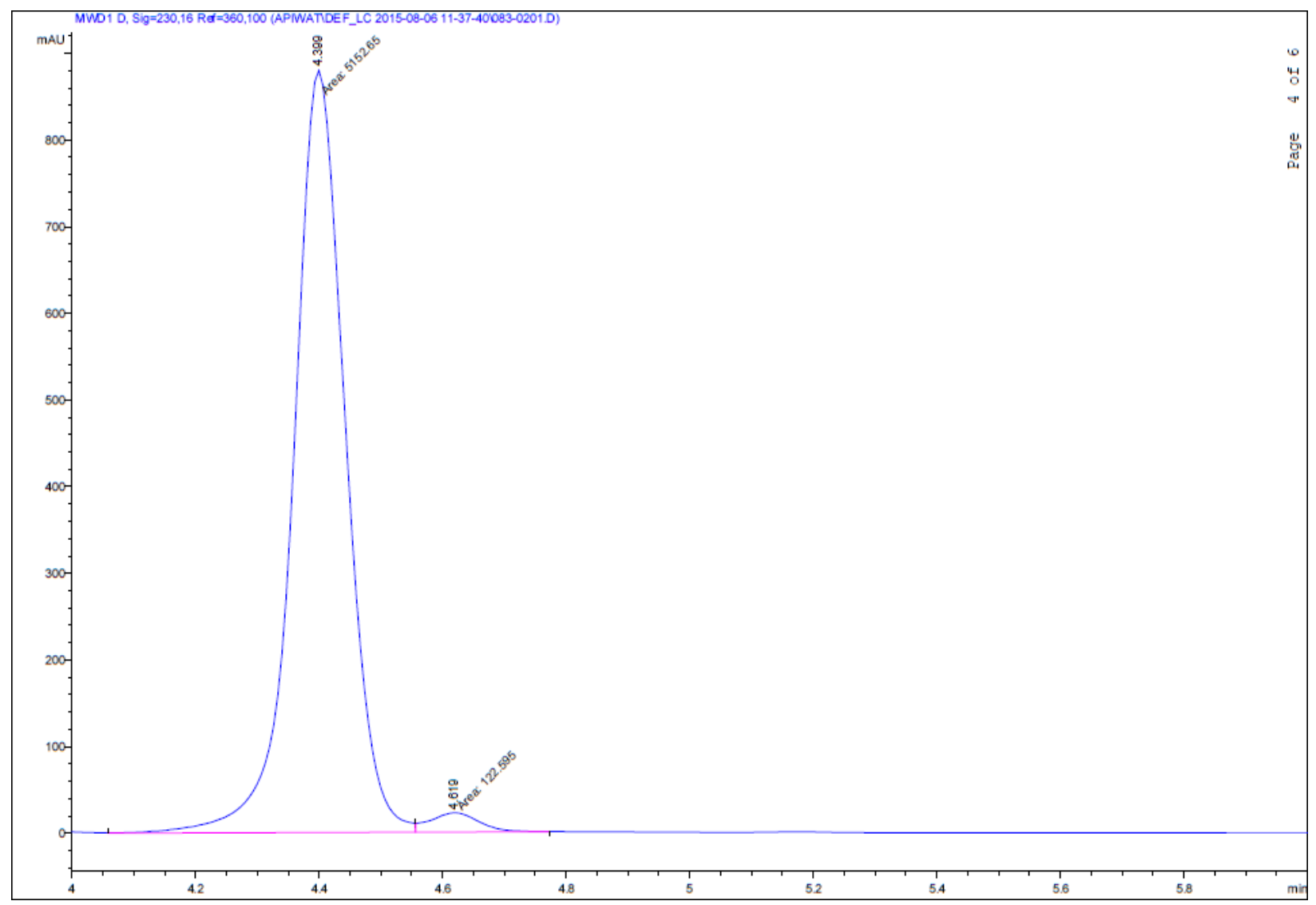

Signal 3: MWD1 D, Sig=230,16 Ref $=360,100$

\begin{tabular}{|c|c|c|c|c|c|c|}
\hline $\begin{array}{c}\text { Peak } \\
\#\end{array}$ & $\begin{array}{c}\text { RetTime } \\
\text { [min] }\end{array}$ & Type & $\begin{array}{l}\text { Width } \\
\text { [min] }\end{array}$ & $\begin{array}{c}\text { Area } \\
{\left[\mathrm{mAU}^{\star} \mathrm{s}\right]}\end{array}$ & $\begin{array}{l}\text { Height } \\
{[\mathrm{mAU}]}\end{array}$ & $\begin{array}{c}\text { Area } \\
\&\end{array}$ \\
\hline & & & & |--------- & --------- & ---- \\
\hline 1 & & MF & & 5152.64746 & 880.84 & 97.6760 \\
\hline 2 & 4.619 & FM & 0.0914 & 122.59502 & 22.36165 & 2.3240 \\
\hline
\end{tabular}

Totals : $\quad 5275.24249 \quad 903.20296$ 


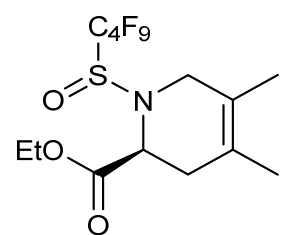

15b-mix (from 15b)

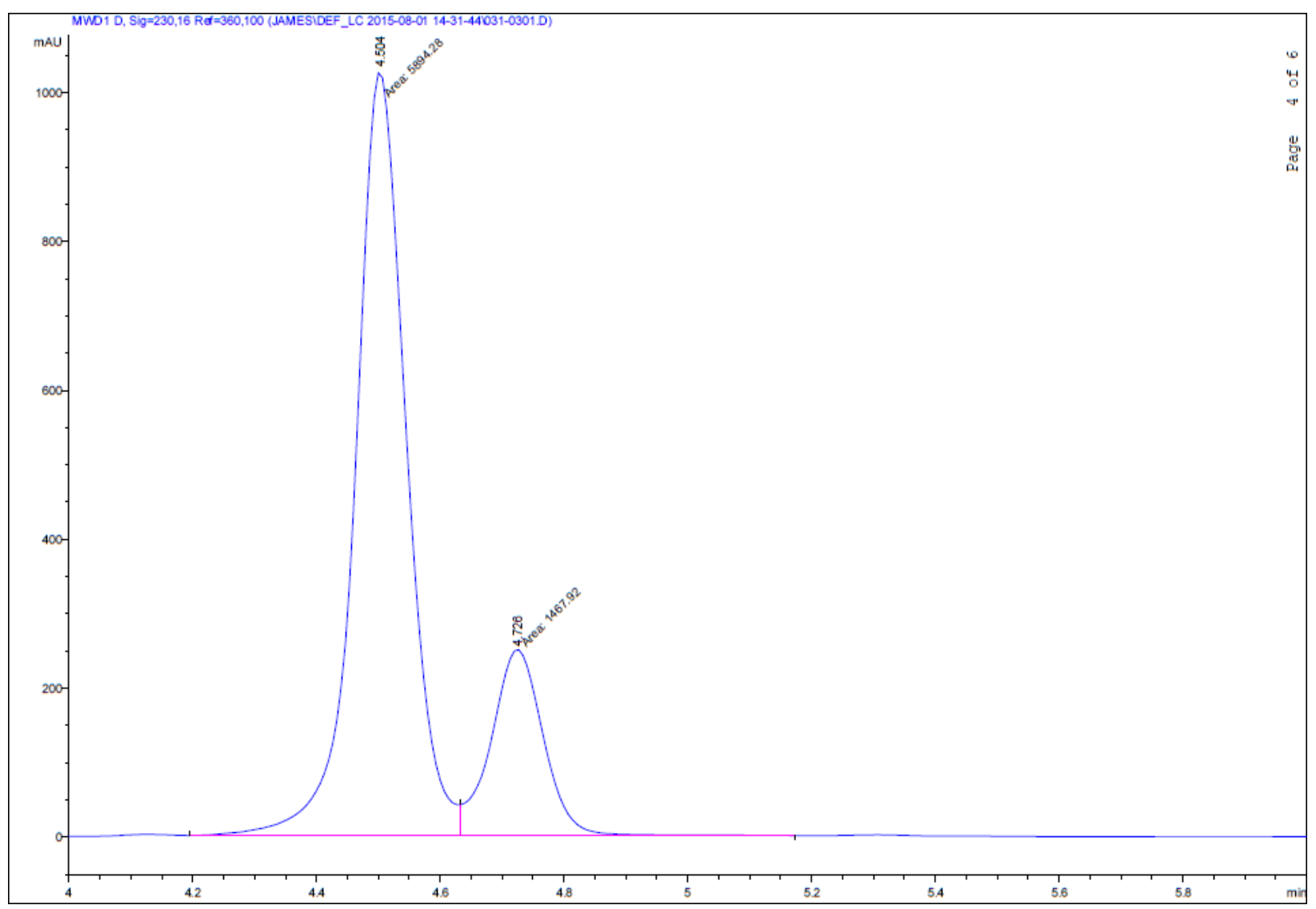

Signal 3: MWD1 D, $S i g=230,16$ Ref $=360,100$

\begin{tabular}{|c|c|c|c|c|c|c|}
\hline $\begin{array}{c}\text { Peak } \\
\#\end{array}$ & $\begin{array}{c}\text { RetTime } \\
\text { [min] }\end{array}$ & Type & $\begin{array}{l}\text { width } \\
\text { [min] }\end{array}$ & $\begin{array}{c}\text { Area } \\
{\left[\mathrm{mAU}^{\star} \mathrm{s}\right]}\end{array}$ & $\begin{array}{l}\text { Height } \\
{[\mathrm{mAU}]}\end{array}$ & $\begin{array}{c}\text { Area } \\
\&\end{array}$ \\
\hline 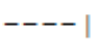 & ------ & & ----- & --------- & |--------- & ------- \\
\hline 1 & 4.504 & MF & 0.0955 & 5894.28467 & 1028.59363 & 80.0614 \\
\hline 2 & 4.726 & FM & 0.0977 & 1467.92346 & 250.42976 & 19.9386 \\
\hline
\end{tabular}

Totals :

7362.208131279 .02339 
Method: Microsorb silica column, 2\% ethanol and 98\% hexanes, $230 \mathrm{~nm}$

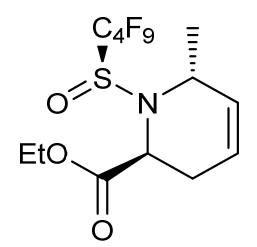

$15 d$

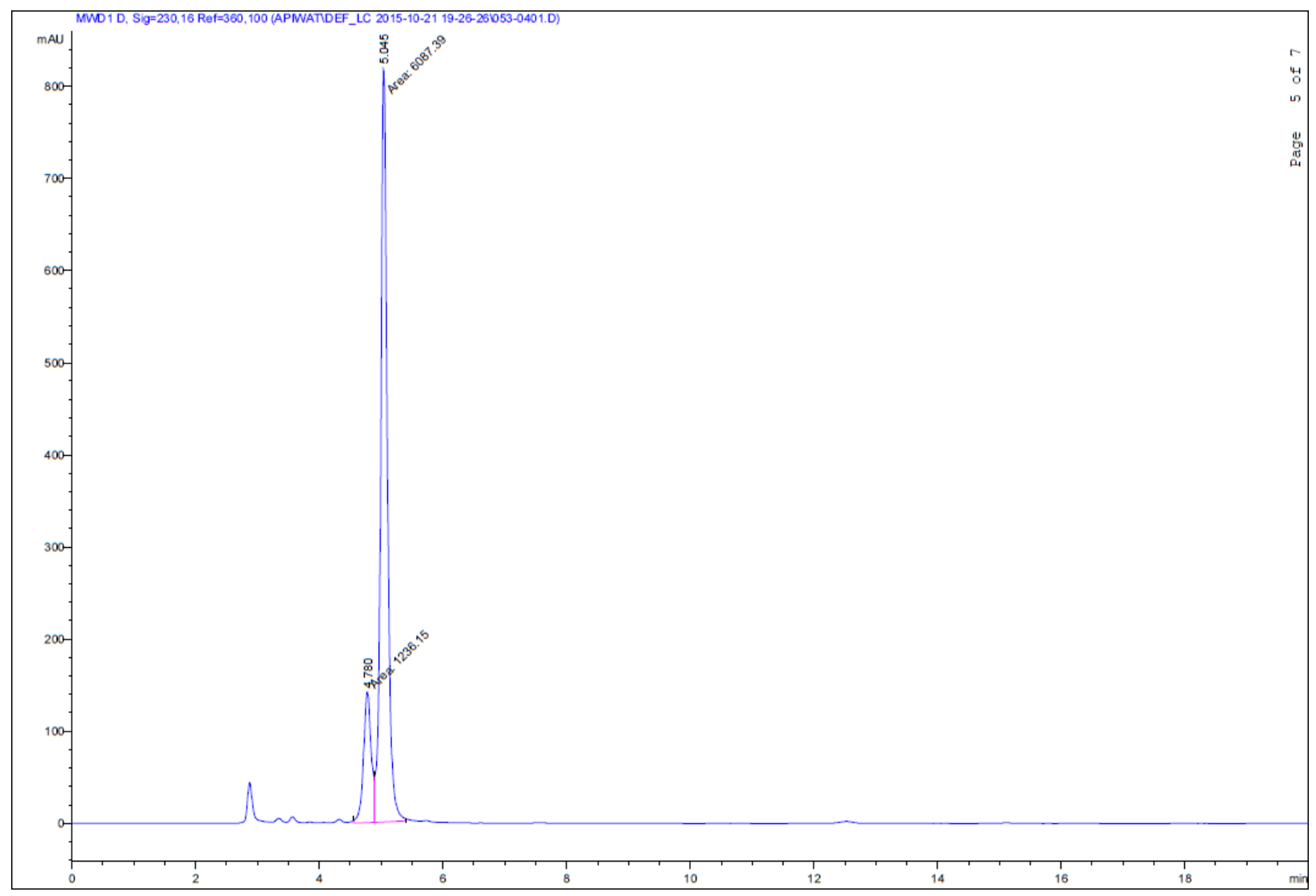

Signal 4: MWD1 D, Sig=230,16 Ref $=360,100$

\begin{tabular}{|c|c|c|c|c|c|}
\hline $\begin{array}{c}\text { Peak } \\
\#\end{array}$ & $\begin{array}{c}\text { RetTime } \\
\text { [min] }\end{array}$ & Type & $\begin{array}{l}\text { Width } \\
\text { [min] }\end{array}$ & $\begin{array}{c}\text { Area } \\
{[\mathrm{mAU} * \mathrm{~s}]}\end{array}$ & $\begin{array}{l}\text { Height } \\
\text { [mAU] }\end{array}$ \\
\hline-- & --- & & & ---- & ---1 \\
\hline 1 & 4.780 & MF & 0.1449 & 1236.15027 & 142.22508 \\
\hline 2 & 5.045 & EM & 0.1239 & 6087.38770 & 819.09125 \\
\hline
\end{tabular}

